\title{
PROLIFERATION, MIGRATION, AND SURVIVAL OF CELLS IN THE TELENCEPHALON OF THE BALL PYTHON, PYTHON REGIUS
}

\author{
A Thesis \\ presented to the Faculty of \\ California Polytechnic State University, \\ San Luis Obispo \\ In Partial Fulfillment \\ of the Requirements for the Degree \\ Master of Science in Biological Sciences
}

by

Thomas B. Bales

June, 2014 
(C) 2014

Thomas B. Bales

ALL RIGHTS RESERVED 


\section{COMMITTEE MEMBERSHIP}

TITLE:

Proliferation, migration, and survival of cells in the telencephalon of the ball python, Python regius

AUTHOR: $\quad$ Thomas B. Bales

DATE SUBMITTED: June, 2014

COMMITTEE CHAIR: $\quad$ Christine R. Strand, PhD

Associate Professor of Biological Sciences

COMMITTEE MEMBER: Emily Taylor, PhD

Associate Professor of Biological Sciences

COMMITTEE MEMBER: Jason M. Blank, PhD

Assistant Professor of Biological Sciences 


\begin{abstract}
Proliferation, migration, and survival of cells in the telencephalon

of the ball python, Python regius
\end{abstract}

Thomas B. Bales

Reptiles exhibit neurogenesis throughout the brain during adulthood. However, very few studies have quantified telencephalon-wide neurogenesis in adulthood, and no studies have performed these investigations in snakes. Quantifying neurogenesis in the adult snake is essential to understanding class-wide adult neurogenesis and providing insight into the evolution of this trait. The thymidine analog 5-bromo-2'deoxyuridine (BrdU) was used to quantify cell proliferation, migration, and survival in the ball python (Python regius). First, to determine the proper dose of BrdU for injection we subcutaneously injected $50 \mathrm{mg} / \mathrm{kg}, 100 \mathrm{mg} / \mathrm{kg}$, and $250 \mathrm{mg} / \mathrm{kg}$ into 15 adult male $P$. regius. We found the $250 \mathrm{mg} / \mathrm{kg}$ dose marked significantly more cells than the $50 \mathrm{mg} / \mathrm{kg}$ dose, but not the $100 \mathrm{mg} / \mathrm{kg}$ dose. Then we subcutaneously injected $100 \mathrm{mg} / \mathrm{kg} \mathrm{BrdU}$ into 15 juvenile male P. regius at 3 different time points (2 days, 2 weeks, 2 months) prior to sacrifice to quantify proliferation, migration, and survival of cells in several telencephalic subregions. After sectioning and immunohistochemical staining, we found proliferation to be highest in the accessory olfactory bulb (AoB), retrobulbar regions (AD, AV), dorsal ventricular ridge (DVR), and dorsolateral amygdala/lateral amygdala (DLA/LA). Of the proliferating cells, the proportions of cells that migrated after 2 weeks were highest in the ventral lateral region (VL), anterior medial and lateral cortices (aMC, aLC), and anterior NS (aNS). After 2 months, the highest proportional survival was in the AoB, aLC, aMC, aNS, DVR, and ventral medial regions (VM). Regions involved in long-term functions like spatial memory may require less proliferation and longer survival, while regions involved in short-term functions undergo more proliferation with higher relative attrition.

Keywords: Python, snake, neurogenesis, BrdU, proliferation, telencephalon, CNS, brain, evolution, comparative. 


\section{ACKNOWLEDGMENTS}

Thank you to CSUPERB for funding this study. Thank you to the Cal Poly Biological Sciences Department for supporting funds. Thank you Daniel Pfau for help with perfusion and tissue preparation, Kelsee Buskirk for immunochemistry assistance, Rob Brewster and Doug Brewster for technical support. Thank you to Emily Taylor and Tony Frazier for lending us your snake handling and husbandry expertise. Thank you to Chris Gouisos and Amanda Wagner for your help with handling snakes and tissues. Thank you to my committee, especially to my committee chair, Christy Strand, for your guidance and support. 


\section{TABLE OF CONTENTS}

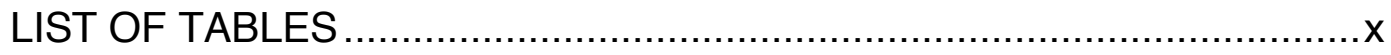

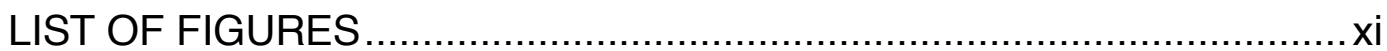

CHAPTER

1.

THE USE OF PYTHONS FOR STUDYING ADULT

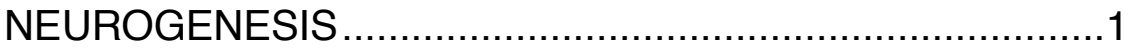

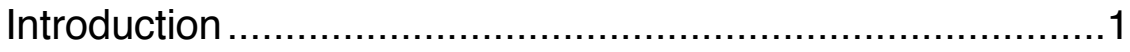

1. Python regius in the laboratory ......................................

2. Python regius in its native and altered habitat..................4

3. Sensory systems of Python regius ...............................

4. Evolution and phylogenetic analysis of $P$. regius .............

5. Evolution, anatomy, and physiology of the squamate

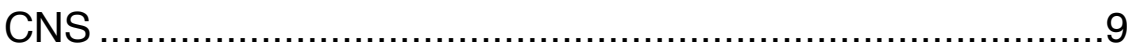

Squamate olfactory system..................................12

The Dorsal Ventricular Ridge ..................................21

DLA and PDVR nomenclature ..............................24

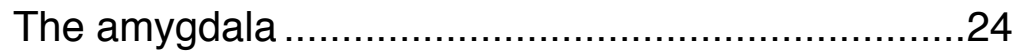

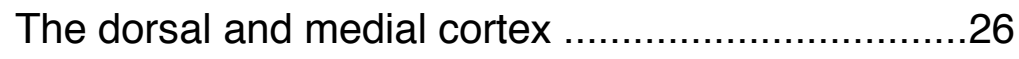

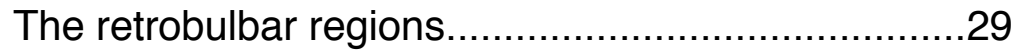

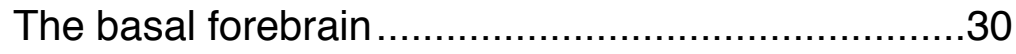

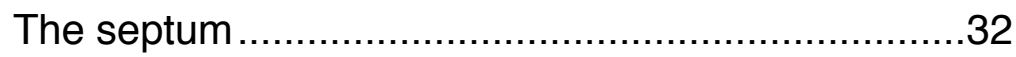


6. History of adult neurogenesis research

7. Use of markers to study neurogenesis ...........................35

8. Comparative studies of adult neurogenesis; Adult

neurogenesis in reptiles

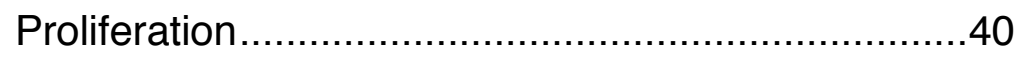

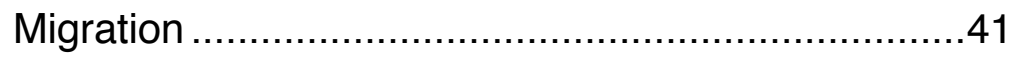

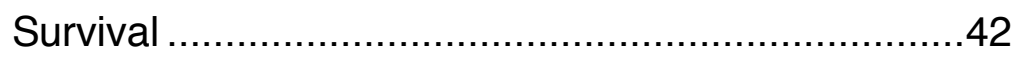

General comparisons......................................... 42

9. Plasticity and environment................................................

10. Regeneration in the adult telencephalon ......................45

11. Future studies of adult neurogenesis in reptiles ............47

2. A BRDU STUDY OF PROLIFERATION, MIGRATION, AND SURVIVAL IN THE TELENCEPHALON OF THE

BALL PYTHON, PYTHON REGIUS....................................

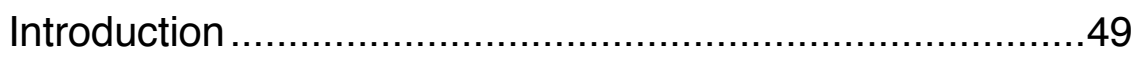

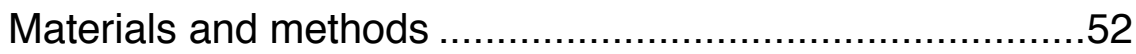

Experiment 1 ................................................... 52

Procurement and treatment ........................52

Sacrifice and perfusion................................54

Sectioning and histochemistry ......................55

Measurement ............................................57

Statistical Analysis ........................................61 
Experiment 2 62

Procurement and treatment ........................62

Sacrifice and perfusion..................................64

Sectioning and histochemistry .....................64

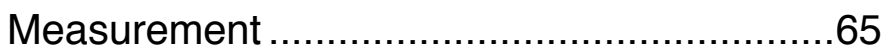

Results. .74

Experiment 1 .................................................. 74

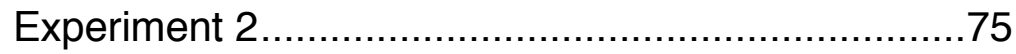

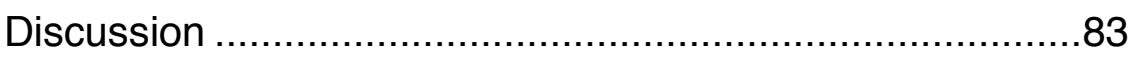

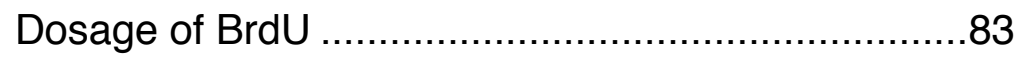

Proliferation, migration, and survival........................84

MC and DC: Hippocampal homologues ..........85

The basal regions: The striatum and the

nucleus accumbens ................................... 86

Amygdaloid regions .....................................8

Olfaction and the RMS ...............................89

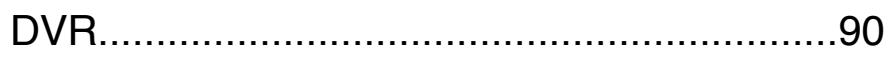

Olfactory and chemosensory processing.......92

The septum ...............................................94

Rostral-caudal effects ................................95

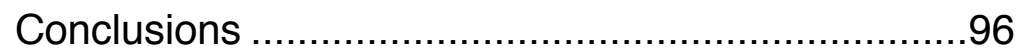

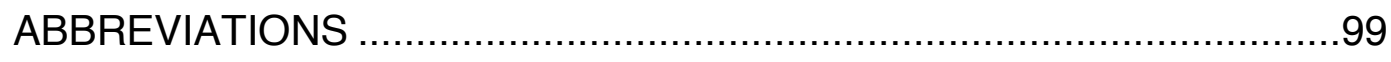




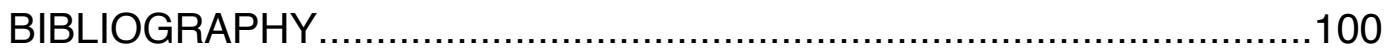

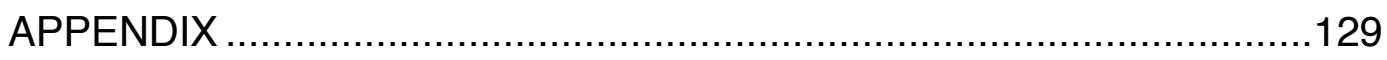




\section{LIST OF TABLES}

Table

Page

1. Stratified random placement of snakes by mass $(\mathrm{g})$ into one of three treatment groups with different dosages of bromodeoxyuridine $(50,100$, or $250 \mathrm{mg} \mathrm{BrdU/kg} \mathrm{body}$

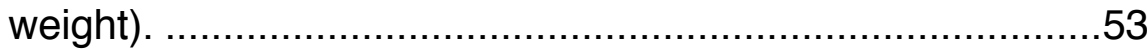

2. Stratified placement of snakes into treatment groups at

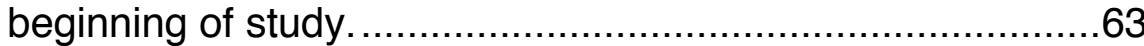

3. Telencephalon regions organized by high or low proliferation combined with high or low migration, and

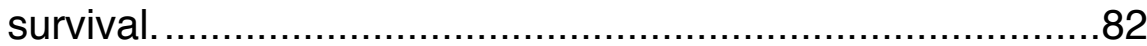




\section{LIST OF FIGURES}

Figure

Page

1. Distribution of $P$. regius in western Africa highlighted in

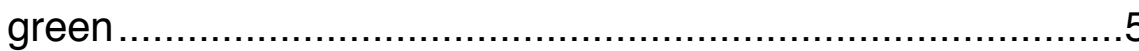

2. Coronal sections from rostral to caudal through the telencephalon of $P$. regius highlighting regions determined by comparison of cresyl violet stained sections to Halpern (1980) and Smeets (1988). The telencephalon can be organized into: main olfactory bulb (OB), accessory olfactory bulb $(\mathrm{AOB})$, retrobulbar region, cortical mantle (cortex; Medial Cortex, Dorsal Cortex, Lateral Cortex, Posterior Cortex), septum (S), dorsal ventricular ridge (DVR), the dorsolateral amygdala (DLA) and lateral amygdala (LA), the basal telencephalic structures which are mainly the nucleus accumbens (ACC) in the ventralmedial (VM) region and the striatum (STR) in the ventrallateral (VL) region, and the nucleus sphericus (NS). Also labeled are the diencephalon (D), pineal gland $(P)$ and midbrain (MB). .13

3. An extracted, perfused, complete $P$. regius brain. The dorsal side of the telencephalon (pallium) is shown. AOB: 
accessory olfactory bulb, OB: olfactory bulb, OT: optic tectum, P: pineal gland.

4. The stack of images taken from cresyl violet stained sections (every 16th section shown) of snake \#7 used to create a 3D model and determine study regions for experiment 1 .56

5. $\quad$ Predetermined regions defined for P. regius telencephalon. Regions were divided according to rostrocaudal landmarks (1-5). AOB: Accessory olfactory bulb. Rostral-caudal regions defined according to morphological changes to determine areas where changes in cellular density occur. Then regions with similar and consistent cell densities were used for the study area. 58

6. Supraventricular ependymal surface area used for counting cell density for $3 \mathrm{BrdU}$ treatments. 59

7. Count of new cells per hemisection (mean +/- SE) within each rostro-caudal region, for the $250 \mathrm{mg} / \mathrm{kg}$ treatment group.

8. Timeline of Experiment 2. Snakes were sacrificed 2 months, 2 weeks, and 2 days after BrdU injection .63

9. Every 16th section taken from python number 11, marked with colors depicting cellular nuclei regions determined by 
observing cellular changes in cresyl violet stained tissues. $\mathrm{ACC}=$ nucleus accumbens, $\mathrm{TUB}=$ olfactory tubercle, $\mathrm{Ccl}$ $=$ cortical cell layer of the retrobulbar region, $\mathrm{MCcl}=$ medial cortex cell layer, $\mathrm{DCcl}=$ dorsal cortex cell layer, $\mathrm{LCcl}=$ lateral cortex cell layer, $\mathrm{PCcl}=$ posterior cortex cell layer, $\mathrm{STR}=$ striatum, DVR = dorsal ventricular ridge, $\mathrm{S}=$ septum, IS = lateral septal nucleus, $\mathrm{mS}=$ medial septal nucleus, $\mathrm{P}=$ pineal gland, $\mathrm{NScl}=$ nucleus sphericus cell layer.

10. P. regius brain reassembled as a 3D image in Image using Java3D for experiment 2. Colors only denote different regions and no other factors. 69

11. Every 16th section taken from a representative python cresyl violet stained, photographed and labeled using Photoshop CS3. Study regions determined for cell counts are highlighted. Regions correspond with quantification data in figs. 11,12 , and 13. .70

12. Mean cell new cell density (cells/mm2; $\pm \mathrm{SE})$ in the supraventricular ependymal zone for snakes exposed to $50 \mathrm{mg} / \mathrm{kg}, 100 \mathrm{mg} / \mathrm{kg}$, or $250 \mathrm{mg} / \mathrm{kg}$ BrdU. .75

13. Density of new cells (cells/mm3; mean \pm SE) located in regions of the $P$. regius telencephalon denoted in fig. 10 , 
A. 2 days, 2 weeks, and 2 months post-injection. B. 2

days post-injection only. C. 2 weeks post-injection only. D.

2 months post-injection only.

.76

14. Regional migration of new cells (\%cells) determined from

$[($ mean regional parenchymal cell density at 2

weeks)/(mean regional ependymal cell density at 2 days)]

in the P. regius telencephalon, 2 weeks post-injection.

15. Regional survival of new cells (\%cells) determined from

$[($ mean regional parenchymal cell density at 2

months)/(mean regional ependymal cell density at 2

days)] in the P. regius telencephalon, 2 months post-

injection

16. Comparison of cell density in the ependymal zone versus

parenchymal zone 2 months post-BrdU injection

17. Heat map representing proliferation (2 days) in the

telencephalon of P. regius. Hot colors (yellow, orange, red) represent areas of high proliferation, while cold colors (purple, blue, light blue) represent areas of low proliferation. The rostral end and caudal end are topmost and bottommost, respectively. 3D video can be found at http://youtu.be/zMj8d42o3_4 
18. Heat map representing migration (2 weeks) in the telencephalon of P. regius. Hot colors (yellow, orange, red) represent areas of high migration, while cold colors (purple, blue, light blue) represent areas of low migration. The rostral end and caudal end are topmost and bottommost, respectively. 3D video can be found at http://youtu.be/QZXKkCTCHsM

19. Heat map representing survival (2 months) in the telencephalon of P. regius. Hot colors (yellow, orange, red) represent areas of high proliferation, while cold colors (purple, blue, light blue) represent areas of low proliferation. The rostral end and caudal end are topmost and bottommost, respectively. 3D video can be found at http://youtu.be/usnQ5F0AQJk. 


\section{Chapter 1. The use of pythons for studying adult neurogenesis}

\section{Introduction}

This chapter is a comprehensive review of the literature pertaining to comparative neurology of the adult ball python, Python regius. First, I will provide information about $P$. regius in the laboratory and their natural habitat with a brief overview of their unique peripheral sensory systems. Then, I will discuss the evolution of the python and review past studies of the python central nervous system (CNS). The rest of this chapter will cover various aspects of adult neurogenesis, providing an overview of past adult neurogenesis research and techniques used for studies and the use of reptiles in adult neurogenesis studies, including information regarding the remarkable ability of the reptile CNS to regenerate. Lastly, I will comment on the future of research on adult neurogenesis in reptiles and include proposals for future python studies.

\section{Python regius in the laboratory}

Python regius (commonly known as "Ball Pythons" or as "Royal Pythons") are not regularly used in the laboratory for physiology studies. This is unexpected because $P$. regius are ideal organisms for laboratory study. Due to considerable use in the international exotic pet trade, they are typically byproducts of captive breeding for several generations. This process reduces the variation in the developmental environment and genetic diversity, potentially improving the internal validity of 
experiments. Instead of requiring labor-intensive strategies for capturing them in the wild, they can be purchased from online retailers and can be easily maintained in cages. They are very docile and easy to handle without risk of injury to the handler or the snake. They do not require intricate laboratory housing and can be maintained by giving them access to water ad libitum, a heating device, and regular access to feeder mice. In fact, contrary what many researchers might expect, pythons are easier to handle and maintain than rats (Secor et al., 2001).

Yet there are also drawbacks to using snakes and other reptiles in the laboratory. Genetic and developmental laboratory studies of reptiles have been hindered by the class's slow maturation rates, ectotherm metabolism, habituation needs, and seasonal reproduction. Studies of the cellular and molecular evolution of development in reptiles are limited by the technical difficulties of embryonic manipulation (Nomura et al., 2013a). Even with these hindrances, P. regius has the potential to be an excellent laboratory study species. Considerable laboratory research has been done on several reptile species including anoles (Greenberg et al., 1984) and garter snakes (Morris and Crews, 1990). These studies can help provide points of comparison to prompt future examination of neurophysiology in $P$. regius.

Studies of $P$. regius are beneficial to comparative research because snakes have so many distinctive traits. For example, snakes are limbless, so comparisons of brain physiology between snakes and limbed reptiles may provide insight into the evolutionary development or loss of brain regions responsible for limb control and 
motor function. Snakes are missing motor neurons at the limb level of the spinal cord. Instead a single medial motor column developed along the entire spinal cord (Fetcho, 1987). The rubrospinal tract is also missing in some snakes such as the boidae (ten Donkelaar, 1988). Python regius also have special sensory systems (e.g. vomeronasal, pit organ/infrared, and completely internalized hearing), for which there have been virtually no reptilian studies of telencephalic neurogenesis (Font et al., 2012).

Most pythons are constricting, sit-and-wait predators (Enok et al., 2012). Since they consume large prey relative to their body size, several of their physiological systems undergo metabolic changes, including the digestive and cardiovascular systems (Andersen et al., 2005; Secor and Diamond, 1998). Some species of female pythons will also undergo shivering thermogenesis. In order to keep their eggs warm during brooding, female pythons will shiver, moving from a series of muscular contractions of the whole body thus generating heat (Harlow and Grigg, 1984; Stahlschmidt and DeNardo, 2008; 2009; 2010; Vinegar et al., 1970). In order to determine the role the CNS plays in these systems, it is important to do preliminary studies of neuroanatomy and neuroplasticity, and then perform experiments modifying these systems to determine their effect on the brain and vice versa.

Recently, there has been progress in understanding reptilian cognition and intelligence, which can provide insights into the evolution of cognition, social function, and the CNS. Behavioral laboratory studies of reptiles are very challenging, 
because the classic behavioral studies are modeled on stimulus-reward, a practice not easily applied to large ectothermic reptiles that eat only every few weeks.

Several researchers have attempted cognitive laboratory studies in reptiles, which have supported, at minimum, limited memory and learning (Baird Day et al., 1999b; Manrod et al., 2008; Wilkinson et al., 2007; Wilkinson et al., 2010). As examples, Gaalema (2011), using Varanus rudicollis (rough-necked monitor lizards), paired either black or white $5 \mathrm{~cm}$ disk stimuli with reinforcement (thawed pinkie mice). $V$. rudicololis not only successfully learned to discriminate between the two colors, but also successfully learned two reversals, with the second reversal requiring fewer sessions than the first. Davis and Burghardt (2011) discovered that Pseudemys nelsoni (the Florida redbelly turtle) can observe conspecifics using visual object cues to obtain food, and then perform the task of using cues themselves to feed, even when the conspecific demonstrator is absent, regardless of spatial position. As these studies become more refined and accepted we may be able to do comparative studies of learning behavior, neurogenesis, and neuroplasticity.

\section{Python regius in its native and altered habitat}

Little is known about African pythons including $P$. regius in their native habitat (Luiselli et al., 2007; Luiselli and Angelici, 1998; Starin and Burghardt, 1992). Python regius has been most researched in Togo (Aubret et al., 2005a; Aubret et al., 2003;

Aubret et al., 2005b; Aubret et al., 2005c), Ghana (de Buffrenil, 1995; Gorzula et al., 1997) and Nigeria (Luiselli, 2006; Luiselli et al., 2007; Luiselli and Angelici, 1998). 
They are widely distributed in western Africa and abundant in southern Nigeria (Fig.

1).

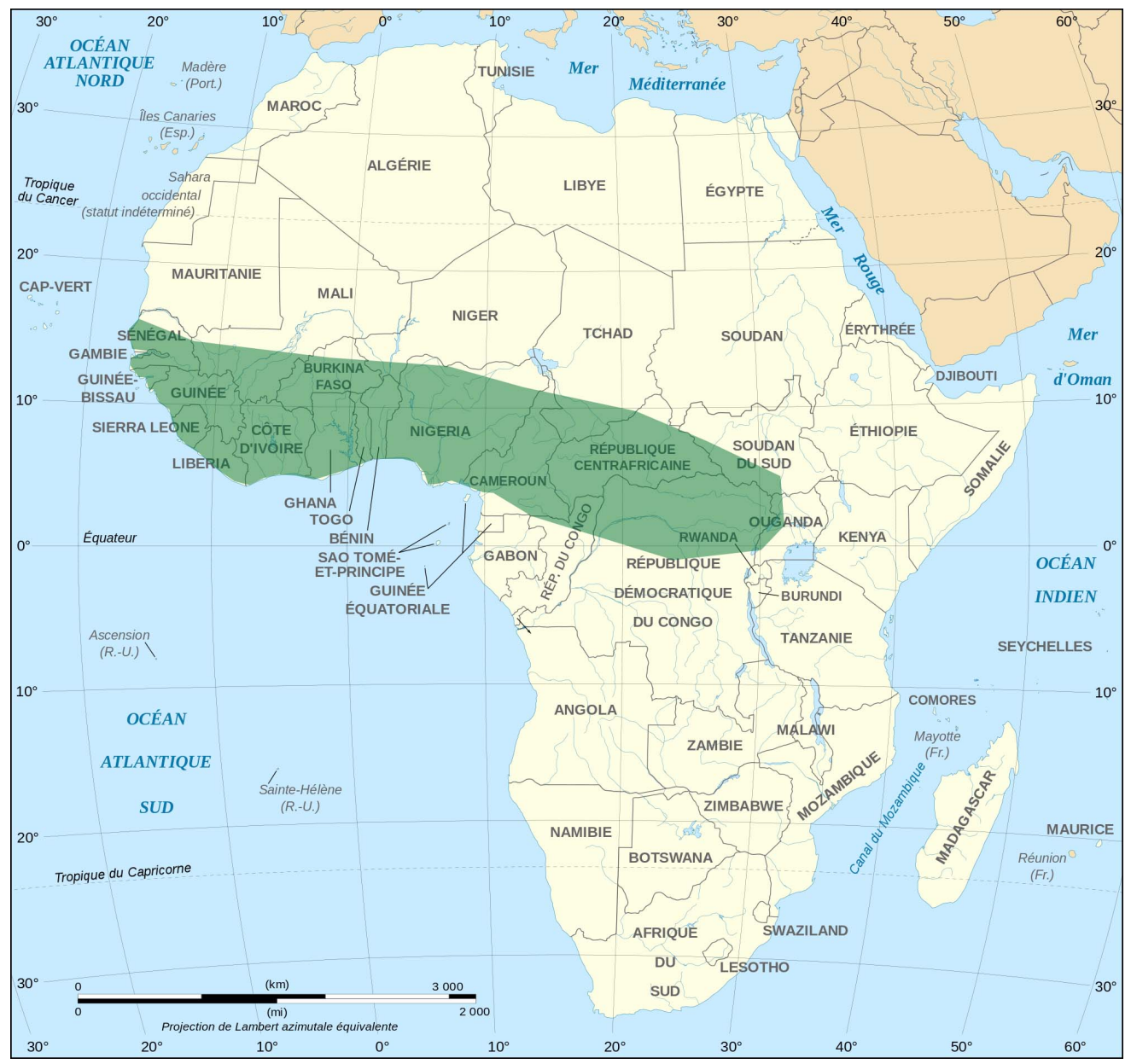

Figure 1: Distribution of $P$. regius in western Africa highlighted in green.

Python regius are habitat generalists, well adapted especially to disturbed forest areas like plantations and farmland (Luiselli et al., 2007). Butler and Reid (1986) considered $P$. regius to be among those snakes with the highest degree of habitat generalism in the forested regions of southeastern Nigeria. In fact, $P$. regius are challenging to find in their unaltered habitat, and deforestation has allowed for an increase in their population size (Gorzula et al., 1997). It is also likely that $P$. regius 
are more abundant than they are predicted to be from surveys, especially those in heavily forested areas (Barker and Barker, 2006).

Above-ground activity in $P$. regius peaks and remains continuous during the wet months (June-August) and then is comparatively reduced during the dry season (Luiselli et al., 2007). Most observations of these snakes are during nocturnal hours; they are rarely seen during mid-day, when they are resting in burrows during both the wet and the dry seasons. In Togo, they are in very high density, especially in fields where rodents are present, and both males and females spend most of the daytime in rodent burrows or termite mounds, where females also protect and incubate eggs (Aubret et al., 2005a).

Female $P$. regius attain significantly larger body sizes than males, which is associated with their ability to lay 3-11 large, leathery eggs per clutch (most commonly 4-6) (Barker and Barker, 2006). Typically the female incubates her eggs underground, where they hatch after 55 to 60 days (Luiselli et al., 2007). While parental care of eggs is rare among squamate reptiles, it is ubiquitous in the python lineage, as female pythons coil tightly around their eggs throughout incubation and shiver to generate warmth (Hutchison et al., 1966).

Both age and weight are involved in determining when a python is capable of breeding. Males reach sexual maturity at $6-18$ months, and for females sexual maturity is reached at $12-36$ months. Males will breed at 500 grams or less, but in captivity they are often not bred until they reach approximately 800 grams; females will begin breeding at 800 grams, though 1200 grams or more is most common. 
Parental care of the eggs ends once they hatch and the females leave their offspring (McCurley, 2005).

Python regius are long lived and typically grow to exceed $1 \mathrm{~m}$ in length.

Several have been captive for over 30 years in U.S. zoos (Barker and Barker, 2006), and the record for longest lived snake in captivity exceeds 47 years (Conant, 1993). When Gorzula et al. (1997) conducted a field survey of 206 adult specimens in Ghana, the range in total length was from $83.9 \mathrm{~cm}$ to $185.9 \mathrm{~cm}$. The average total length of all male and female specimens at 3 years was $125 \mathrm{~cm}$. These populations can, although rarely, reach lengths exceeding $185 \mathrm{~cm}$ (Cansdale, 1961).

Python regius are primarily terrestrial and climb frequently. They have also been observed spending substantial time in water, but to date, their overall ecological water presence remains unquantified. The diet of $P$. regius consists almost entirely of homeothermic prey, which is typical of other pythons of varying sizes (Luiselli et al., 2007; Shine et al., 1999; Shine et al., 1998). They consume a large proportion of arboreal species, mostly birds, in southern Nigeria (Luiselli et al., 2007; Luiselli and Angelici, 1998).

\section{Sensory systems of Python regius}

Contrary to popular belief, snakes are not deaf, even though they lack an external ear opening. Snakes, including $P$. regius, have a well-developed inner ear, even though they have lost a functional outer and middle ear (Christensen et al., 2012). In order for snakes to form a gape to consume large prey items, the mandibular tips of snake jaws must be able to move freely. In turn, they must be 
stabilized by a complex muscular system. Snakes have evolved to hypertrophy these muscles, which has excluded the tympanic cavity, making the snakes' hearing ability inferior to that of other reptiles (Berman and Regal, 1967). Christensen et al. (2012) measured evoked potentials dorsal to the VIIIth cranial nerve and the brainstem in response to a wide range of frequencies and found they have lost effective pressure hearing, but have maintained or developed vibration sensitivity via sound-induced head vibrations.

Reptiles, including snakes, possess a Jacobson's organ for vomeronasal chemical sensing (mainly for detecting pheromones and prey chemoattractants). Distinctively, only sceroglossans (skinks, gekkos, varanoids, amphisbaenids, mosasaurs, and snakes) perform tongue-flicking in order to bring chemical stimuli to their Jacobson's organ from the environment. Snakes may have the most developed vomeronasal system, and are considered models for determining the structure, function, and behaviors involved with vomeronasal sensing and processing (Lanuza and Halpern, 1997b).

Furthermore, a select group of snakes, in which pythons are included (pit vipers, pythons, and boas), possess pits (containing what is commonly referred to as a "pit organ") which serve as very sensitive infrared detectors, linked to the CNS via the trigeminal ganglion (Molenaar, 1978a; Molenaar, 1978b). Information from labial pits synapses at the visual center of the brain, thus they act as infrared vision sensors allowing for the python to "see" in the infrared spectrum (Goris, 2011; Kobayashi et al., 1992). 


\section{Evolution and phylogenetic analysis of $P$. regius}

Python regius has been placed in the Linnaean classification: Animalia Chordata Vertebrata Reptilia Squamata Serpentes Pythonidae Python regius. The order Squamata includes lizards ( 4770 species), snakes ( 3000 spp.), and amphisbaenians ( 170 spp.) Snakes can be organized into two main groups: Fossorial scolecophidians (blindsnakes and threadsnakes, 340 sp.), and Alethinophidians (all other snakes, 2640 sp.) (Heise et al., 1995; Vidal and David, 2004). Python regius belongs to Alethinophidia, which diverged from scolecophidians approximately 150MYA, and is typically divided into caenophidians (advanced snakes, 2470 sp.), also known as venomous snakes, and henophidia, which includes several other groups that utilize constriction. Pythonidae belongs to the constrictive group, of which Python is one of the 8 genera, and regius is one of the 33 species (Vidal and David, 2004). The evolutionary history of snakes is controversial. Currently, it is expected they are secondly-most basal to lizards (Bruce, 2007). Pythons are the most basal extant macrostomatan species (Castoe et al., 2011; Slowinski and Lawson, 2002), thus, P. regius may provide insight into the evolutionary origins of adult neurogenesis and the evolution of brain morphology.

\section{Evolution, anatomy, and physiology of the squamate CNS}

Amniote brains are organized according to the species-specific development of the highly-divergent telencephalon. Since mammalian and avian brains have highly specialized structures, the evolutionary development of the amniote brain can be determined by comparing the brain structures of prototypic taxa. Owen (1848) 
coined the term "homology" to refer to organs that have originated similarly regardless of form and function in different species. Studying homologs allows researchers to deduce the evolution of brain structure and function by determining similar origin.

Brain morphology and neural networks have diverged greatly between vertebrate species in accordance with each clade's unique environment. Several species have developed very specialized brain anatomy and physiology in response to environmental pressures (Butler and Hodos, 2005; Nieuwenhuyis et al., 1998; ten Donkelaar, 1988) while others have simply inherited ancestral traits, thus providing extant evidence for tracing the evolution of morphology (Nomura et al., 2013b). For example, reptiles and birds share several characteristics, including presence of the dorsal ventricular ridge (DVR) and absence of callosal projections. Yet both the structure and function of the avian DVR seem to be entirely different from the reptilian DVR. Understanding the similarities and differences of the DVR not only gives insight into regional function in both of these classes, but it can also give clues as to why the DVR originally formed and how it will continue to develop.

Warner's $(1931 ; 1946 ; 1947)$ and Carey's (1967) investigations were the first studies of the snake telencephalon, and have served as the foundation leading to the advent of morphology and pathway studies begun by Ulinski and Halpern in the 1970s (Halpern, 1980; Ulinski, 1974; Ulinski, 1975; Ulinski, 1978). Reptiles are the first vertebrate class in which distinct cortical regions become obvious. They develop physically in a way that is between the amphibian and mammalian telencephalon, 
which allows for an intermediate comparison point for making generalizations across vertebrata (Halpern, 1980).

The three clearest distinctions in the reptilian forebrain are the ventricles, the telencephalon, and the diencephalon (fig. 2). The lateral ventricle extends almost completely along the lengthwise aspect of the superior medial telencephalon, bilaterally. It begins as ovoid in shape in the main olfactory bulb, and becomes slitlike and "C shaped" moving caudally into the accessory olfactory bulb and the retrobulbar region. Reptilian brains exhibit a simple, laminated dorsal telencephalon with a 3-layered cortex, expected to be inherited from their amniote ancestry (Bruce, 2007; Wise et al., 2009). Continuing caudally into the midtelencephalon, the ventricle becomes shaped like a "lowercase n" and then a "wishbone." In the mid-caudal regions the septum becomes surrounded by the medial aspect of the ventricle. Further back it makes room for the pineal gland and the medial portion of the ventricle disappears with the septum. The diencephalon and telencephalon separate in the rostral most region as the lateral aspect of the ventricle continues to expand linearly and form a thin circular ependymal border. In this area the lateral ventricle separates the nucleus sphericus (NS) completely from the cortex. Due to the importance of pheromone perception, the NS is very well developed in snakes and occupies almost the entire caudal half of the subcortical telencephalon (Halpern, 1980; Lanuza and Halpern, 1998; Schwenk, 1993). 


\section{Squamate olfactory system}

Generally, squamates are highly olfactory-dependent as evidenced by their well-developed main olfactory bulbs (Halpern, 1992; Mason, 1992). Predatory, mating, and courtship behaviors are all, in turn, dependent on hypothalamic input in response to these olfactory afferents (Friedman and Crews, 1985a; Friedman and Crews, 1985b). The olfactory system consists of the main olfactory bulb, responsible for capturing odors at the olfactory epthelium and transmitting them to the olfactory bulb, and the accessory olfactory bulb (AOB), responsible for processing pheromones responsible for chemical social communication. These project to the lateral cortex (LC) in reptiles, which is considered homologous to the mammalian olfactory cortex (Hoogland and Vermeulen-Vanderzee, 1995; Martinez-Garcia et al., 1986). 


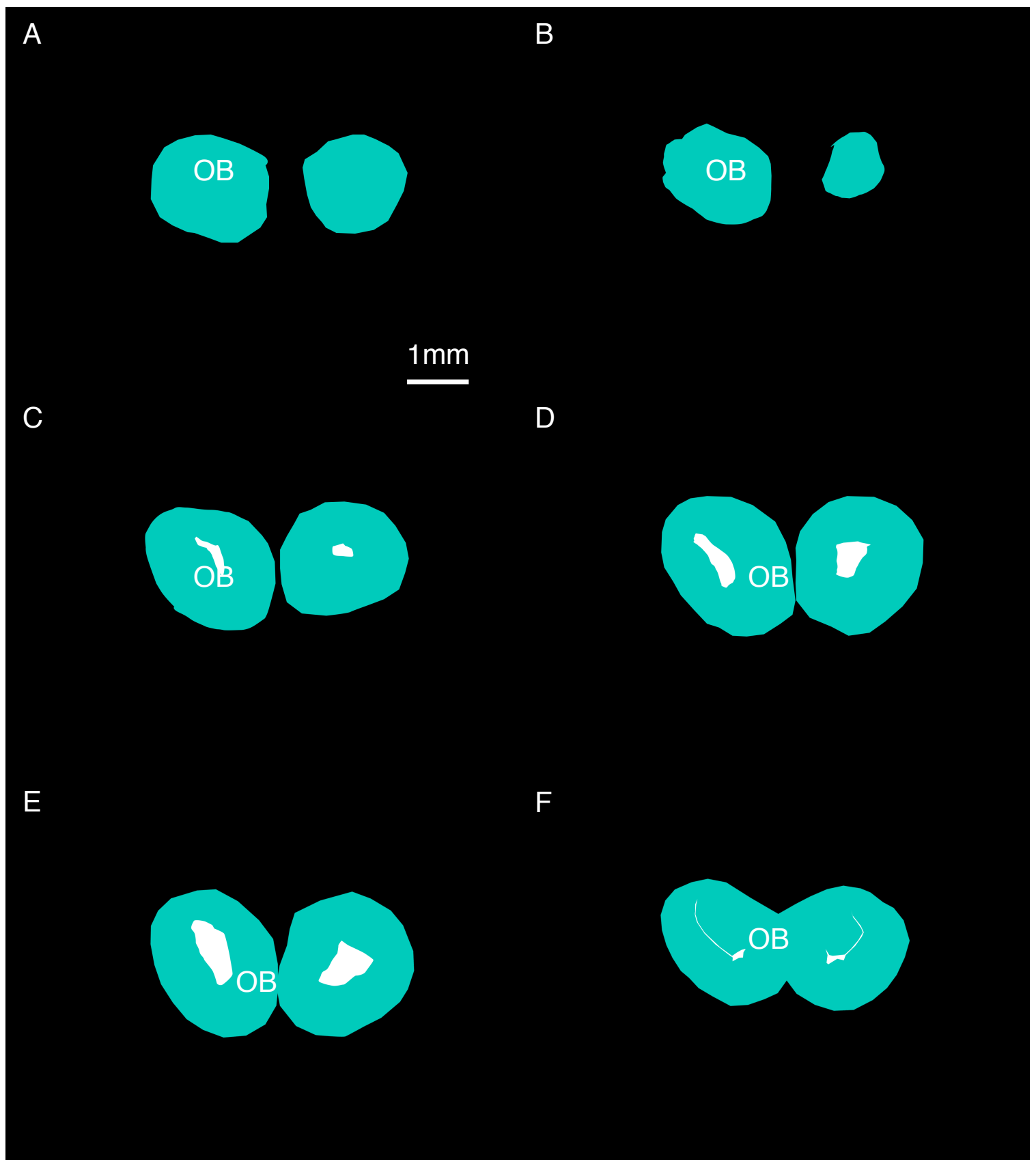




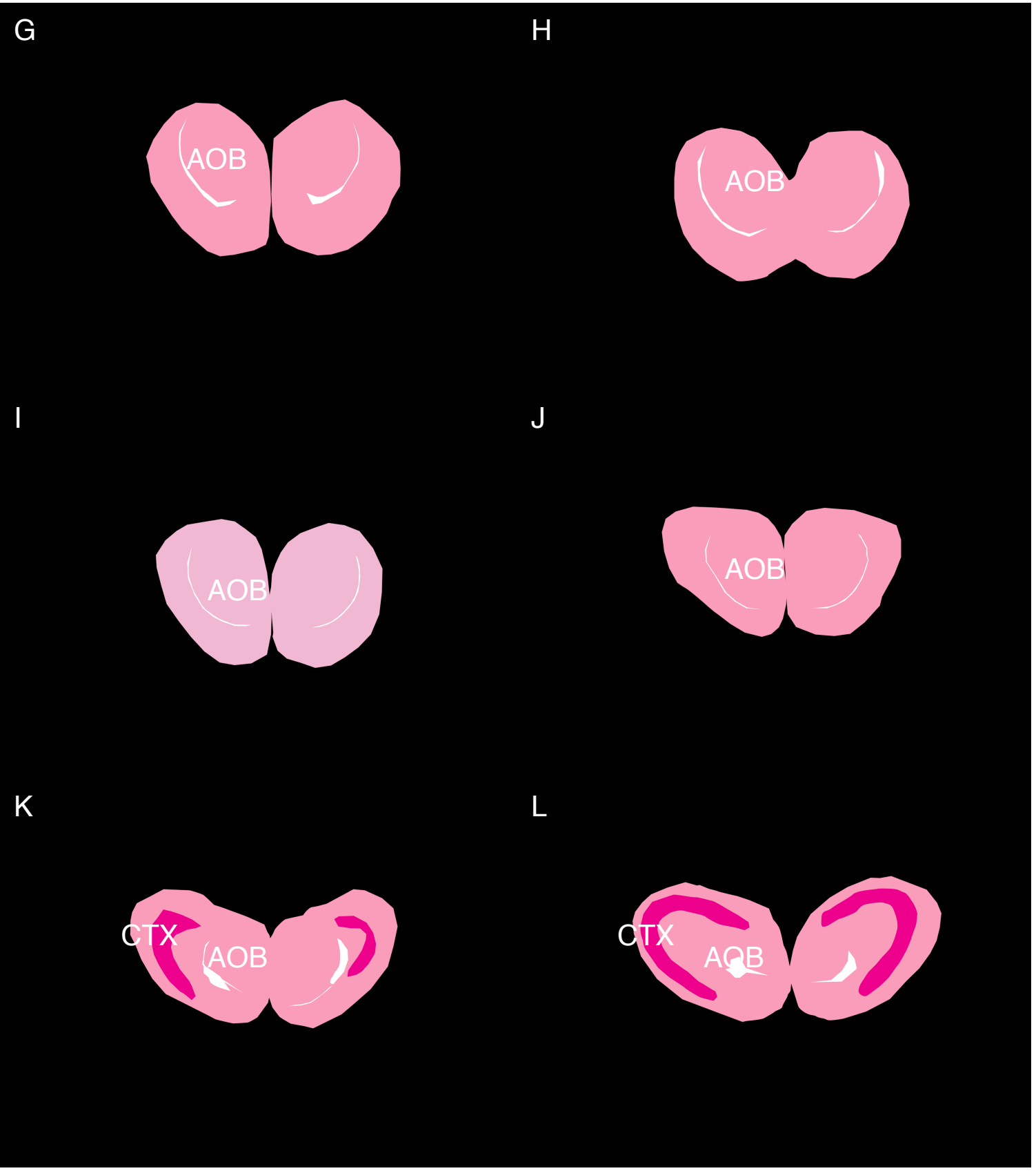




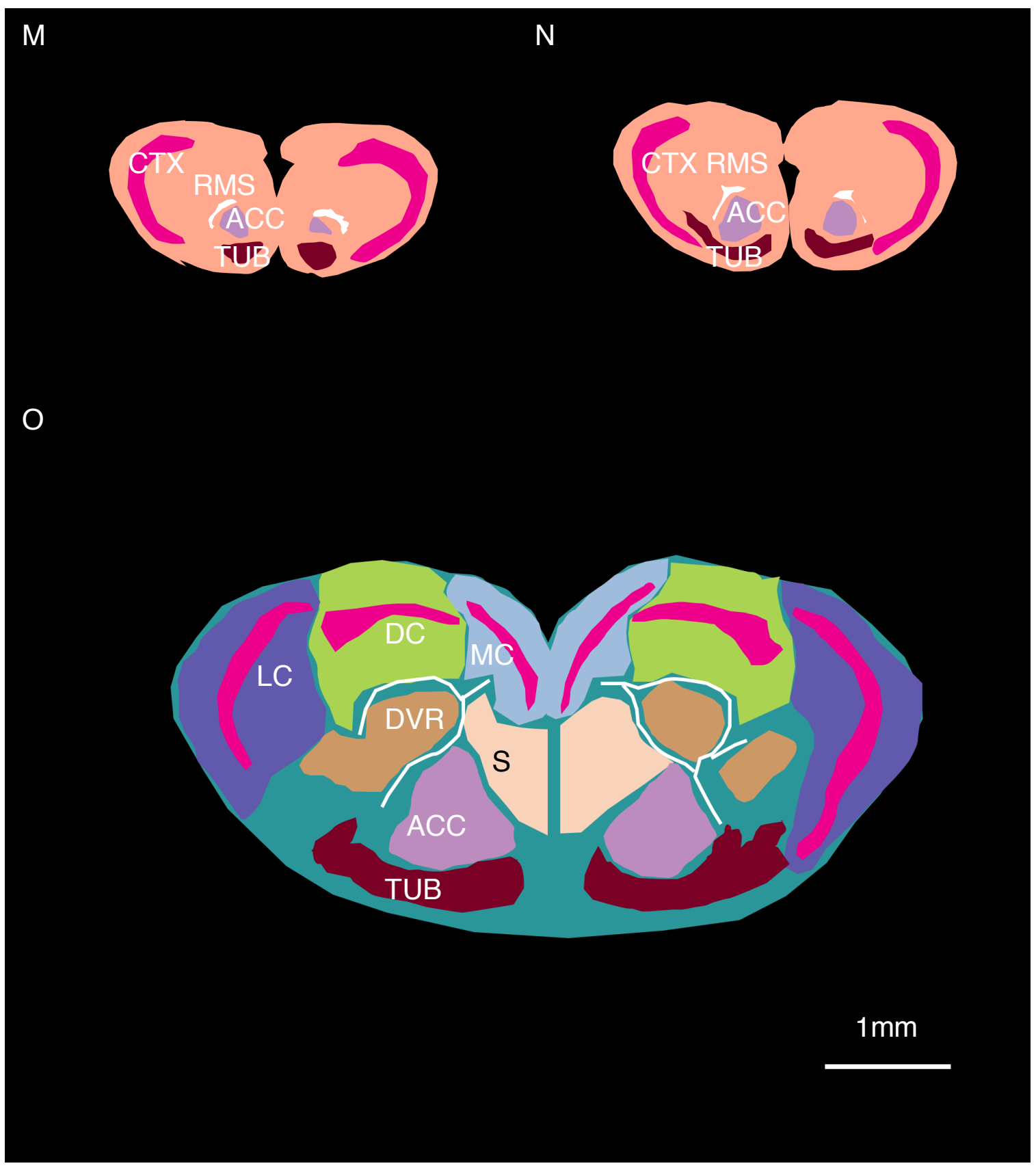




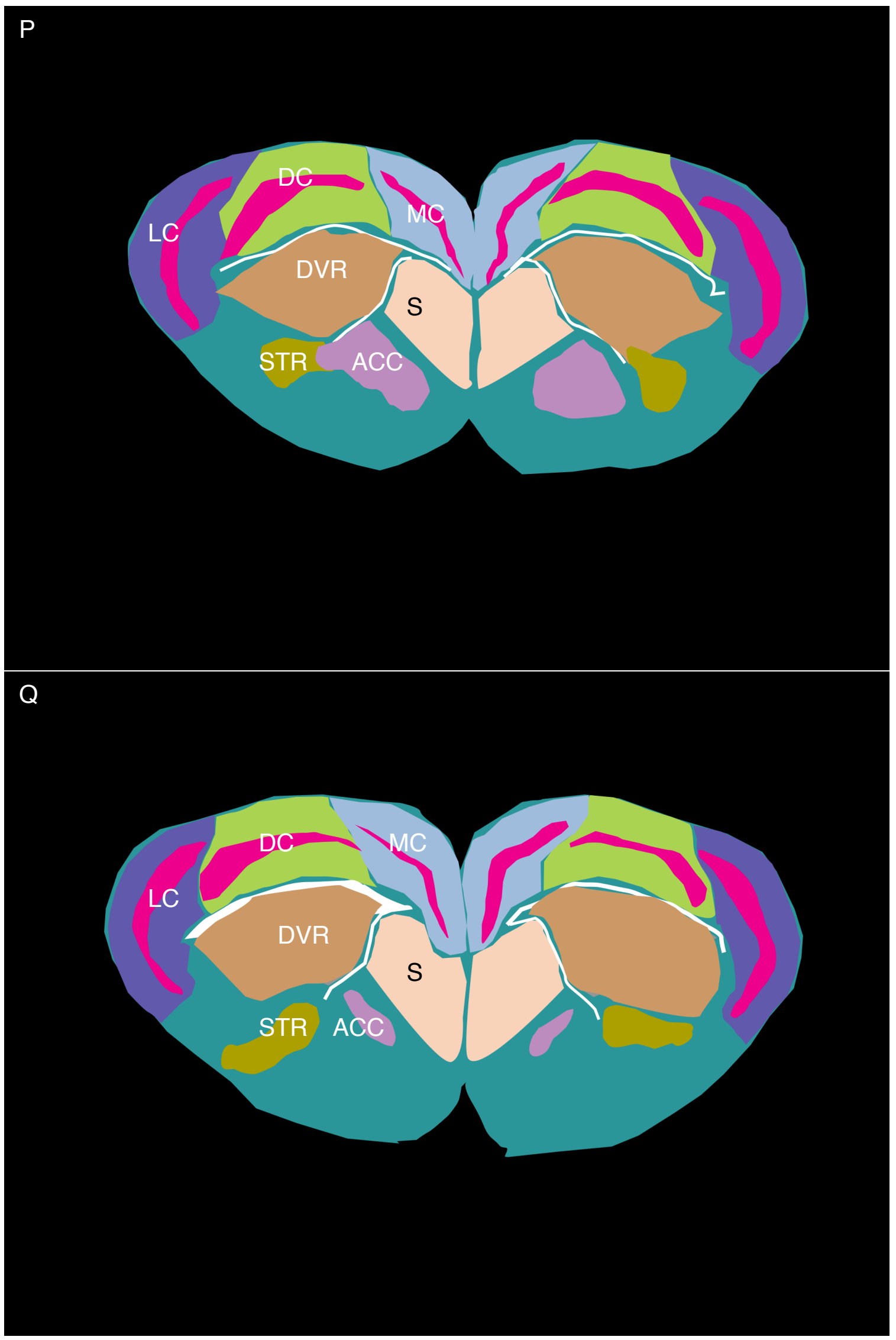




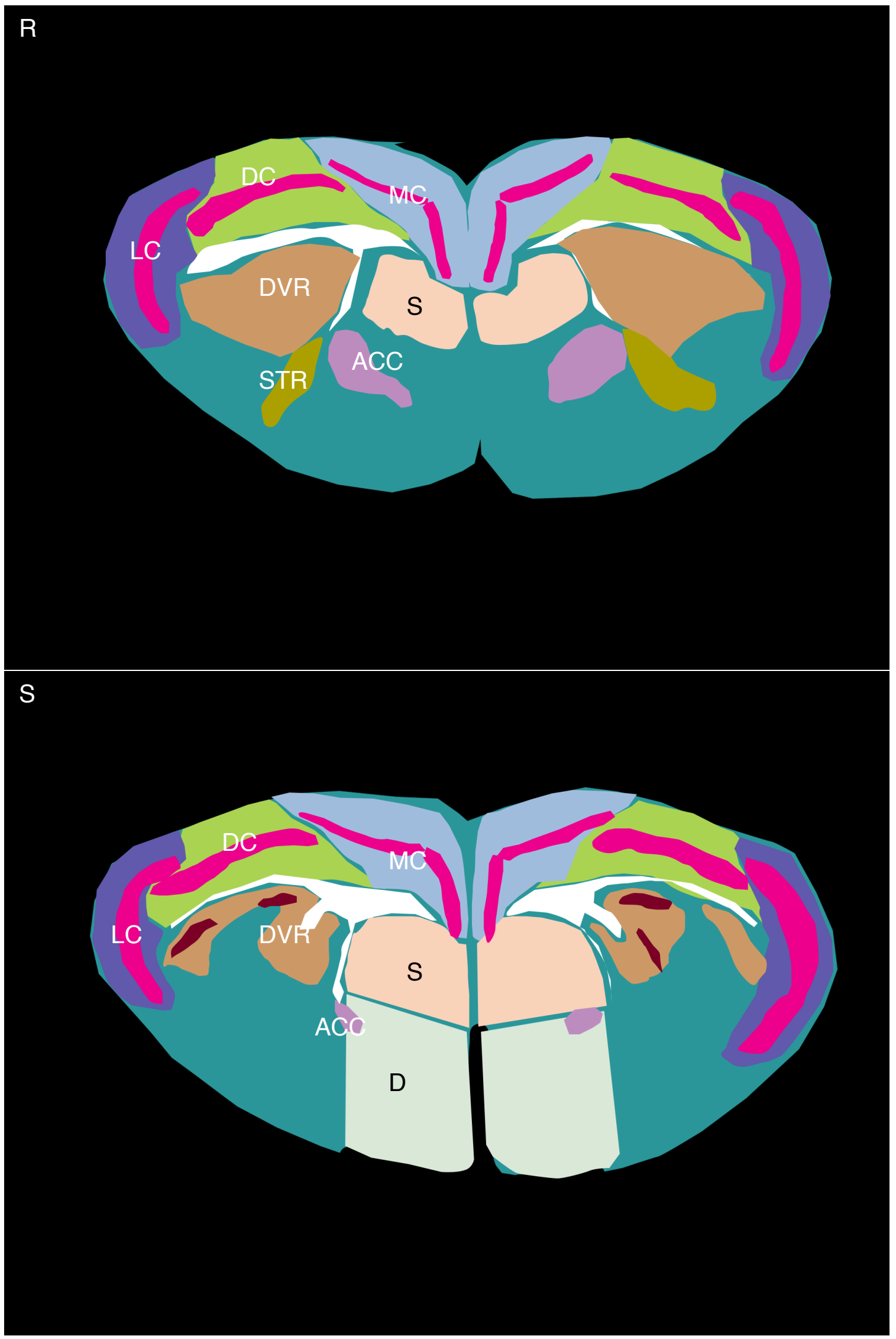




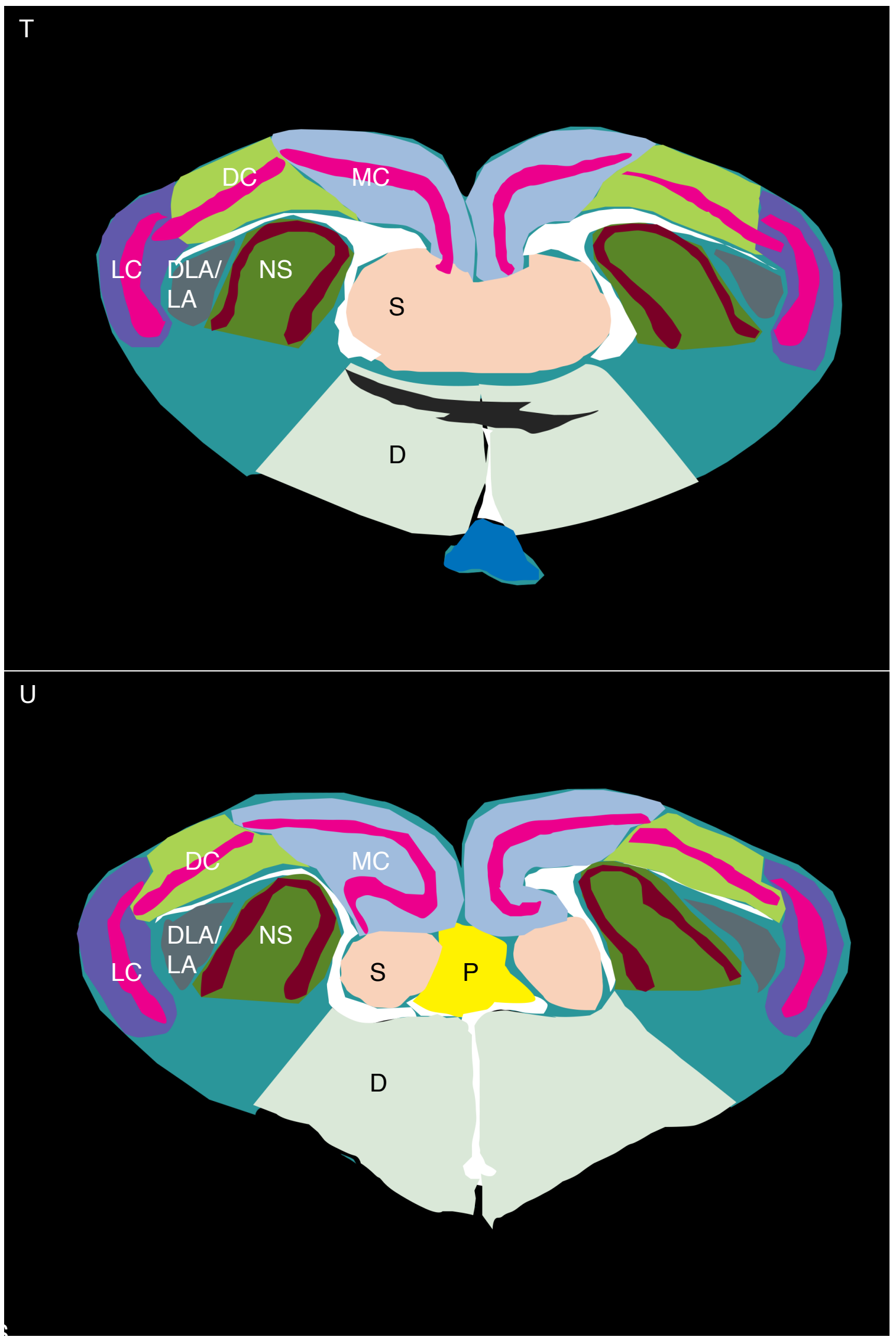




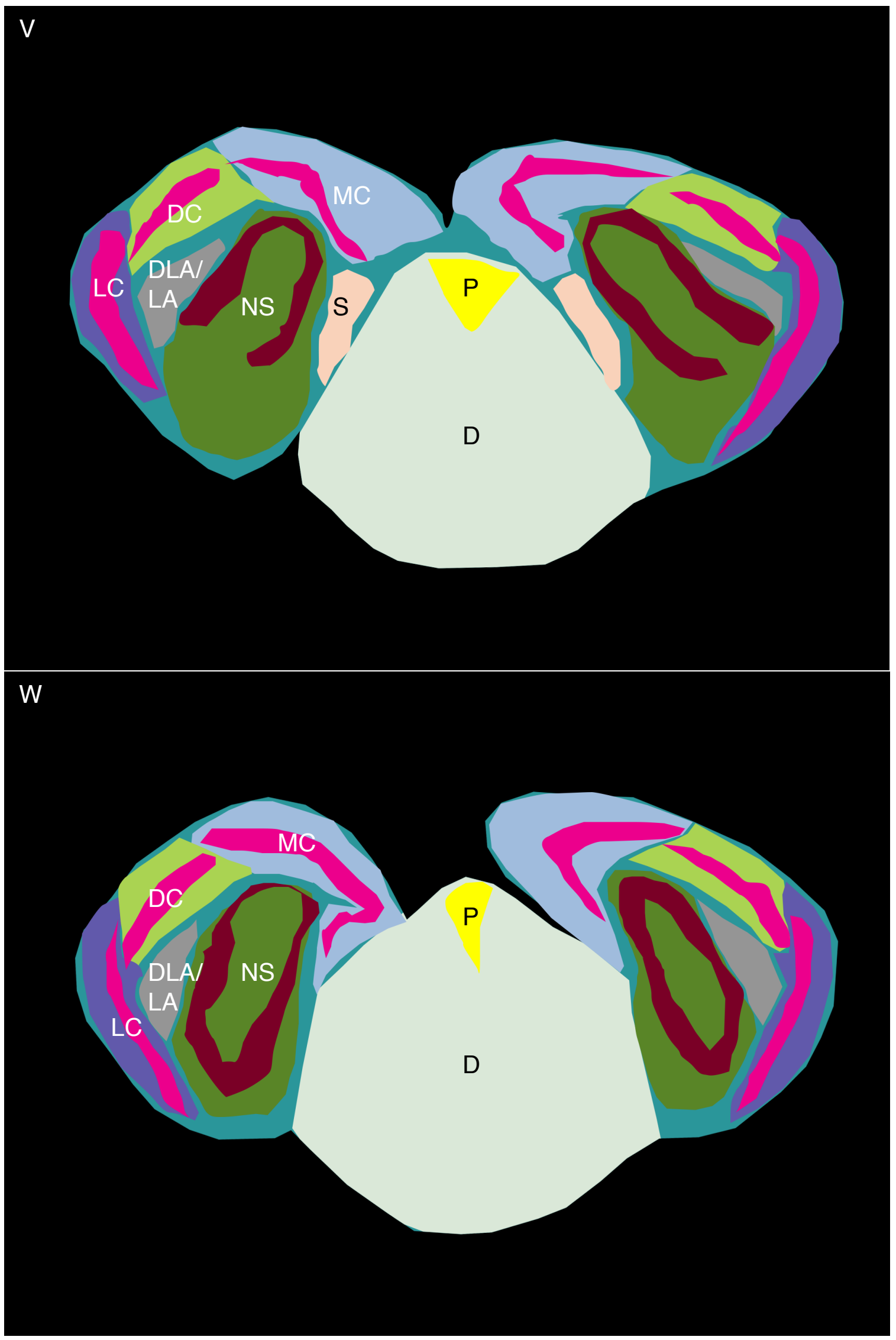




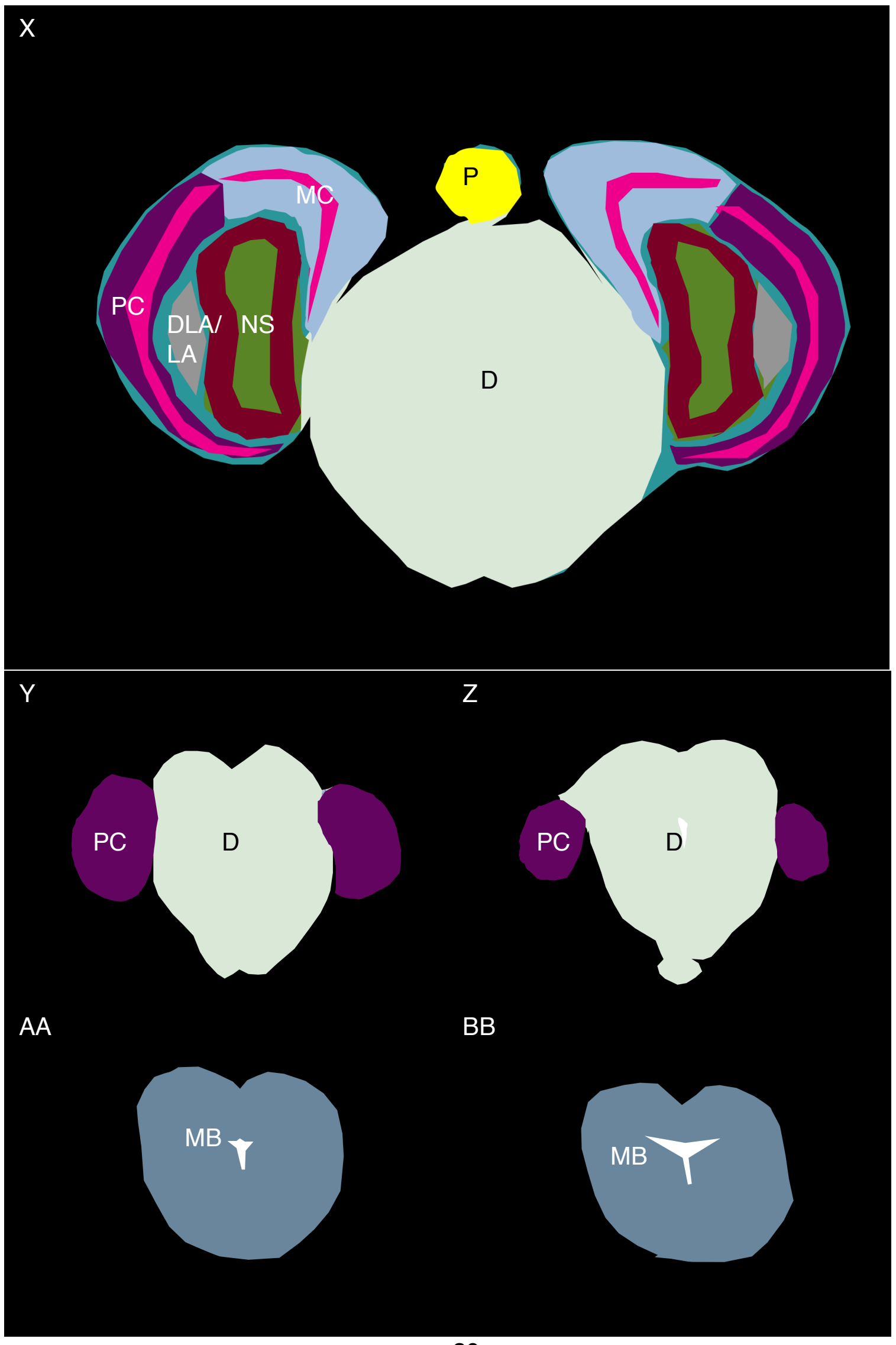


Figure 2 (previous pages): Coronal sections from rostral to caudal through the telencephalon of $\mathrm{P}$. regius highlighting regions determined by comparison of cresyl violet stained sections to Halpern (1980) and Smeets (1988). The telencephalon can be organized into: main olfactory bulb $(\mathrm{OB})$, accessory olfactory bulb $(\mathrm{AOB})$, retrobulbar region, cortical mantle (cortex; Medial Cortex, Dorsal Cortex, Lateral Cortex, Posterior Cortex), septum (S), dorsal ventricular ridge (DVR), the dorsolateral amygdala (DLA) and lateral amygdala (LA), the basal telencephalic structures which are mainly the nucleus accumbens (ACC) in the ventral-medial (VM) region and the striatum (STR) in the ventral-lateral (VL) region, and the nucleus sphericus (NS). Also labeled are the diencephalon (D), pineal gland (P) and midbrain (MB).

\section{The Dorsal Ventricular Ridge}

The dorsal part of telencephalon, including both the cortex and DVR, is called the Pallium. Across Reptilia, the most prominent pallial structure is the DVR (Holmgren, 1922; Northcutt, 1981; Ulinski, 1983). Structurally, the DVR is considered the linkage between sources of sensory information and the brain structures that modulate behavior. The anterior portion (ADVR) is considered a polisensorial processing center. Discrete auditory, somatosensory, and visual thalamic pathways terminate in the ADVR, including the infrared pathway from the pit organ. (Bruce and Neary, 1995; Martínez-Garcıa et al., 2009; Striedter, 1997).

Pit organs project to the ipsilateral medullary nucleus of the lateral descending trigeminal tract, which projects to the optic tectum (Kobayashi et al., 1992; Molenaar, 1978b; Newman et al., 1980). Experiments using rattlesnakes have supported that both visual and infared information are then relayed through the nucleus rotundus of the thalamus to the ADVR (collothalamic pathway) (Berson and Hartline, 1988; Schroeder, 1981). Whether the pathway is conserved throughout snakes with pit organs is yet to be determined. 
The PDVR on the other hand is an associative center for visual, auditory, somatosensory, and olfactory information. It receives convergent inputs from the thalamus, and direct input from the parabrachial region-most likely visceroceptive, nocioceptive, and/or gustatory signals, and lastly amygdaloid input from the DLA/LA (dorsolateral amygdala and lateral amygdala) (Lanuza et al., 1998; Martínez-Garcıa et al., 2009).

There have been functional studies involving lesioning, stimulus and behavior in reptiles (Distel, 1978; Ivazov, 1983; Sugerman and Demski, 1978; Tarr, 1977), but these studies provide only scarce glimpses into the function of the DVR. Using green iguanas, Distel (1978) found stimulus of the DVR to be associated with only minimal physiological response: Locomotion, head movement, and tongue-flicking were associated with stimulation, however no response was found in approximately $40 \%$ of subjects stimulated with the high intensity stimulus, and an even greater proportion elicited no response when stimulated with low intensity. Ivazov (1983) found a decrease in conditioned response when the DVR was lesioned bilaterally in Pseudopus apodus (the European legless lizard). The conditioned response was most disturbed by lateral lesioning, which likely affected visual function. Sugerman and Demski (1978) found DVR stimulation elicited defensive responses in Crotaphytus collaris (western collared lizards), including defensive display, escape response, and gular extension display. So far there have not been any patterns linking general function of the DVR to stimulus or lesion, and the DVR may in fact be 
more heterogeneous than expected in reptiles, so the lack of data at this point limits any structural-functional hypotheses.

The dominant majority of functional studies of the DVR are in avian species and have shown that the DVR is involved in imprinting, song learning, avoidance learning, tool manufacture, tool use, flexible behaviors, high-order associations, and complex cognition (Rattenborg and Martinez-Gonzalez, 2011). Even these studies, which are considerably greater in number than reptile studies only provide early insights into DVR function. Moreover, functional homology between the avian and reptilian DVR is not clear-cut. While there are many structural similarities, the reptilian pallial thickening, which is outside the reptilian DVR, makes connections more comparable to those of the avian mesopallium than any region inside the DVR (Bruce, 2009).

In studies of birds and reptiles the DVR has been compared to the pallial amygdala and claustrum/endopiriform/piriform amygdalar complexes of mammals (Aboitiz et al., 2003; Bruce and Neary, 1995; González-Granero et al., 2011; Holmgren, 1922; Martínez-Garcia et al., 2009; Nomura et al., 2013b; Striedter, 1997). This comparison is controversial, however, for some researchers have proposed it is homologous to the lateral (extrastriate and auditory) neocortex, instead (Jarvis et al., 2005; Karten, 1997). Lastly, Molnár and Butler (2002) propose that it is, instead, a combination of both. Molnár and Butler expect the sauropsid ADVR is structurally homologous to the lateral neocotex, basolateral amygdalar complex, and claustrum-endopiriform nucleus because they originate from the same 
collopallial field. Ongoing research is attempting to resolve this discrepancy (Aboitiz, 2011; Butler et al., 2011; Karten, 2013; Luzzati et al., 2009; Martínez-Garcıa et al., 2009; Medina et al., 2013; Medina et al., 2011; Nomura et al., 2008).

\section{DLA and PDVR nomenclature}

The DLA and the PDVR have been distinguished in different ways in previous studies. Following Curwen (1939), snake studies labeled the region lateral to the caudalmost NS as "pDVR" (Halpern, 1980; Krohmer and Crews, 1987b; Ulinski and Rainey, 1980). Subsequently, Martinez-Garcia et al. (1991) labeled the region as DLA in lizards, and limited the PDVR to the caudal DVR region without this additional area (Martínez-García et al., 1993). This system has been implemented in many contemporary snake and squamate brain studies (Lanuza and Halpern, 1997b; Lanuza and Halpern, 1998; Martínez-García et al., 2007). Simultaneously, several snake brain studies have continued to use the previous system (Holding et al., 2012;

Krohmer et al., 2010; Krohmer et al., 2011). A dialogue should occur between researchers to further consistency in future studies. I will use DLA/LA combined, separately from the PDVR, for labeling this region in its entirety. The medial amygdala was not labeled as a region for this study because it could not be discerned using cresyl violet stain.

\section{The amygdala}

In reptiles, the amygdala is a general term used to refer to amygdalohypothalamic circuits that (a.) relay chemosensory input to the hypothalamus to influence chemically-guided behaviors (Martínez-Marcos et al., 1999) and (b.) 
receive inputs from sensory and associative areas (Martínez-García et al., 2007). It is not a monolithic structure, but instead a collection of nuclei-a somewhat arbitrary assemblage that is "neither a structural nor functional unit" (Swanson and Petrovich, 1998). The amygdala of the common garter snake, Thamnophis sirtalis, has been shown to be part of a complex system, in which the following amygdalohypothalamic projections occur: (a) The olfactory amygdala receives input from the NS and then projects back to the NS, PDVR, and hypothalamus; (b) the NS projects directly to the hypothalamus; (c.) the medial amygdala receives input from the LC and NS and transmits to the hypothalamus; (d.) the PDVR receives afferents from the LC and amygdala and projects to the hypothalamus; (e.) the DLA receives inputs from the LC and NS to project to the hypothalamus (Martínez-Marcos et al., 1999); and (f.) the medial amygdaloid nucleus and the NS are efferents of the accessory olfactory bulb (Bruce and Dear, 1995a, 1995b).

When making comparisons to the mammalian amygdala, the comparable reptilian structures are yet to be clarified. This occurs partly because the mammalian amygdala is still being characterized using developmental, neurochemical, and hodological (interconnection and pathway-based) approaches (Martínez-García et al., 2007). The reptilian LC may be homologous to the mammalian posterior lateral cortical amygdala, and the NS might be homologous to the posterior medial cortical amygdala (Eisthen and Polese, 2007; Martínez-Garcıa et al., 2009). As previously mentioned, the PDVR not included in the DLA has been considered a homolog of the mammalian pallial amygdala, but this comparison is still awaiting clarification. 
The DLA is the main link between the striatum (STR) and the amygdalar pathways and is likely the reptilian homologue to the basal nuclei of the mammalian amygdala (Bruce, 2009; Martínez-Garcıa et al., 2009). The mammalian basal nuclei seem to have an essential function in the acquisition and expression of fear conditioning (Amano et al., 2011). While comparisons have been attempted in birds (Bruce, 2009), the lack of a vomeronasal system, and poorly developed olfactory system has considerably limited the accuracy of comparison (Moreno and González, 2007). In anurans, three main amygdaloid subdivisions have been discovered, the lateral amygdala, medial amygdala, and central amygdala. Similar to the basal nuclei

of mammals, the anuran lateral amygdala is responsible for association and labeling of chemical odors, pheromones and non-chemical visual, auditory, somatosensory, stimuli. It provides emotional labeling of stimuli, creating an "emotive memory," allowing for conditioning of stimuli (Moreno and González, 2007).

\section{The dorsal and medial cortex}

The reptilian cortex is comprised of three-layered laminar structures that may have been acquired by early amniotes (Wise et al., 2009). The cortex consists of a cell-dense central layer surrounded by cell-sparse outer and inner plexiform layers (Ulinski, 1990). The ophidian cerebral cortex is divided into three primary regions, the medial, dorsal, lateral, and posterior cortices (MC, DC, LC), and a fourth subregion, the dorsomedial cortex. The dorsomedial cortex, located between the medial and dorsal cortex, was first described as a separate subregion as early as 1917 , and was originally named "zona piramidial curvilinear" by Ramon y Cajal (1917); (1918). 
It has only been found in squamates and it does not develop independently until after birth (Lopez-Garcia et al., 1984). For this study it was difficult to distinguish dorsomedial cortex from the medial cortex so only the three main regions are used. They all extend longitudinally from the anterior olfactory bulb (rostralmost) to a fifth region, the posterior cortex (PC; caudalmost) of the telencephalon. I have noted the PC as a separate part of the cortex because it is difficult to distinguish different cell layers in the hindmost portion of the cortex, and while it is most likely the caudal continuation of the MC, cells could also originate from the DC and LC layers.

In mammals, the hippocampus is considered a center for spatial memory. The reptilian $\mathrm{MC}$ and $\mathrm{DC}$ are generally regarded as homologous to the mammalian and avian hippocampus (Bruce and Butler, 1984; Butler and Hodos, 2005; Rodriguez et al., 2002). In reptiles, spatial learning has been demonstrated in Elaphe guttata guttata (corn snakes) (Holtzman et al., 1999) and Tiliqua rugosa (blue tongued skinks) (Zuri and Bull, 2000). Also, lesioning the medial and dorsal cortices of turtles causes a reduction in maze navigation ability (Lopez et al., 2003; Rodriguez et al., 2002) and produces deficits in a variety of non-spatial tasks such as discrimination and restraint habituation (Blau and Powers, 1989; Grisham and Powers, 1989; Moran et al., 1998). In squamate reptiles including snakes, the MC is also associated with navigation ability (Baird Day et al., 1999a; Baird Day et al., 1999b; Crews and Wilczynski, 2000; Holding et al., 2012; LaDage et al., 2009; Roth et al., 2006). 
Similarities also exist in the development and growth of the reptilian MC and mammalian hippocampus. Neuroblasts of the reptilian MC express PSA-NCAM during migration similarly to the neuroblasts of the mammalian hippocampus (Ramirez-Castillejo et al., 2002b; Seki and Arai, 1993). Also similar to the hippocampus in birds, the two neuronal types that make up the $M C$ in lizards are small (type I) and large (type II) neurons (Kirn et al., 1999; Lopez-Garcia et al., 1984). As lizards age the neurons in the MC convert from large to small, possibly due to the chromatin condensation process. This transformation either is species specific or has not been explored at enough time points in enough species to capture its universality (Pérez-Cañellas and García-Verdugo, 1996).

Nevertheless, there is some question as to whether the MC is indeed homologous to the hippocampus. Baird Day et al. (2001) argued that perhaps only navigation, and not spatial memory are altered by lesioning. When challenging Cnemidophorus inornatus (little striped whiptail lizards) to locate a heated rock in a circular arena they found lesioning the DC and MC slowed the lizards' ability to locate objects, and altered their search strategies. Still, none of the lizards in the cortex-lesioned or sham-lesioned groups adopted a spatial strategy for locating objects, indicating that lizards may not be utilizing true "spatial memory" per se. Instead the MC may be necessary for flexible navigational learning, and the DC may be involved in remembering unchanging external cues. This has been supported by Jacobs (2003) who expects lizards are orienting according to directional cues like magnetic fields, temperature, color, auditory or light cues, and not with true spatial 
memory. Jacobs also gives two potential explanations for the discrepancies between turtles and lizards: (a) turtles are relying on a bearing map instead of a sketch map, or (b) turtles visual cognition is functionally and anatomically different from lizards (Bruce and Butler, 1984; Hall and Ebner, 1970). This is actively a point of contention among researchers and is still undergoing investigation (LaDage et al., 2012).

\section{The retrobulbar regions}

Rostral to the cortices, the retrobulbar region is the region directly caudal to the AOB. It is where the dorsal and lateral pallium forms, and becomes semicircular on the dorsal surface posteriorly, forming the rostralmost cortex. The cortex is not yet distinguishable as three different cell layers (MC, DC, LC) and instead forms a single cell layer. The pallium rapidly enlarges caudally, laterally and dorsomedially, to comprise the majority of the dorsal telencephalon.

The largest nucleus of the retrobulbar anterior ventral (AV) region is the olfactory tubercle (TUB). The TUB links directly to the olfactory bulb, to relay and processes olfactory signals. In reptiles there has been very little study of the TUB, other than some afferent and efferent tract tracing studies (Halpern, 1976; Lanuza and Halpern, 1997a; Lanuza and Halpern, 1998). Yet the TUB has been considerably studied in mammals, and these studies have uncovered that it receives afferents from multiple sensory, storage, neuroendocrine and limbic structures (Budinger et al., 2006; Fallon, 1983; Groenewegen et al., 1987; Mick et al., 1993;

Scott et al., 1980; Ubeda-Bañon et al., 2008; Vertes and Hoover, 2008). This 
aggregation of so many systems at the mammalian TUB indicates that it may actually be an integrator of multimodal information (Wesson and Wilson, 2010).

Functional studies in humans have shown the TUB is essential to the discrimination of the source (type) of olfactory information (Zelano et al., 2007), and the direction of attention to smells (Zelano et al., 2005). In other mammal studies, the TUB also plays a role in behavior (Hitt et al., 1973). Bilateral lesioning has been found to reduce copulation in male rats (Hitt et al., 1973). Lesioning has also been found to cause hyperphagia and attenuates increases in locomotion associated with dextroamphetamine. (Koob et al., 1978). The most studied aspect of the TUB is its role in addiction and reward systems (Heimer, 2003; Ikemoto, 2007). Ikemoto (2003) found that when rats are able to self-administer intracerebral infusions of cocaine to several brain regions, the olfactory tubercle is more rewarding than the ACC, and successfully elicits conditioned place preference. It is likely the TUB plays an essential role in odor-motivated behavior, including approach/avoidance, conditioning, and learning. Given our lack of information on the function of the TUB in non-mammalian vertebrates, there is a whole area of comparison to nonmammalian species open for discovery.

\section{The basal forebrain}

In the ventral side of the retrobulbar telencephalon, the striatum (STR) and olfactostriatum form (Durward, 1930). The nucleus accumbens (ACC) lies between the septum and paleostriatum (Warner, 1947), and may be considered part of the paleostriatum (Halpern, 1980). Compared to other reptiles, the python has a very 
large ACC and a small STR (personal observation), however no researchers have investigated functional or evolutionary aspects of this distinction (Smeets, 1988).

The ACC is the dominant structure of the VM portion of the $P$. regius telencephalon. In mammals, it has been implicated as responsible for motivation and reward-seeking behavior (Cador et al., 1989; Knutson et al., 2001), to the point where rats will self-administer amphetamine directly to the ACC in a feedback loop of addiction (Hoebel et al., 1983). Furthermore, the ACC is essential to the flexible facilitation of rewards and the avoidance of negative stimuli, and the construction of learned incentive structures (Ikemoto and Panksepp, 1999). The mammalian ACC is structurally, hodologicallly, neurochemically, and developmentally similar to the reptilian ACC (Gonzalez et al., 1990; Guirado et al., 1999; Russchen and Jonker, 1988; Smeets and Medina, 1995; Smeets, 1988; Smeets et al., 1986; Smeets et al., 1987). When male Eublepharis macularius (leopard geckos) hatch from eggs incubated at female-biased temperatures, they maintain higher dopamine (DA) levels in the ACC when encountering females, compared to those hatched at malebiased temperatures (Dias et al., 2007). Since males hatched at female-biased temperatures are more sexually active (Flores et al., 1994; Sakata and Crews, 2003) and exhibit greater anticipatory behavior when exposed to females (Sakata and Crews, 2003), these findings may serve as a jumping-off point for studying the function of the ACC and its influence on behavior in reptiles.

The STR embodies the majority of the VL region. In mammals, it is the key nucleus of the basal ganglia, involved in the selection of non-adverse (Darvas et al., 
2011; Dombrowski et al., 2013) and pro-rewarding actions (Da Cunha et al., 2012;

Kravitz et al., 2012; Yin et al., 2004). It is densely innervated with dopaminergic neurons from the midbrain nigrostriatal pathway, and its dysfunction is implicated as responsible for hypokinesia (e.g. Parkinson's disease) (Li et al., 2009) or hyperkinesia (e.g. chorea, dystonia) (Mink, 2003).

Currently, the mammalian, avian, and reptilian STR all appear to be hodologically, neurochemically, and developmentally similar (Gonzalez et al., 1990; Moreno et al., 2010; Russchen and Jonker, 1988; Smeets, 1988; Smeets et al., 1986; Smeets et al., 1987). Lesioning the reptilian STR in male A. carolinensis causes a reduction in male-typical assertation display (Greenberg, 1977). Stimulation, on the other hand, elicits assertation display, challenge display, and locomotor responses in S. occidentalis (Tarr, 1982).

\section{The septum}

The septum is the region medial to the lateral ventricle. Carey (1967) determined that there are eight septal nuclei in Coluber constrictor constrictor (Blacksnakes). Crosby et al. (1967) determined that there are nine nuclei in $C$. constrictor constrictor. Some clarification has also been found in other reptiles (Font et al., 1995a; Font et al., 1998a; Font et al., 1998b; Font et al., 1997a). In comparative studies, there are three major divisions to the septum (lateral, medial, and caudal), which all tetrapod vertebrates share (Lanuza and Martínez-García, 2009). Lanuza and Martínez-García (2009) argue the similarities of these divisions can serve as evidence of the essential and conserved functions of the septum. 
Studies in reptiles confirm some homology with the mammalian septum, and have revealed: (a.) The lateral septal complex receives excitatory input from the hippocampal cortex and generates inhibitory efferents to the medial ventral pallidum and motor parts of the hypothalamus; (b.) the medial septal complex sends inhibitory signals to the hypothalamus; and (c.) the caudal division (triangular nucleus) projects mainly to the habenula (Font et al., 1998b; Swanson and Risold, 2000).

Font et al. (1998b) posited that the lateral septum is involved in the expression of appetitive behaviors (e.g. food and water intake), aggressive/defensive behavior, and reproductive physiology in reptiles, and may be considered a "distributor of behaviors" (Distel, 1978; Krohmer and Crews, 1987a; Tarr, 1977). Concurring with functional rat studies, the septum may mediate social memory including olfactory cues, parental behavior, intraspecific aggression, dominantsubordinate relationships, defensive/agonistic behaviors and territoriality; which is why it is considered key to the social behavior network (Dantzer et al., 1988; Lanuza and Martínez-García, 2009; Numan, 2000; Sheehan and Numan, 2000; Yang and Wilczynski, 2007). The main afferent to the lateral septum is a projection from the hippocampal formation, which provides spatial and non-spatial contextual information in mammals (Sheehan et al., 2004). Hence the lateral and medial septum are possibly responsible for initiating territorial behaviors in reptiles, like in mammals, in response to contextual cues (Newman, 1999). 


\section{History of adult neurogenesis research}

Over the past 50 years, the study of adult neurogenesis has developed from marginal origins to become an integral part of neuroscience research. For most of the $20^{\text {th }}$ century, neurogenesis (the process of generating new neurons from progenitor cells) was assumed to occur only in prenatal and early developmental stages of organisms (Gross, 2000; Ramón y Cajal, 1928). The proliferation of neurons in adult mammals was first discovered by Altman (1962) but received little attention. It was the development of techniques like 5-bromo-2'deoxyuridine (BrdU) immunohistochemistry (IHC) and confocal microscopy in the 1980s and 1990s that convinced researchers that adult neurogenesis indeed occurs across a wide range of taxa. The discovery of neurogenesis in birds during the 1980s prompted researchers to look at mammals again (Goldman and Nottebohm, 1983). In 2000, Gross declared that the long-standing dogma that new neurons cannot be added to the adult brain had been substantially overturned.

While the advent of biotechnology has generated considerable interest in neurogenesis, researchers have not yet elucidated the mechanisms of adult neurogenesis or how it impacts behavior, particularly in non-mammalian species. Several investigators have emphasized the importance of studying adult neurogenesis in a wide range of species, in both laboratory and natural environments (Font et al., 2001; Lindsey and Tropepe, 2006). Others have proposed that organisms need to be subjected to various experimental manipulations in order to discern what factors affect neurogenesis (Kaslin et al., 2008; Kempermann et al., 
1997). In rats, for example, learning tasks, larger cages and novel objects reduce the death rate in newly born neurons (Gould et al., 1999; Kempermann et al., 1998). Further, in mammals, sleep and exercise both positively affect neurogenesis (Meerlo et al., 2009; Olson et al., 2006; van Praag et al., 1999) and stress negatively affects neurogenesis (Gould et al., 1997; Gould et al., 1998). Powers and Hanusch (2012) have begun to investigate the effect of enriched environments on neurogenesis in reptiles using painted turtles (Chrysemys picta).

\section{Use of markers to study neurogenesis}

Tritiated thymidine autoradiography is a technique used to study cell proliferation, migration and differentiation. The injected tritiated thymidine is incorporated into the DNA during S-phase of the cell cycle marking only new cells during their mitosis. After the organism is sacrificed and the tissue is fixed, sections are observed by autoradiography, which provides a snapshot of new cells undergoing dynamic processes of birth and development. While this method marks new cells very effectively for observation and quantification under microscopy, tritiated molecules emit beta radiation, and can be absorbed through the air or the skin, and remain in the body as a long-term carcinogen.

In the 1980 s BrdU was developed as a marker for proliferating cells (Gratzner, 1982; Miller and Nowakowski, 1988). BrdU has subsequently become the preferred neurogenesis marker in developing and adult brains because it utilizes immunohistochemistry (IHC) instead of autoradiography (Abrous et al., 2005;

Christie and Cameron, 2006; Kuhn and Cooper-Kuhn, 2007; Wojtowicz and Kee, 
2006). Like tritiated thymidine, BrdU is a thymidine analog that incorporates into

DNA during S-phase. However instead of potentially dangerous radiolabelled molecules, BrdU uses brominated molecules. Anti-BrdU antibodies can then bind to the brominated region and be bound by biotinylated or fluorescent antibodies for observation.

While early studies used $50 \mathrm{mg} / \mathrm{kg}$ doses of BrdU, Cameron and Mckay (2001) and Gould and Gross (2002) determined that increasing the dose of BrdU injected in rats to $300 \mathrm{mg} / \mathrm{kg}$ labeled significantly more new cells at the end of 24 hour and 4 week periods. In contrast, Burns and Kuan (2005) double labeled with lododeoxyuridine (IdU) and found that the standard doses of $50 \mathrm{mg} / \mathrm{kg}-100 \mathrm{mg} / \mathrm{kg}$ labeled only $\sim 10 \%$ fewer cells than the $300 \mathrm{mg} / \mathrm{kg}$ dose in mice. Hancock et al. (2009) also found significant differences between the BrdU doses of $40 \mathrm{mg} / \mathrm{kg}$ and $240 \mathrm{mg} / \mathrm{kg}$, but did not find differences between $240 \mathrm{mg} / \mathrm{kg}$ and $480 \mathrm{mg} / \mathrm{kg}$ doses, supporting Gould \& Gross's original finding and implying the optimum dose in rats may in fact be between $200 \mathrm{mg} / \mathrm{kg}$ and $300 \mathrm{mg} / \mathrm{kg}$. So far all dosage studies have been performed in mammals and differences in the effect of dosage are yet to be determined in reptiles and birds.

When administering BrdU, there is a distinct difference between embryonic and postnatal brains in regard to toxic effects. Bannigan (1985) found that BrdUlabeling induced cell death in embryonic mouse brain cells. Cameron and Mckay (2001) found that adult rat brains, on the other hand, are not harmed. This result was 
also supported by Hancock et al. (2009), who did not find damage to the rat hippocampus after BrdU administration.

Inconsistency among previous BrdU-based adult neurogenesis experiments has prevented researchers from being able to make direct comparisons.

Quantification practices are inconsistent among experiments due to differences in dosages and antibodies used for detection. For example, (Leuner et al., 2009) found that Dako, Roche, BD, and Accurate brand antibodies against BrdU labeled more rat hippocampal cells than those from Vector and Novocastra.

In mammals, the number of cells labeled with a single injection of BrdU doubles between 2 hours and 24 hours after injection. This indicates that BrdU must be labeling only dividing cells. A concern has been whether or not BrdU is not just integrated into new cells, but also cells undergoing DNA repair. In studies of the normal mammalian brain, DNA repair is constant (Korr et al., 1989; Korr and Schultze, 1989; Schmitz et al., 1999). DNA repair has only been marked by BrdU in studies where cultured non-neuronal cells are damaged by genotoxic chemicals or UV exposure (Selden et al., 1994; Selden et al., 1993). Schmitz et al. (1999) found that no studies have identified BrdU labeling of DNA repair (in vivo) in mice. Molecularly, the anti-BrdU antibody clone commonly used (IU-4) requires divalent antigen binding, which is not likely to occur during in vivo repair (Selden et al., 1994).

The use of subcutaneous injections may also influence the required dose of BrdU necessary for studying adult neurogenesis in snakes because of the permeability of the blood brain barrier to nucleosides. Previous studies of 
neurogenesis in mammals support the likelihood that the blood-brain barrier restricts thymidine entry into the brain (Bradbury, 1979; Das and Altman, 1971; Kaplan, 1982). BrdU is transported by active and facilitative nucleoside transport systems comparable to thymidine (Lynch et al., 1977). However, no studies have been performed comparing injections into the peritoneum (intraperitoneal; IP) or subcutaneous injections to direct injections in the cerebral ventricles (intracerebroventricular; ICV) in snakes or other reptiles. Thus the permeability of the blood-brain barrier to thymidine or BrdU and the density of nucleoside transporters are yet to be established.

To determine whether ${ }^{3} \mathrm{H}$-Thymidine- or BrdU-marked cells are neurons, people have used a variety of techniques to demonstrate anatomically that these cells are neurons, such as electron microscopy to show the presence of dendrites and synapses (Lopez-Garcia et al., 1988) or light microscopy to identify the large nucleus and prominent nucleoli of neurons (Goldman and Nottebohm, 1983). Possibly the most accurate and convenient way to determine the phenotype of different brain cell types is to use antibody markers such as doublecortin (DCX), glial fibrillary acidic protein (GFAP), hexaribonucleotide binding protein-3 (Fox-3/NeuN), protein gene product 9.5 (PGP 9.5) and III- $\beta$ tubulin (Tuj1). For neurogenesis studies, antibodies for these neuronal or glial markers can be paired with anti-BrdU antibodies to perform double- or triple-immunofluorescence. The cells can then be observed with fluorescence or confocal microscopy to determine whether new cells are neurons or glia. Generalized surveys quantifying adult neurogenesis using 
confocal methods have been very limited in reptiles and no studies have used these techniques for surveys in snakes (Delgado-Gonzalez et al., 2011; Pérez-Cañellas and García-Verdugo, 1996; Sampedro et al., 2008; Shao et al., 2012).

\section{Comparative studies of adult neurogenesis; Adult neurogenesis in reptiles}

Adult neurogenesis is widespread and varies both among and within taxa (Barker et al., 2011). In order to make generalizations about the nature of adult neurogenesis, further studies of a wide range of taxa will allow for further clarification of the trait's evolutionary development. Relying on a few models prevents the delineation of evolutionary trends (Lindsey and Tropepe, 2006). Further, comparison between several members of the same class allows for the determination of consistency of structure and function within the given class (Rakic, 2002). For example, adult neurogenesis has not been found in adult Sorex shrews (Bartkowska et al., 2008) or the hippocampus of some bat species (Amrein et al., 2007), yet it is present in the six other mammalian orders investigated thus far. Understanding which evolutionary pressures have distinguished some vertebrates as better or worse at adult neurogenesis might help clarify the functions and benefits of this physiological process.

Neurogenesis is very limited in the adult mammalian brain. Reptiles, in contrast, are model examples of extensive adult neurogenesis in vertebrates. While birds are included in the monophyletic reptilian group, "reptiles," for the purposes of this paper, I will refer to reptiles without including birds. All reptiles examined to this 
point exhibit adult neurogenesis. Yet there are considerable differences in the rate and distribution of adult neurogenesis among species within this group (Font et al., 2001).

As early as the 1950s, researchers claimed that neurogenesis might occur in adult reptiles along the ependymal lining of the ventricles (Fleischhauer, 1957; Källen, 1951; Kirsche, 1967; Schultz, 1969). Subsequently it was assumed that these regions were merely embryonic remnants that persisted into adulthood. In the 1980s and 1990s it was determined that new adult brain cells proliferate at the ventricular zone $(\mathrm{VZ})$, the lining of the ventricles, and migrate away to their final destination in the parenchyma (Goffinet, 1983; Lopez-Garcia et al., 1988; LopezGarcia et al., 1990; Pérez-Cañellas and García-Verdugo, 1996).

\section{Proliferation}

The production of new cells in birds and reptiles is restricted primarily to the ependymal VZ of the lateral ventricle (Alvarez-Buylla et al., 1990; Lopez-Garcia et al., 1988; Lopez-Garcia et al., 1990). Reptilian ependymal cells lining the ventricular wall proliferate continuously, generating new neurons that integrate into established circuits (Lopez-Garcia et al., 2002; Marchioro et al., 2005). The ependymal regions associated with highest proliferative capacity are referred to as the sulcus lateralis, sulcus septomedialis, sulcus ventralis, and sulcus terminalis located along the lateral ventricles (Kirsche, 1967; Schultz, 1969; Tineo et al., 1987; Yanes-Méndez et al., 1988) The third, tectal and fourth ventricles may also be a source of new neurons and should be investigated further (personal observation; Margotta et al., 1999; 
Saijo, 2007). In lizards, the neurogenic regions are composed of two main cell types. Most are radial glial cells while the rest are young migrating neurons (GarcíaVerdugo et al., 1981; Yanes et al., 1990; Yanes-Méndez et al., 1988; Yanes-Mendez et al., 1988). Radial glial cells in the VZ are likely the stem cells for adult neurogenesis in reptiles but evidence supporting this hypothesis in reptile studies is limited (Font et al., 1995b).

\section{Migration}

All vertebrates studied thus far have exhibited cells which migrate tangentially away from the ventricular wall of the telencephalon (Doetsch and Scharff, 2001).While these new cells migrate throughout the telencephalon, the olfactory bulbs, and the $\mathrm{AOB}$, there are differences in how they incorporate across species (Font et al., 2001). The morphology of migrating neurons in the Western Canaries lizard (Gallotia galloti) changes during migration in a way that indicates maturation en-route. Near the ependymal (VZ) layer the cell nucleus is $3-4 \mu \mathrm{m}$ in diameter and elongated in shape with a visible centralized nucleolus and spongy chromatin. During migration, the chromatin becomes clumped and the nucleus increases in volume by up to $35 \%$ (Garcia-Verdugo et al., 1986). New neurons in the MC mature and extend axons to their targets upon their arrival at their destination and are incorporated into pre-existing functional circuits (Lopez-Garcia et al., 1990; Ulinski, 1990). 


\section{Survival}

Newly generated neurons appear to have long survival at their targets in the telencephalon of lizards (Pérez-Cañellas et al., 1997). While neurogenesis coincides with neuron death in birds (Barnea and Nottebohm, 1994; Barnea and Nottebohm, 1996) and mammals (Hastings and Gould, 2003), no studies have directly linked naturally occurring neuronal degeneration or apoptosis to neurogenesis in reptiles (Barker et al., 2011; Lopez-Garcia et al., 1990).

The $\mathrm{MC}$ is continuously neurogenic throughout the life of reptiles (Bruce and Butler, 1984; Butler and Hodos, 1996; Casini et al., 1986; Hoogland et al., 1987, 1998; Lopez-Garcia et al., 1992, 2002), yet the rate of maturation appears to be agedependent. Molowny et al. (1995) observed more reactive neurogenesis in the MC of young adult Iberian wall lizards (Podarcis hispanica) compared to older counterparts. Furthermore, cell maturation in a 2-4 year old $P$. hispanica takes only 7 days (LopezGarcia et al., 1990), but takes 90 days in 6-year-old Gallotia galloti (DelgadoGonzalez et al. 2011).

\section{General Comparisons}

Interspecific regional differences in neurogenesis are evident among reptiles. For example, the new neuron incorporation rate in $P$. hispanica is highest in the NS and lowest in the septum, which contrasts with $T$. mauritanica, in which incorporation is highest at the MC. This contrasts further with the turtle, T. s. elegans, wherein incorporation is highest in the STR and the lowest in the MC (Font et al., 2001). 
Another discrepancy is that lizards have considerably higher cell recruitment into the telencephalon compared to turtles, which thus far has gone unexplained.

The main and accessory OB undergo considerable neurogenesis relative to the rest of the brain in all reptiles studied thus far including snakes (personal observation; Font et al., 2001). There has been limited evidence that cells born in the sulcus ventrails/terminals tangentially migrate from the rostral forebrain to the $\mathrm{OB}$ in T. mauritanica, Podarcis sicula, Psammodromus algirus (the large psammodromus), and turtles (Font et al., 2001; Margotta et al., 1999; Peñafiel et al., 1996; Pérez-Cañellas and García-Verdugo, 1996). While this process is considered similar to the mammalian rostral migratory stream (RMS), the similarities still have only been investigated on a superficial level. Further study needs to be done to determine the mechanistic similarities between reptilian and mammalian RMS. For example, it has not been determined whether tubes of glial cells surround migrating neurons or whether there are guidance cues influencing or restricting migration in reptiles (Font et al., 2001).

Kaslin et al. (2008) expect that the extensive post-embryonic brain neurogenesis in non-mammalian vertebrates can be attributed to the continued development of pathways involving sensory systems after birth. They hypothesized that neurogenesis in fish, amphibians, and reptiles is due to the demand for increased CNS processing power in response to increased primary sensory input. Goss (1992) gave another explanation in which neurogenesis is not an adaptive function, but instead an ontogenetic residue of embryonic development that has 
simply persisted in these taxa since the Paleozoic era. Self-repair of mild brain injuries or diseases could potentially be selected for, however it would require brain damage to be frequent enough that it could potentially influence fitness and selection (Goss, 1992). Gross (2000) hypothesized that adult neurogenesis is essential to mammalian learning and memory formation. This system may also be applicable to reptiles and warrants further exploration.

\section{Plasticity and environment}

Bird and mammal studies have demonstrated that several environmental variables affect adult neurogenesis, yet environmental studies in reptiles are severely lacking (Gould et al., 1998; Kempermann and Gage, 1999; van Praag et al., 1999). For example, seasonally breeding birds' testosterone levels are influenced by photoperiod. Exposure to longer days in springtime increases testosterone, which is associated with reductions in cell mortality and increases in brain volume in specific regions (Tramontin and Brenowitz, 2000).

Delgado-Gonzalez et al. (2011) investigated the role of season in proliferation and migration rates of new brain cells in G. galloti. They found that in autumn, winter, and especially spring, the quantity of BrdU labeled cells in the VZ were significantly greater after 30 days, implying they were not migrating to the parenchyma. However, in the summer, the ventricular zone lost considerable cells after the 30 day period due to migration. In P. hispanica, Ramirez et al. (1997) found that lizards maintained in long photoperiods had significant increases in proliferation. Short photoperiods, on the other hand, reduced the number of proliferating cells but did not affect migration. 
Ramirez et al. (1997) also investigated effects of temperature in $P$. hispanica. They found cold temperatures led to a reduction in migration of the new cells, preventing cells from leaving the sulcus medialis and causing new cells to accumulate at the ependyma. Ramirez et al. also found $8 \mathrm{~h}$ photoperiods reduced cell proliferation compared to $16 \mathrm{~h}$ photoperiods. In P. algirus cold temperatures have been found to reduce proliferation $70-90 \%$ and reduce migration (Penafiel et al., 2001). Radmilovich et al. (2003) demonstrated significant increases in proliferation for warm-acclimated Chrysemys d'orbigny (black-bellied slider) turtles compared to cold-acclimated turtles. This contrasts with Marchioro et al. (2012) who found a reduction in migration rate but not proliferation due to cold temperatures in $T$. hispidus. In order to determine whether these phenomena can be generalized among all reptiles or how environmental variables like temperature and photoperiod impact neurogenesis, further studies investigating these variables should be conducted in snakes. Also, further studies must be done in the natural environment (Amrein et al., 2004) to confirm laboratory findings and provide the behavioral and environmental variables to better understand the "dynamics" of neurogenesis (Lindsey and Tropepe, 2006).

\section{Regeneration in the adult telencephalon}

Neuronal regeneration is a rare occurrence in the vertebrate CNS. In adult lizards, neuron proliferation and migration in the medial cortex are increased after lesioning with the neurotoxin 3-acetlypyridine (3AP) (Font et al., 1995b; Font et al., 1991; Kaslin et al., 2008). The damage from 3AP varies greatly among lizards of the 
same species (for both $P$. hispanica and Anolis carolinensis) and between regions. For example, in P. hispanica $34 \%$ to $97 \%$ of neurons in the MC displayed pyknotic nuclei, but in other regions 3AP affected less than $50 \%$ of neuronal populations (Font et al., 1997b). Proliferation of microglia and radial glia increases in response to the damage so these cells can remove axonal and cellular debris (Font et al., 1995b; Lopez-Garcia et al., 1994; Nacher et al., 1999). Simultaneously, adult neurogenesis is upregulated and replacement cells begin to migrate from the VZ. After one to two weeks, neurons begin to enter and fill the void left by 3AP damage and completely replace the damaged area within a 6-8 week period (Font et al., 1991). Some replacement neurons establish synaptic contacts and join functional circuits (Molowny et al., 1995). By two months the previously damaged telencephalon is virtually indistinguishable from one that never received 3AP treatment (Font et al., 1997b). However, comparative studies using 3AP are limited because preliminary 3AP studies in snakes resulted in inconsistent distribution of damage (Font et al., 2001).

Minelli et al. (1977) found reactive proliferation in the cortical tissues of Lacerta viridis in response to surgical ablation, however the regeneration was not complete within 260 days. On the other hand, neuronal regeneration as a result of 3AP exposure is probably the most successful case of forebrain neurotoxic damage and neuronal regeneration in any vertebrate to date. While there are some examples of fish, amphibians, songbirds, and mammals that undergo induced regeneration or 
reactive neurogenesis, lizards are the only tetrapods that can regenerate entire cerebral cortex regions bilaterally into adulthood (Font et al., 2001).

\section{Future studies of adult neurogenesis in reptiles}

Currently, the paucity of neurogenesis research in reptiles hinders the discovery of the evolutionary nature of neurogenesis (Lindsey and Tropepe, 2006). The reptilia are very diverse, and the paucity of snake studies has prevented the move from a collection of isolated studies to a comparative data set that can be used to identify meaningful patterns in adult neurogenesis. Furthermore, only one reptilian study investigates regional differences in neurogenesis over the organism's lifespan (Marchioro et al., 2005).

I propose that future studies need to be performed in snakes in the laboratory to determine baseline regional and developmental differences in adult neurogenesis. Then field studies should be conducted to determine changes in response to environmental variables including, but not limited to: (a.) changes in metabolic rate including those in response to digestion of prey and environmental temperature

changes; (b.) scent and pheromone exposure; (c.) age; (d.) light cycle; (e.) exposure to stressors; and (f.) while gravid. The next chapter of this manuscript provides baseline laboratory data on neurogenesis in $P$. regius, to use as a comparative model species to study the evolutionary and physiological significance of adult neuroplasticity and neurogenesis. Additionally, the impact of neurogenesis on animal behavior must first be determined, so generalizations can be made and applied to 
understanding the correlations between human neurogenesis and behavior (Boonstra et al., 2001). 


\section{Chapter 2. A BrdU study of proliferation, migration, and survival in the telencephalon of the ball python, Python regius.}

\section{Introduction}

Adult neurogenesis is widespread throughout vertebrates and varies in presence and rate both among and within taxa (Barker et al., 2011). Over the past 20 years considerable research has focused on elucidating both the mechanisms and functions of adult neurogenesis. However, the overwhelming majority of neurogenesis studies have investigated the process in the mammalian brain, in which adult neurogenesis is very limited. Quantitative studies of neurogenesis in reptiles have focused on only a few lizard and turtle species. The lack of reptilian studies is both unexpected and detrimental to research not only because reptiles undergo extensive adult neurogenesis, but also because they are exceptional neural regenerators. Comparative studies of this trait among vertebrates may better clarify its evolution and function (Font et al. 2001; González-Granero, Lezameta, and García-Verdugo 2011). Relying on only a few models prevents the delineation of evolutionary trends (Lindsey and Tropepe, 2006). Further, comparison among several members of the same class can support patterns of structure and function within the given class (Rakic, 2002). For example, adult neurogenesis is absent in adult shrews (Bartkowska et al., 2008) and in the hippocampus of some bat species (Amrein et al., 2007), yet it is present in the six other mammalian orders investigated thus far (Barker et al., 2011). 
Brain morphology and neural networks have diverged greatly among vertebrate classes as they have been shaped by natural selection. Several species have developed very specialized brain anatomy and physiology in response to environmental pressures (Butler and Hodos, 2005; Nieuwenhuyis et al., 1998; ten Donkelaar, 1988) while others have retained ancestral traits, thus providing extant evidence for tracing the evolution of morphology (Nomura et al., 2013b). Determining why some species have undergone selection for or against adult neurogenesis will further evolutionary research.

Reptilian brains exhibit a simple, laminated dorsal telencephalon with a 3layered cortex, thought to be inherited from their amniote ancestry (Bruce, 2007; Wise et al., 2009). When Platel (1974) conducted morphometric studies of the developed reptilian brain he found continued growth of brain volume from young to old lizards. Examining Podarcis hispanica (Iberian wall lizards), Lopez-Garcia et al. (1984) determined that the volumetric change throughout life was associated with continuous addition of newly generated neurons (Martínez-Guijarro and LópezGarcía, 1994). It is yet to be determined whether the increase in brain volume in reptiles is also associated with increases in neuron size, quantity, or spacing. The primary function of adult neurogenesis in reptiles may be supplying the brain structures with new cells as the structures enlarge during development (Barker et al., 2011).

Snakes diverged from lizards approximately 92 million to 161 million years ago (Gorr et al., 1998). Among snakes, pythons are the most basal extant 
macrostomatan species (Castoe et al. 2011; Slowinski and Lawson 2004). The basal origins of these snakes may provide insight into the evolutionary origins of adult neurogenesis and adult brain development. Pythons exhibit many unique traits that can further our understanding of adult neurogenesis from a comparative perspective. Most are constricting sit-and-wait predators that consume large prey relative to their body size, resulting in metabolic changes and plasticity of other physiological systems, including the digestive and cardiovascular systems (Andersen et al., 2005; Secor and Diamond, 1998). Some species of female pythons also maintain the temperature of their eggs by shivering thermogenesis when brooding. Shivering thermogenesis occurs when a series of muscular contractions of the whole body generates heat for incubating eggs (Harlow and Grigg, 1984; Stahlschmidt and DeNardo, 2008; 2009; 2010; Vinegar et al., 1970). Pythons experience vomeronasal chemical sensing and possess labial pits for infrared detection (Molenaar, 1978a; Molenaar, 1978b).

Python regius (commonly known as "Ball Pythons" or "Royal Pythons") are native to western Africa, but are commonly bred as exotic pets internationally. They are very docile and easy to handle without risk of injury to the handler or the snake. They do not require intricate laboratory housing and can be maintained by giving them access to water ad libitum, a heating device, and regular access to feeder mice. In fact, contrary what many researchers might expect, pythons are easier to handle and maintain than rats (Secor et al., 2001). 
In two experiments the following were determined: (a) the dose of the cell birth marker, 5-bromo-2'-deoxyuridine (BrdU), that best marks proliferating cells in the $P$. regius telencephalon, (b) the brain regions in which telencephalic proliferation occurs, and (c) the rate of migration and survival of the newborn cells. In accordance with previous studies (Cameron \& McKay, 2001; Hancock et al., 2009), higher doses of BrdU should mark more newborn cells than lower doses. Based on previous studies of squamates, I expected higher cell proliferation and migration at the anterior olfactory bulb (AOB), medial cortex (MC), dorsoventricular ridge (DVR), and nucleus sphericus (NS) than in other regions (Font et al., 2001; Pérez-Cañellas and García-Verdugo, 1996).

Results of this study will provide groundwork for future studies investigating the evolutionary trends pertaining to environmental, hormonal, and age-related effects on adult neurogenesis. Future studies may provide evidence for whether properties unique to snake physiology affect neurogenesis, and determine the relationships among telencephalic proliferation, migration, and survival.

\section{Materials and Methods}

\section{Experiment 1:}

\section{Procurement and treatment}

The use and treatment of snakes was conducted with the approval of the California Polytechnic State University IACUC protocol No. 915. Fifteen male $P$. regius $(\bar{x}=95.92 \mathrm{~g} \pm 43.03 \mathrm{~g})$ were purchased from Reptile Industries (Naples, FL) 
and delivered on July 8,2011 . Snakes were acclimated in the laboratory for for 14 days. During this period they were housed in $26 \times 45 \times 36 \mathrm{~cm}$ clear plastic containers (Monoflo) on a 12:12 light:dark cycle. Each container had a terra cotta water dish, an ABS pipe cut in half lengthwise to serve as a "shelter" and newspaper lining the bottom for absorption and cleaning.

Each container was marked with the corresponding number and placed randomly on a cage rack. In order to maintain similar metabolic rates among all snakes during treatment, snakes were fed mice selected according to proportional weight on day $3(\bar{x}=2.77 \% \mathrm{~m} / \mathrm{m} \pm 0.21 \%)$ except for snake \#3, which refused to eat. Snakes were haphazardly placed into stratified groups to avoid a possible effect of mass on treatment (Table 1). On day 15 they were subcutaneously injected with BrdU dissolved in $0.9 \% \mathrm{NaCl}$ at $20 \mathrm{mg} / \mathrm{mL}$. Volumes were injected according to the following 3 treatments: $50 \mathrm{mg} / \mathrm{kg}, 100 \mathrm{mg} / \mathrm{kg}$, or $250 \mathrm{mg} / \mathrm{kg}$ Bromodeoxyuridine (BrdU; Sigma Aldrich).

Table 1: Stratified random placement of snakes by mass $(\mathrm{g})$ into one of three treatment groups with different dosages of bromodeoxyuridine $(50,100$, or $250 \mathrm{mg}$ $\mathrm{BrdU} / \mathrm{kg}$ body weight).

\begin{tabular}{|c|c|c|c|c|c|}
\hline \multicolumn{2}{|c|}{$50 \mathrm{mg} / \mathrm{kg}$} & \multicolumn{2}{|c|}{$100 \mathrm{mg} / \mathrm{kg}$} & \multicolumn{2}{|c|}{$250 \mathrm{mg} / \mathrm{kg}$} \\
\hline Snake & Mass $(\mathrm{g})$ & Snake & Mass (g) & Snake & Mass (g) \\
\hline 3 & 744.73 & 8 & 653.23 & 4 & 624.82 \\
\hline 2 & 888.78 & 1 & 721.41 & 5 & 656.74 \\
\hline 14 & 1006.16 & 13 & 996.19 & 11 & 878.97 \\
\hline 12 & 1038.05 & 10 & 1067.25 & 9 & 1003.04 \\
\hline 7 & 1089.52 & 6 & 1149.65 & 15 & 1232.29 \\
\hline $\begin{array}{l}\text { Mean } \\
S E\end{array}$ & $\begin{array}{r}953.45 \\
61.72\end{array}$ & & $\begin{array}{r}986.71 \\
86.84\end{array}$ & & $\begin{array}{r}879.17 \\
112.74\end{array}$ \\
\hline
\end{tabular}




\section{Sacrifice and perfusion}

Twenty-four hours after BrdU treatment, snakes were deeply anesthetized via isofluorane inhalation and were transcardially perfused with $0.9 \% \mathrm{NaCl}, 0.1 \%$ $\mathrm{NaNO}_{2}, 0.1 \mathrm{M}$ phosphate buffer (PB) wash followed by $4 \%$ paraformaldehyde in 0.1 M PB, pH 7.2, with $0.1 \% \mathrm{NaNO}_{2}$. Following perfusion, skulls containing brains were extracted and placed in 4\% paraformaldehyde for at least 2 hours. Brains were then carefully removed from the skulls to postfix for $24 \mathrm{~h}$ in $4 \%$ paraformaldehyde followed by $24 \mathrm{~h}$ in $0.1 \mathrm{M}$ PB solution. An example of a removed, fixed, complete brain is shown in figure 3. Brains were weighed and placed in gelatin overnight until the gelatin formed semisolid blocks around the tissue. Then the blocks were placed in $4 \%$ paraformaldehyde for $24 \mathrm{~h}$ and then $30 \%$ sucrose until they sank, frozen in dry ice, and stored at $-80^{\circ} \mathrm{C}$ until sectioning. 


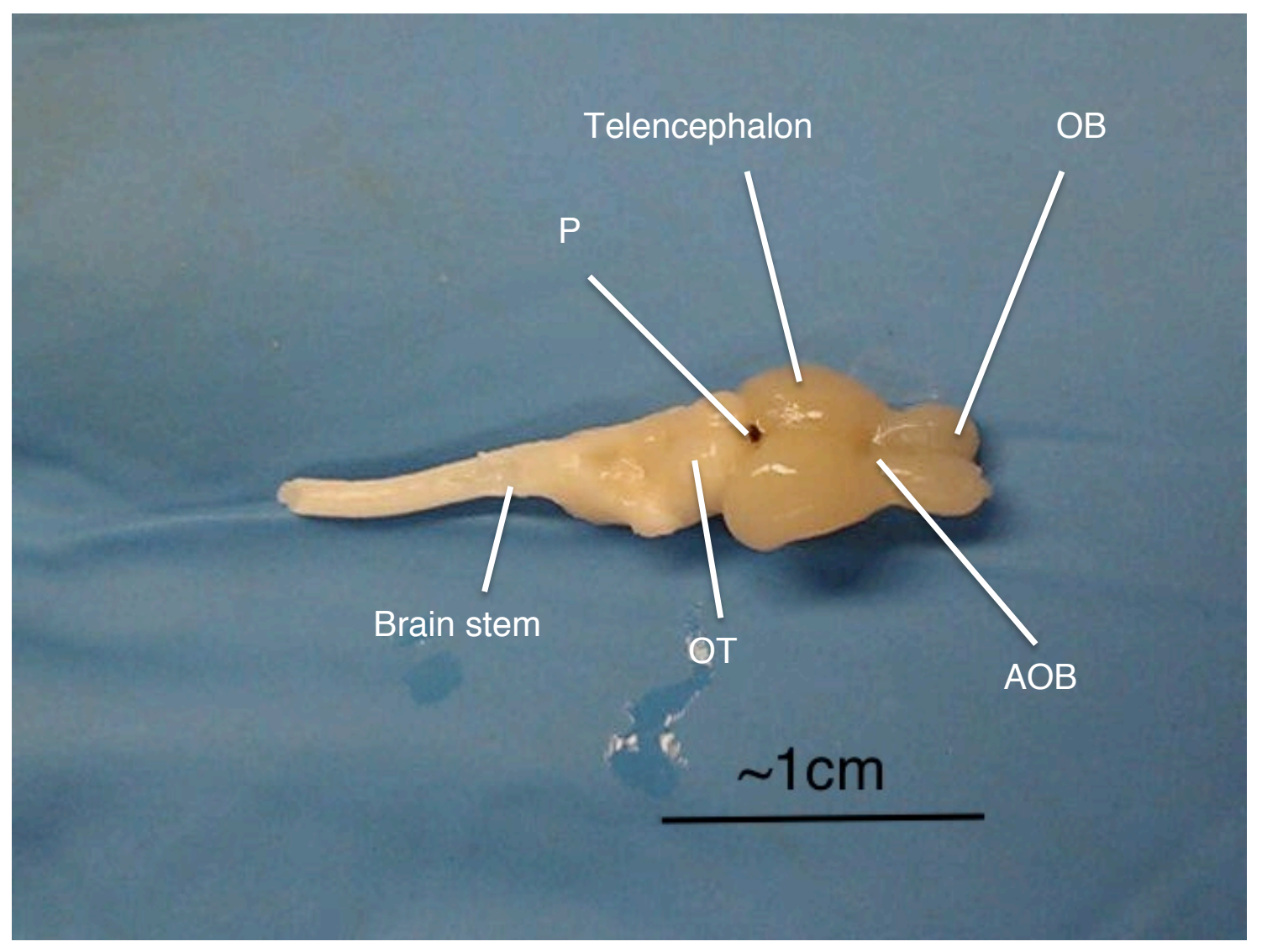

Figure 3: An extracted, perfused, complete $P$. regius brain. The dorsal side of the telencephalon (pallium) is shown. AOB: accessory olfactory bulb, OB: olfactory bulb, OT: optic tectum, P: pineal gland.

\section{Sectioning and histochemistry}

Four series of $40 \mu \mathrm{m}$ thick parallel coronal sections were obtained using a Bright OTF-5000 cryostat. One series (every fourth section) was directly mounted to slides, hydrated with mounting solution, allowed to dry, and stained with cresyl violet. Cresyl violet stained sections were photographed with a Leica EZ4 stereo microscope at 10x magnification and stored as digital images for measurement and identification of brain regions of interest (fig. 4). 


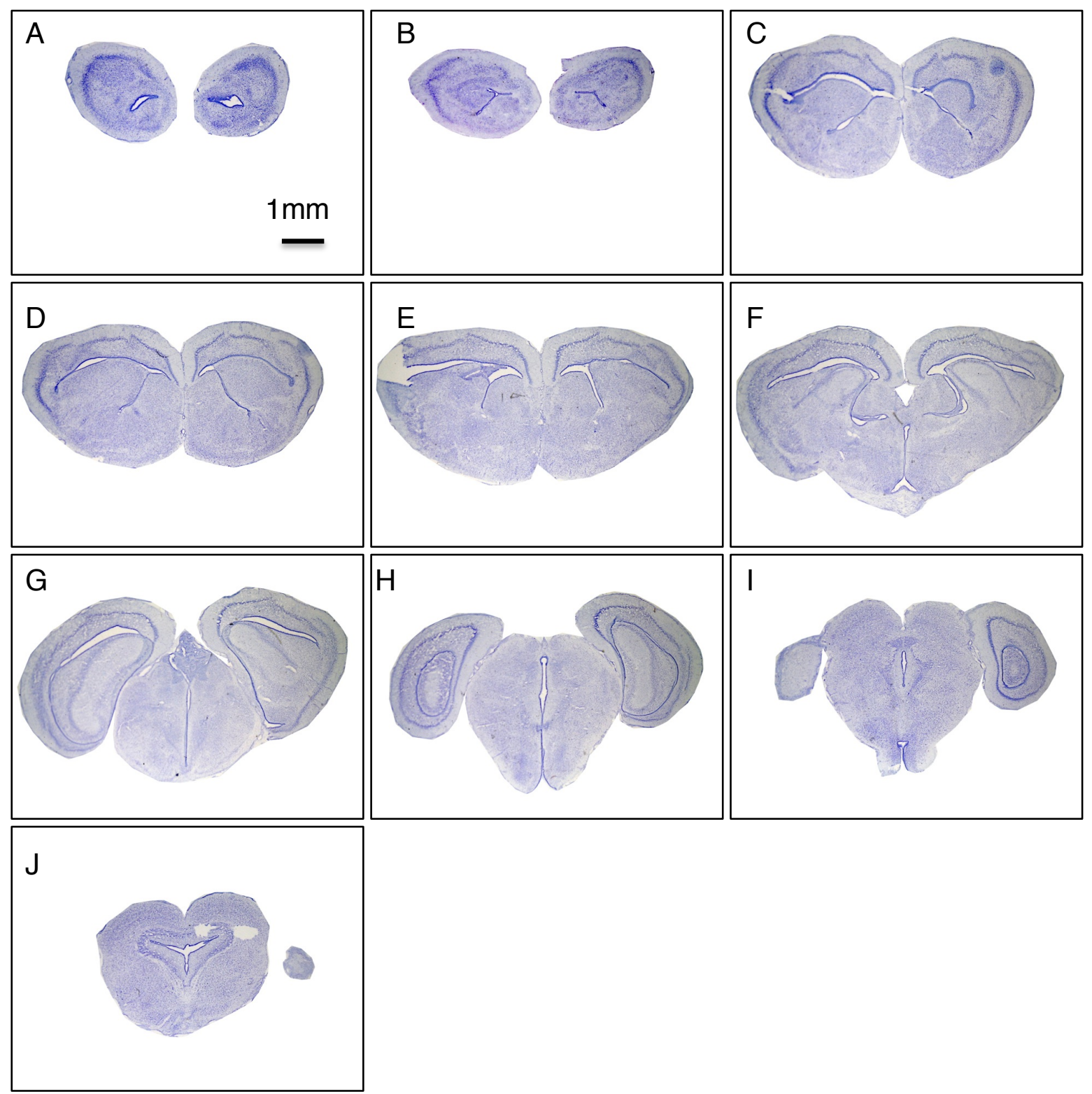

Figure 4: The stack of images taken from cresyl violet stained sections (every $16^{\text {th }}$ section shown) of snake \#7 used to create a 3D model and determine study regions for experiment 1.

The other sections were stored in cryoprotectant at $-20^{\circ}$ until they were ready to be used. Free-floating sections were immunostained for BrdU as follows: Every eighth section was washed with phosphate-buffered saline (PBS) 3 times for 5 minutes prior to DNA denaturation in $4 \mathrm{~N} \mathrm{HCl}$ for 15 minutes. After denaturation, sections were rinsed for 5 min in PBS and neutralized in 3.8\% sodium borate wash 
$(\mathrm{pH}$ 8.5) for 10 min. Sections were rinsed 3 times for 10 minutes in PBS and immediately blocked in a solution of $5 \%$ normal horse serum (Vector Laboratories Inc), $1 \%$ bovine serum albumin, and $0.5 \% \mathrm{H}_{2} \mathrm{O}_{2}$ in $\mathrm{PBS}+0.3 \%$ Triton $\mathrm{X}-100$ (PBST). Immediately following blocking, sections were placed in a 1:1,000 anti-BrdU (clone: Bu20a, isotype: IgG1, kappa, code: M0744, DakoCytomation, Glostrup, Denmark) dilution in PBST and left on a rotator table for $24 \mathrm{~h}$ at room temperature. Another series of three 5-min washes in PBST was followed by $1 \mathrm{~h}$ of incubation in biotinylated anti-mouse secondary antibody (1:100; Vector Laboratories), three 5minute washes in PBST, and a $1 \mathrm{~h}$ incubation in avidin-biotin-peroxidase complex (PK-6100, Vector Laboratories). Finally, sections were washed 3 times for 5 minutes in PBST followed by detection of bound peroxidase complexes via 4-minute incubation in Vector SG Chromagen (Cat. No.SK-4700, Vector Laboratories). The reaction was stopped by two 5 min washes in PBS. Sections were then mounted onto slides and coverslipped.

\section{Measurement}

To define study regions, a digital 3-dimensional model was created from the captured images according to the following process: Images were masked using Photoshop CS6 13.0 and transformed to align with adjacent section images in a stack (supplemental movie 1: http://youtu.be/Lw8nD2V0Frl). The stack was migrated to ImageJ (NIH, USA) and converted to a 3D model using Java3D. The 3D model and 2D stack were used to determine locations where rostral-caudal morphological 
changes occur and clearly define these regions so counting would be consistent between brain sections (fig. 5).

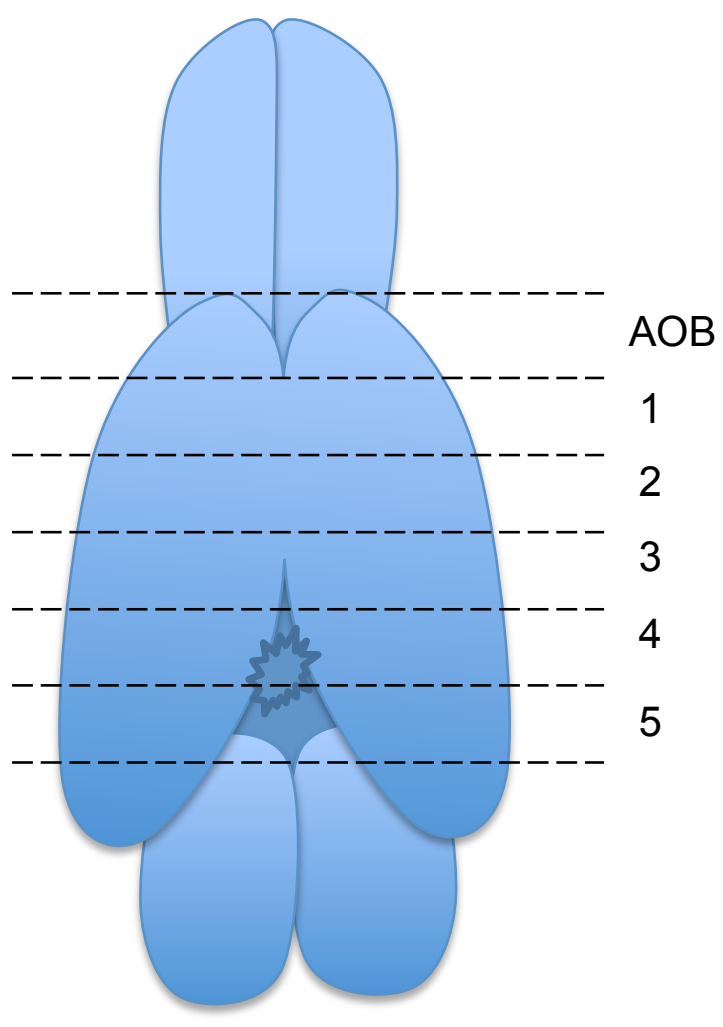

Figure 5: Predetermined regions defined for $P$. regius telencephalon. Regions were divided according to rostro-caudal landmarks (1-5). AOB: Accessory olfactory bulb. Rostral-caudal regions defined according to morphological changes to determine areas where changes in cellular density occur. Then regions with similar and consistent cell densities were used for the study area. 

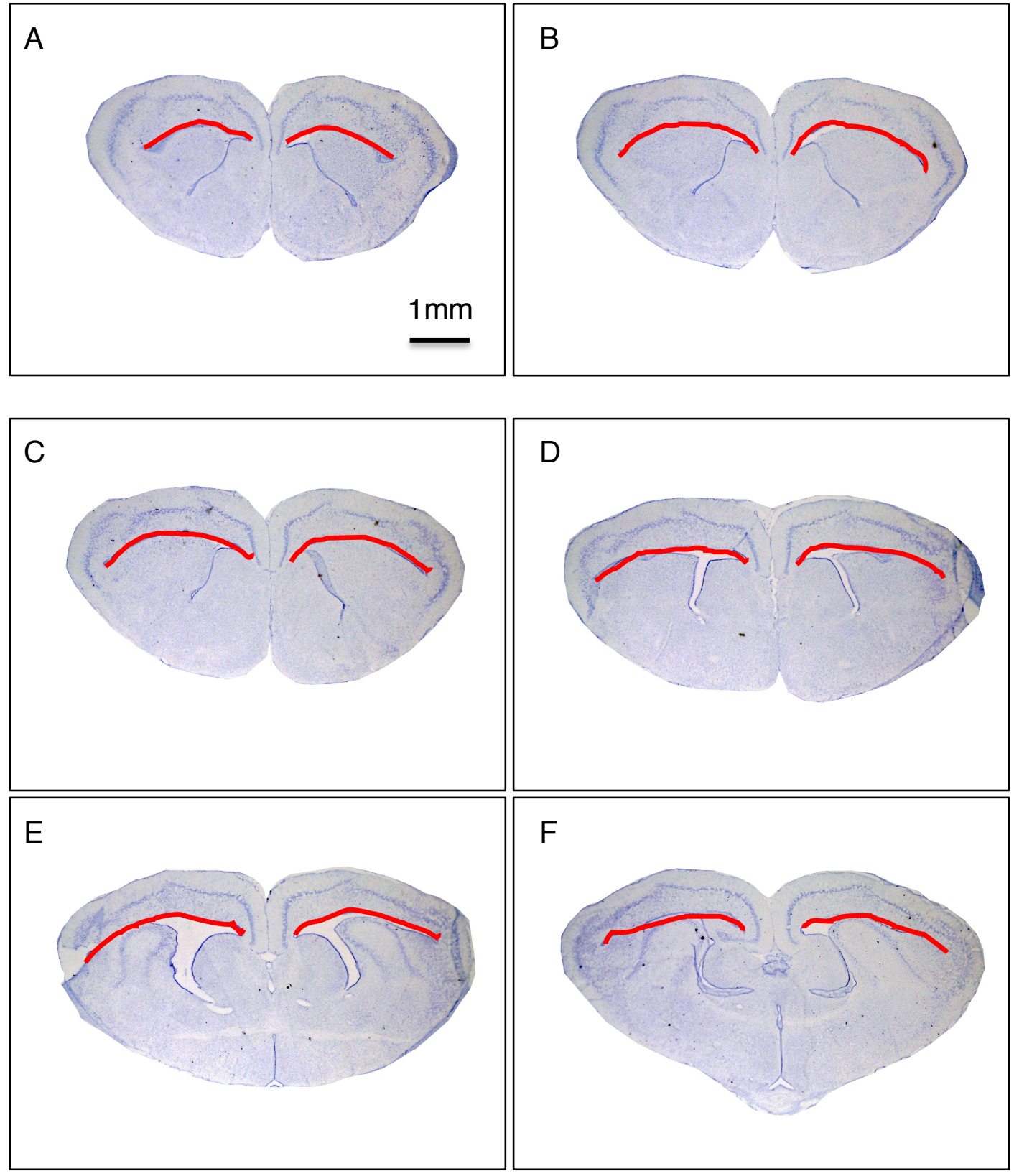

D
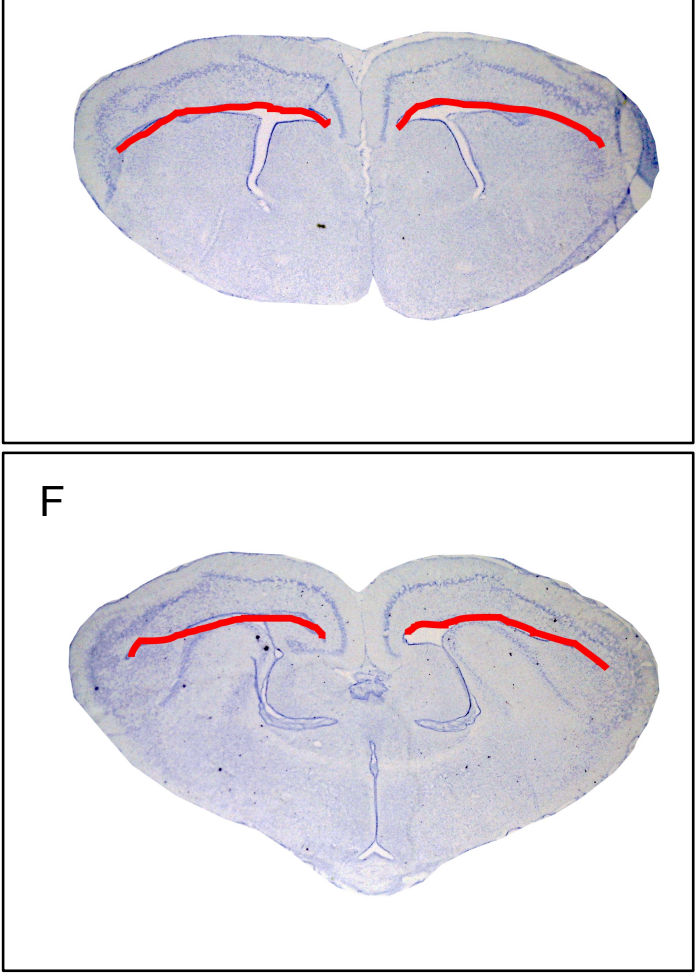

Figure 6: Supraventricular ependymal surface area used for counting cell density for 3 BrdU treatments.

BrdU-immunoreactive (BrdU-ir) cells were observed under an Olympus $\mathrm{CH}$ series light microscope at 400X and counted along the left and right ventricle along 
the ependymal lining from the sulcus septomedialis to the sulcus lateralis for each within each section (fig. 6).

To determine how cell counts and line measurements would be performed to calculate cell density for statistical analysis, cells along the measured line were first counted in the $250 \mathrm{mg} / \mathrm{kg}$ group. Regions $1-3$ were chosen for statistical analysis because they had large enough cell counts to clearly reveal any potential differences among the three treatments (fig. 7; supplemental movie 2:

http://youtu.be/Ka7VirggVPM). Regions 4-5 were excluded because their cell counts were too low to show differences, and because any differences would likely be due to differences in ependymal length measurement instead of cell quantity. The AoB was excluded because the cell counts were too inconsistent within the region and the counts were exceptionally high compared to the rest of the telencephalon.

New cell density was determined for each region by measuring the length of the ependymal lining from the sulcus septomedialis to the sulcus lateralis and by counting anti-BrdU marked nuclei along the measured line (fig. 6). The ependymal layer was defined as the cell layer lining the ventricles and two-to-three cell body diameters from the ventricles. The cell counter was blind to treatments.

Cell densities throughout each region were calculated as follows:

$$
\text { regional cell density }=\left(\frac{\sum \text { marked cells from all sections in region }}{\sum \text { line length from all sections in region }}\right)
$$

For determination of overall cell density across all three rostral-caudal regions, $1-3$, the following calculation was used: 
overall cell density $=\left(\frac{\sum \text { marked cells from all sections in all } 3 \text { regions }}{\sum \text { line length from all sections in all } 3 \text { regions }}\right)$

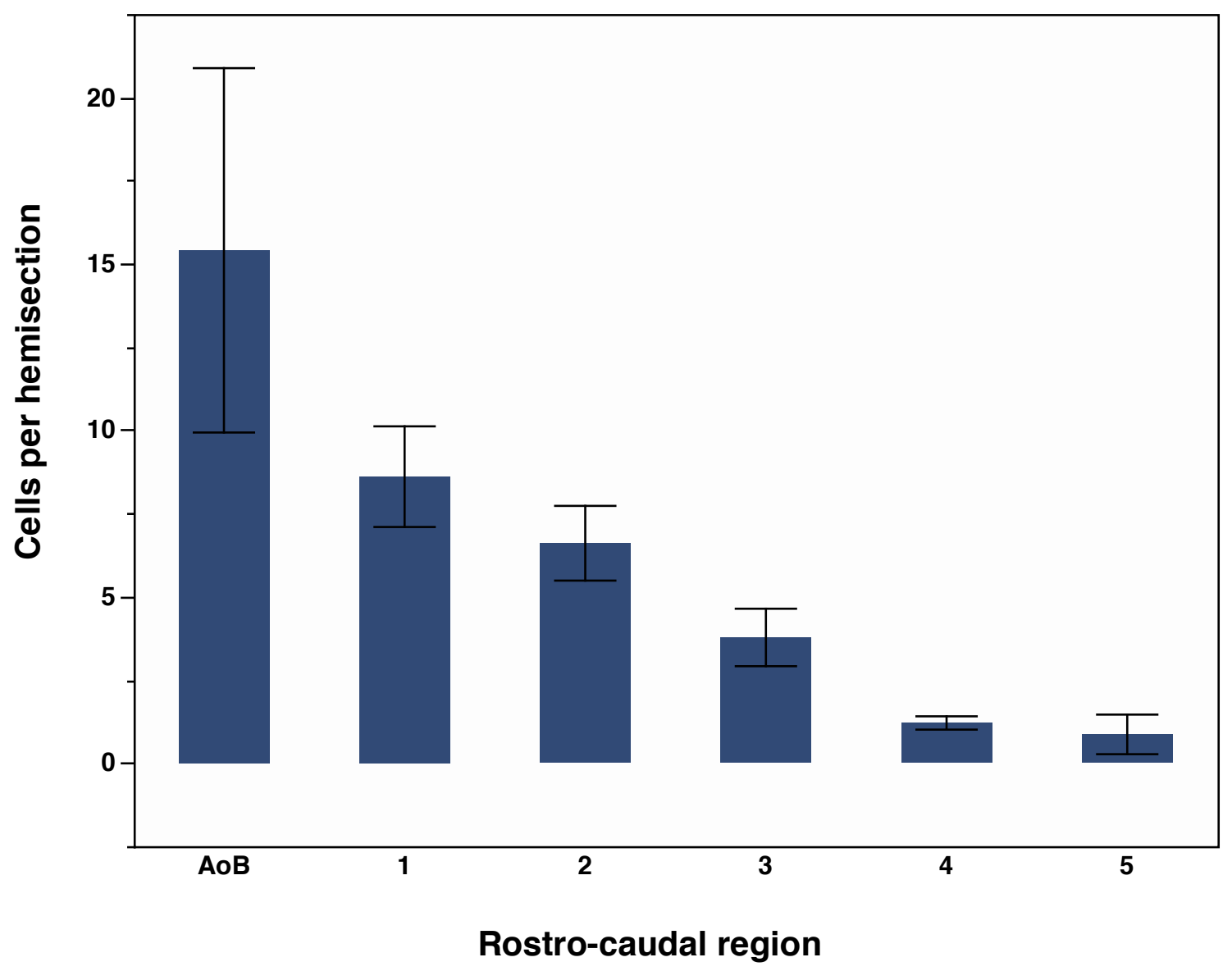

Figure 7: Count of new cells per hemisection (mean +/- SE) within each rostrocaudal region, for the $250 \mathrm{mg} / \mathrm{kg}$ treatment group.

\section{Statistical analysis}

An ANOVA was performed using JMP 10.0 (SAS, 2013) to determine the effect of dosage on cell marking along the selected ependymal surface. Data followed a normal distribution with equal variances and was left untransformed. 
ANOVA was followed by a post-hoc Tukey-Kramer HSD. All differences were considered significant at $a<0.05$.

\section{Experiment 2:}

\section{Procurement and treatment}

Procurement and treatment were performed similarly to experiment 1 and in compliance with California Polytechnic State University IACUC protocol No. 915. Fifteen juvenile male $P$. regius $(\bar{x}=121.44 \mathrm{~g} \pm 5.83 \mathrm{~g})$ were delivered on February 2, 2012. During the 17-day acclimatization period snakes were fed mice on day $2(\bar{x}$ $=11.28 \% \mathrm{~m} / \mathrm{m} \pm 0.21 \% \mathrm{~m} / \mathrm{m})$ and day 14 . After the acclimatization period, snakes were weighed and haphazardly placed in three treatment groups (2 month, 2 week, 2 day) with to prevent a possible effect of mass on treatment (table 2). Snakes in the

"2 month" group received 100mg/kg BrdU 2 months before sacrifice, snakes in the "2 week" group received 100mg/kg BrdU 2 weeks before sacrifice, and snakes in the "2 day" group received 100mg/kg BrdU 2 days before sacrifice (fig. 8). During the 2 month treatment period were fed mice on day $13(\bar{x}=10.03 \% \mathrm{~m} / \mathrm{m} \pm 0.19 \% \mathrm{~m} / \mathrm{m})$, day $27(\bar{x}=11.32 \% \mathrm{~m} / \mathrm{m} \pm 0.32 \% \mathrm{~m} / \mathrm{m})$, and day $40(\bar{x}=9.85 \% \mathrm{~m} / \mathrm{m} \pm 0.17 \% \mathrm{~m} / \mathrm{m})$. 


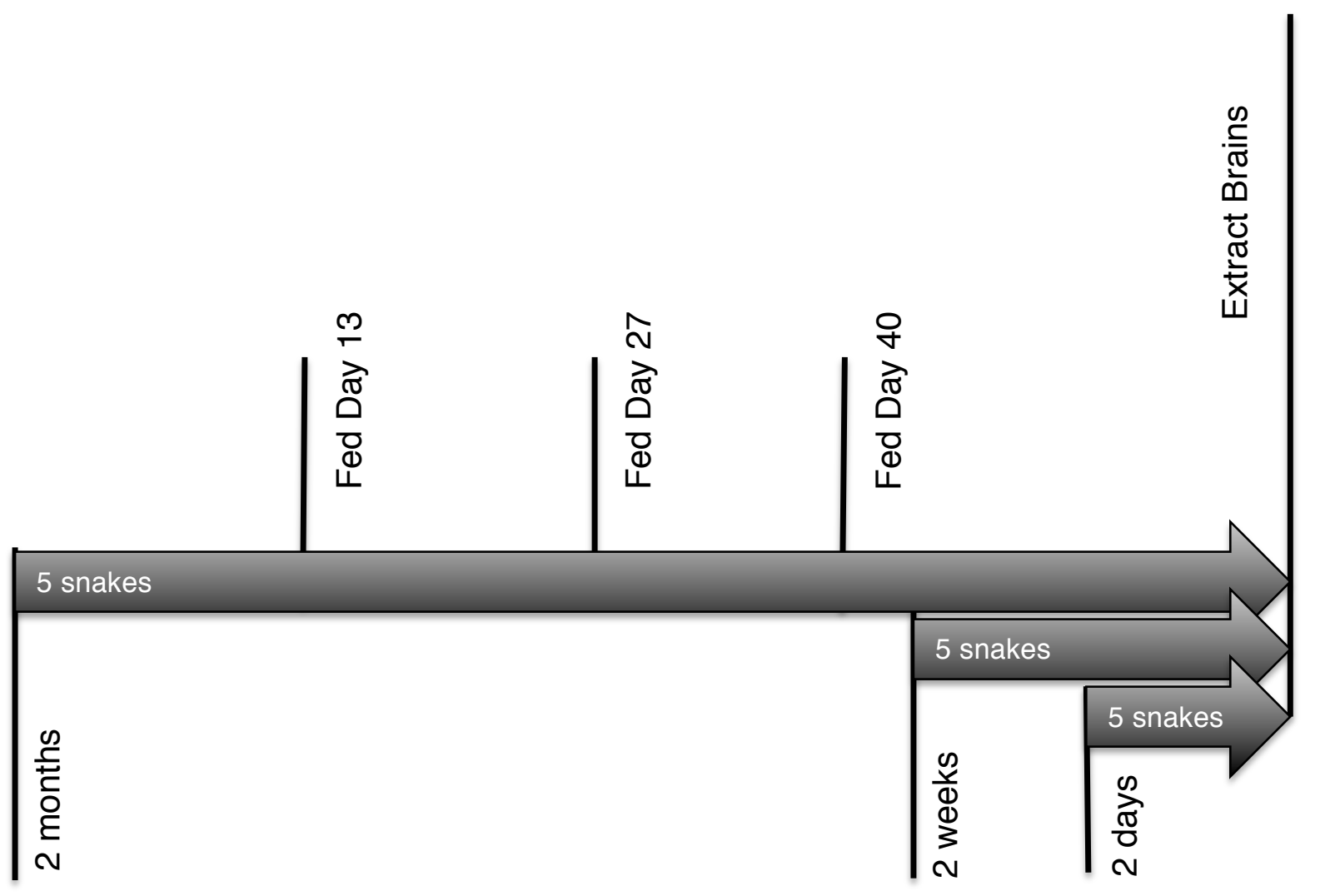

Figure 8: Timeline of Experiment 2. Snakes were sacrificed 2 months, 2 weeks, and 2 days after BrdU injection.

Table 2: Stratified placement of snakes into treatment groups at beginning of study.

\begin{tabular}{|r|r|r|r|r|r|}
\hline \multicolumn{2}{|c|}{2 day } & \multicolumn{2}{|c|}{2 week } & \multicolumn{2}{c|}{2 month } \\
\hline Snake & Mass $(\mathrm{g})$ & Snake & Mass $(\mathrm{g})$ & Snake & Mass $(\mathrm{g})$ \\
\hline 11 & 102.4 & 4 & 96.6 & 8 & 103.3 \\
\hline 10 & 117.6 & 15 & 98.3 & 1 & 108.6 \\
\hline 13 & 131.5 & 5 & 98.5 & 2 & 128.5 \\
\hline 7 & 140.8 & 14 & 142.7 & 3 & 131.8 \\
\hline 6 & 106.6 & 2 & 176.3 & 9 & 138.1 \\
\hline Mean & $\mathbf{1 1 9 . 7 8}$ & & $\mathbf{1 2 2 . 4 8}$ & & $\mathbf{1 2 2 . 0 6}$ \\
SE & 7.28 & & 16.02 & & 6.81 \\
\hline
\end{tabular}




\section{Sacrifice and perfusion}

Upon completion of the 60-day treatment period, snakes were sacrificed, perfused, and whole brains were stored following the protocol described in experiment 1 .

\section{Sectioning and histochemistry}

Four series of $36 \mu \mathrm{m}$ thick parallel coronal sections were obtained by cryostat. A cresyl violet series was mounted according to the methods stated in experiment 1 . Cresyl violet stained sections were photographed at 10x with a Leica EZ4-D, and photos were digitally stored as "jpeg” images. Anti-BrdU fluorescence immunohistochemistry was performed on free-floating sections as follows: Every eighth section was washed in PBST three times for 10 min and placed in $4 \mathrm{~N} \mathrm{HCl}$ for 15 min. Sections were rinsed in PBS for 5 min and neutralized for $10 \mathrm{~min}$ in $3.8 \%$ sodium borate wash $(\mathrm{pH}$ 8.5). Then they were placed in 5x "animal free blocker" diluted at 1:5 in PBS (SP-5030, Vector Laboratories) for 1 hour. Blocking was followed by immediate placement of sections in a 1:1,000 dilution of mouse antiBrdU (clone: Bu20a, isotype: IgG1, kappa, code: M0744, DakoCytomation, Glostrup, Denmark) in PBST for 24 hours shaking on a rotator table. Thereafter sections were washed three times in PBST for 10 min and placed in 1:200 FITC horse anti-mouse IgG antibody (FI-2000, Vector Laboratories) covered on a rotator table for 1 hour. Lastly sections were placed in 3, 10 minute PBST washes, mounted on slides, and coverslipped with Vectashield hard set mounting medium with DAPI $(\mathrm{H}-1500$, Vector Laboratories). 


\section{Measurement}

To determine study regions, sections were compared to those in Halpern (1980) and Smeets (1988), and regions were determined by direct observation of cresyl violet stained cells under the microscope at 400x (fig. 9). Masked images were stacked in image J and Java 3D modeling was used to create a 3-dimensional model (fig. 11 and supplemental movie 3: http://youtu.be//995WMN8mK8). The 3D model was then used to determine and demarcate the study regions including the accessory olfactory bulb (AOB); anterior dorsal (AD) and anterior ventral (AV) regions (retrobulbar regions) including the anterior-most TUB and ACC in the AV region; ventral lateral $(\mathrm{VL})$ and ventral medial $(\mathrm{VM})$ regions containing the central and posterior TUB, ACC, and the anterior commissure in the VM region, and the STR and accessory olfactory tract in the VL; dorsoventricular ridge (DVR); septum (S); anterior dorsal, lateral, and medial cortex (aDC, aLC, and $\mathrm{aMC})$; posterior dorsal, lateral, and medial cortex (pDC, pLC, pMC); anterior and posterior nucleus sphericus (aNS, pNS); and posterior cortex (PC). 


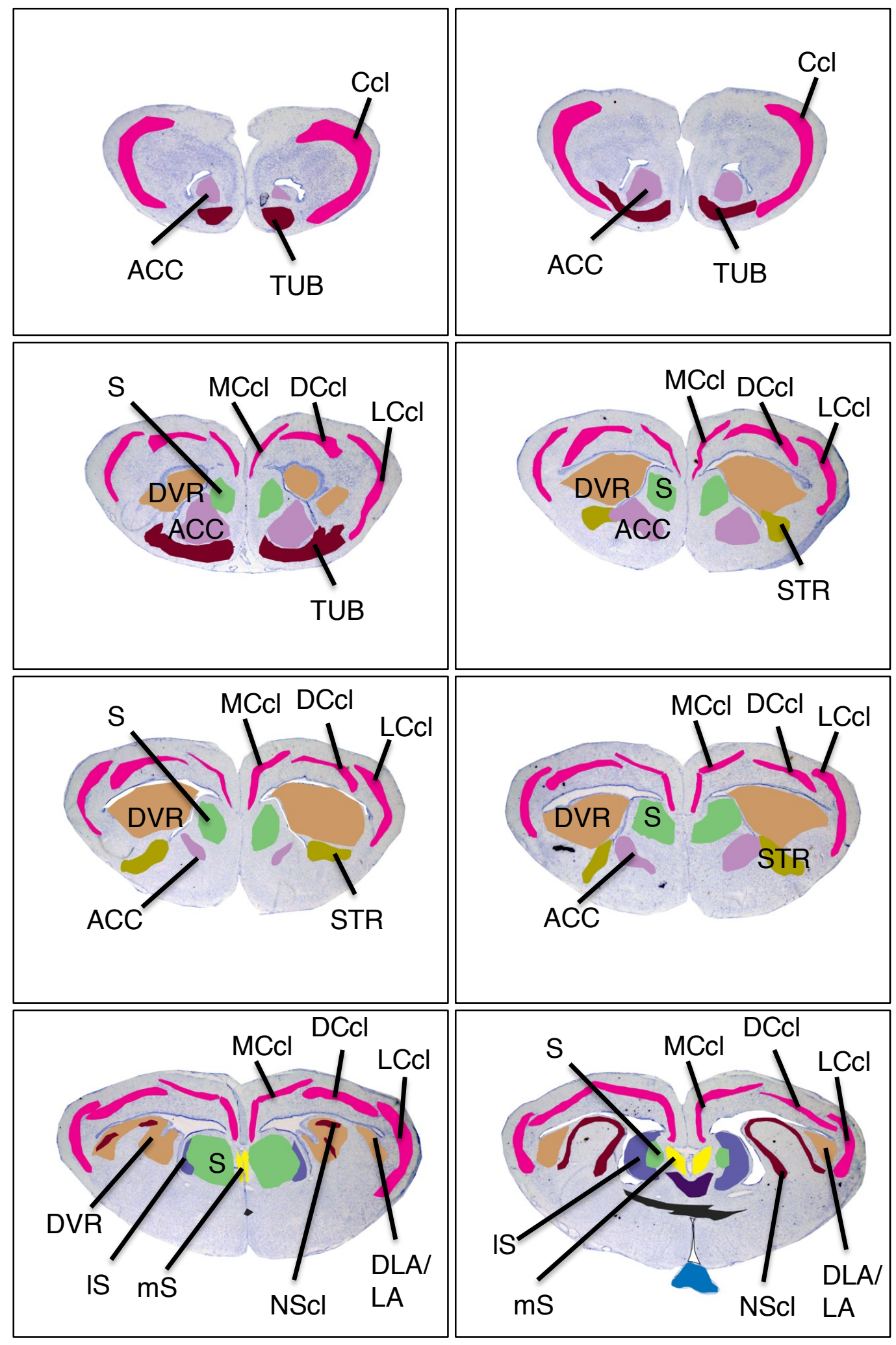




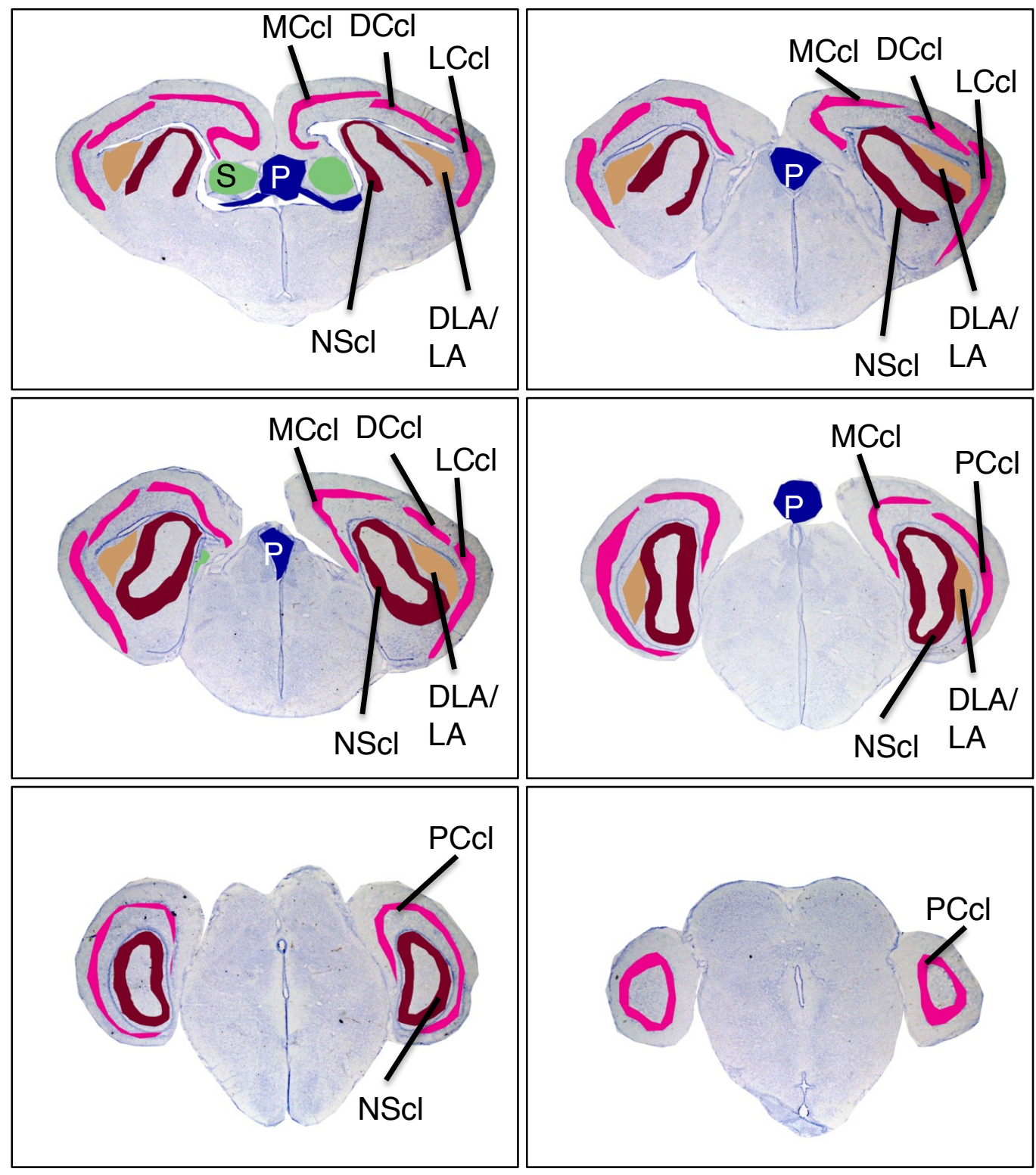

Figure 9: Every 16th section taken from python number 11, marked with colors depicting cellular nuclei regions determined by observing cellular changes in cresyl violet stained tissues. $\mathrm{ACC}=$ nucleus accumbens, $\mathrm{TUB}=$ olfactory tubercle, $\mathrm{Ccl}=$ cortical cell layer of the retrobulbar region, $\mathrm{MCcl}=$ medial cortex cell layer, $\mathrm{DCcl}=$ dorsal cortex cell layer, $\mathrm{LCcl}=$ lateral cortex cell layer, $\mathrm{PCcl}=$ posterior cortex cell layer, $\mathrm{STR}=$ striatum, DVR = dorsal ventricular ridge, $\mathrm{S}=$ septum, IS = lateral septal nucleus, $\mathrm{mS}=$ medial septal nucleus, $\mathrm{P}=$ pineal gland, $\mathrm{NScl}=$ nucleus sphericus cell layer.

The cresyl violet series was used to determine regional area $(\mathrm{RA})$ for all sections. The area of each region on each section was measured with the freehand 
tool in ImageJ. Anti-BrdU stained sections were observed under a fluorescence microscope and compared to corresponding cresyl violet sections. Cell counts were performed in the predetermined regions (fig. 11). Cells were categorized as ependymal if they were within 3 cells of a ventricle, or parenchymal if they were at least 3 cells away from a ventricle. Regional cell density was determined for each snake according to the following calculation:

regional ependymal cell density

$$
=\frac{\sum \text { ependymal cells across all sections in a given region }}{\sum R A \text { from all sections }}
$$

or

regional parenchymal cell density

$$
=\frac{\sum \text { parenchymal cells across all sections in a given region }}{\sum R A \text { from all secctions }}
$$




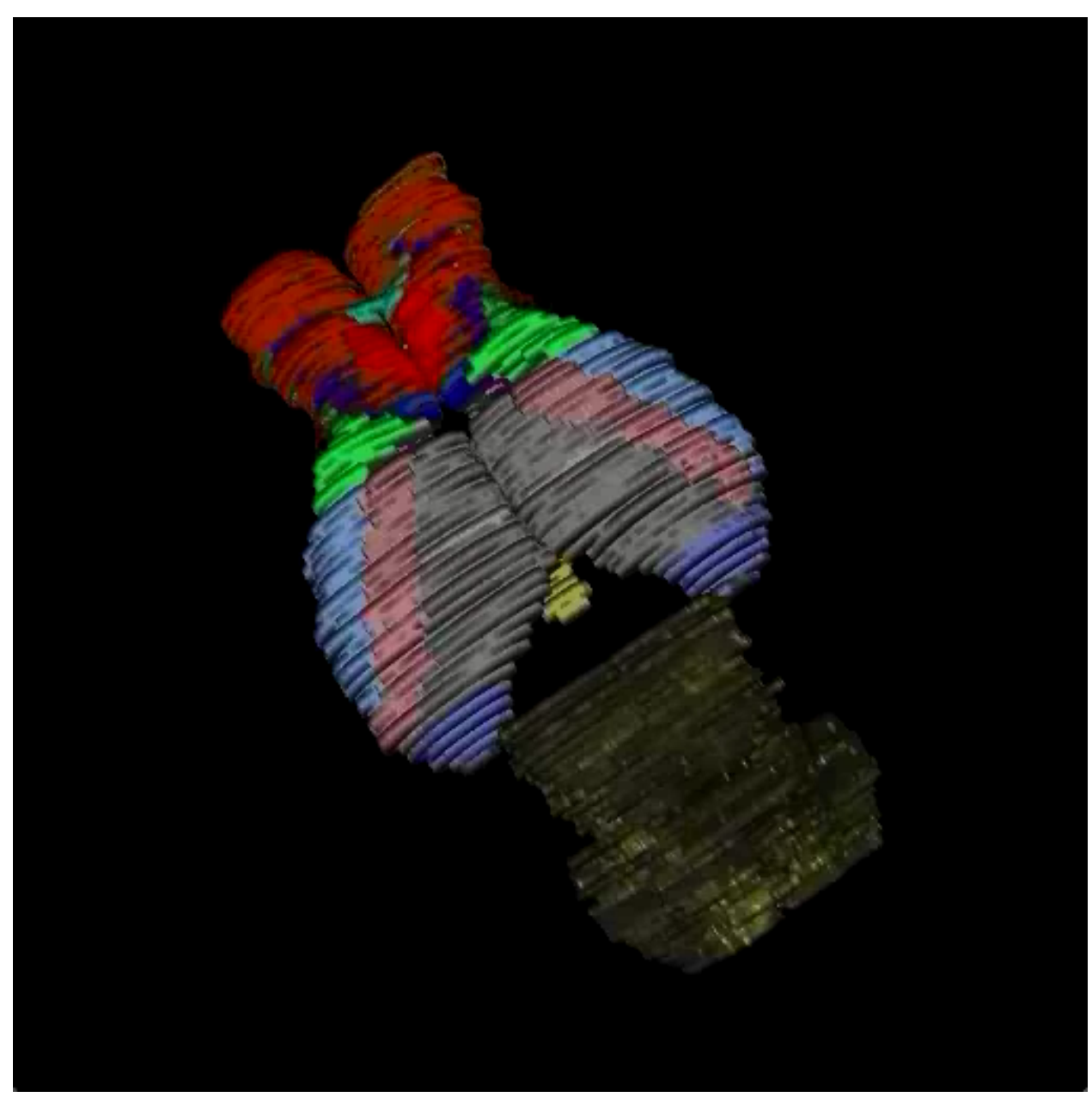

Figure 10: $P$. regius brain reassembled as a 3D image in ImageJ using Java3D for experiment 2 . Colors only denote different regions and no other factors.

Regional ependymal cell density was used as an indicator to determine 2-day proliferation rate. In order to make comparisons between regions and treatments, mean values and standard errors were calculated from regional density values in the same treatment groups. 


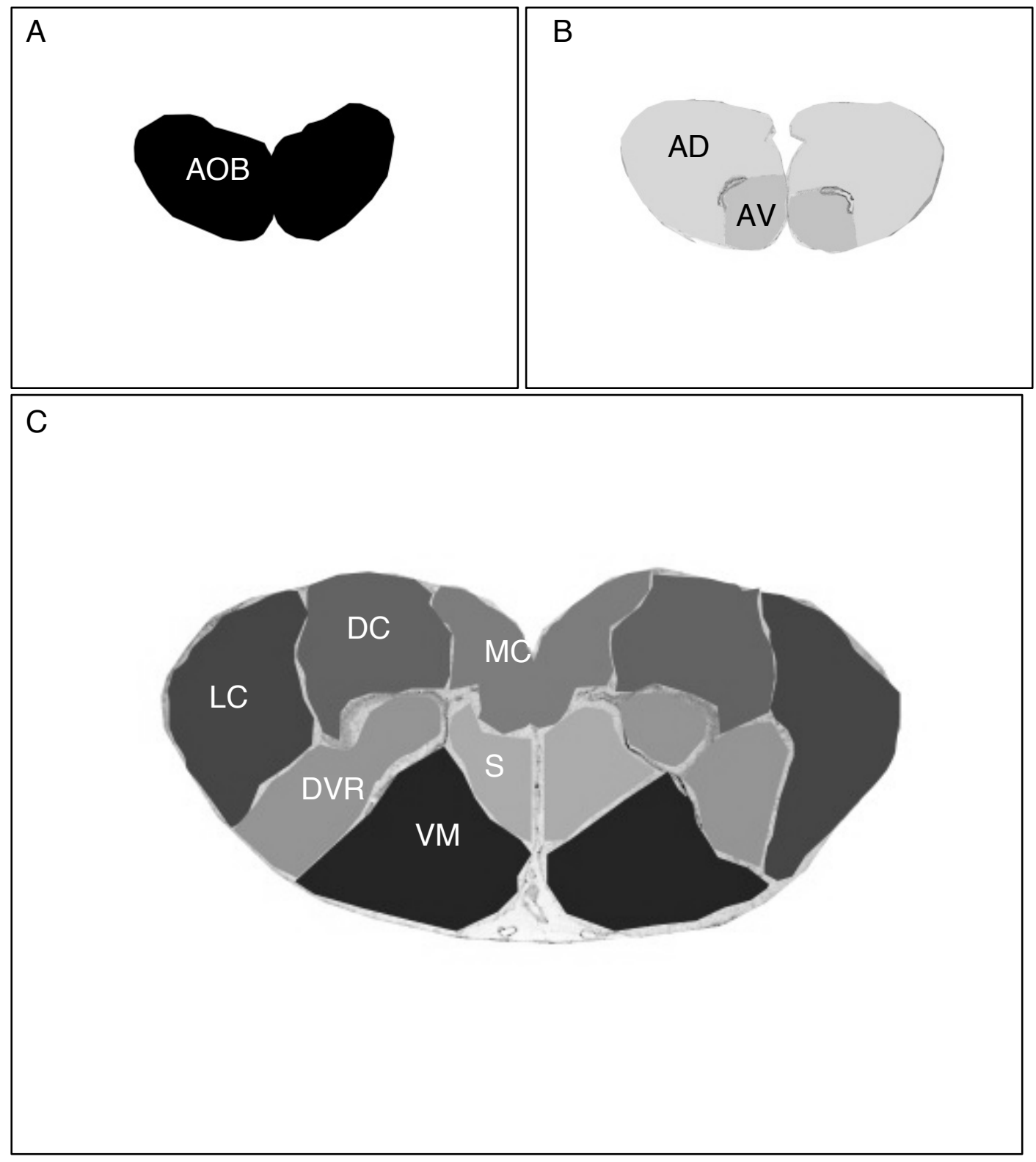




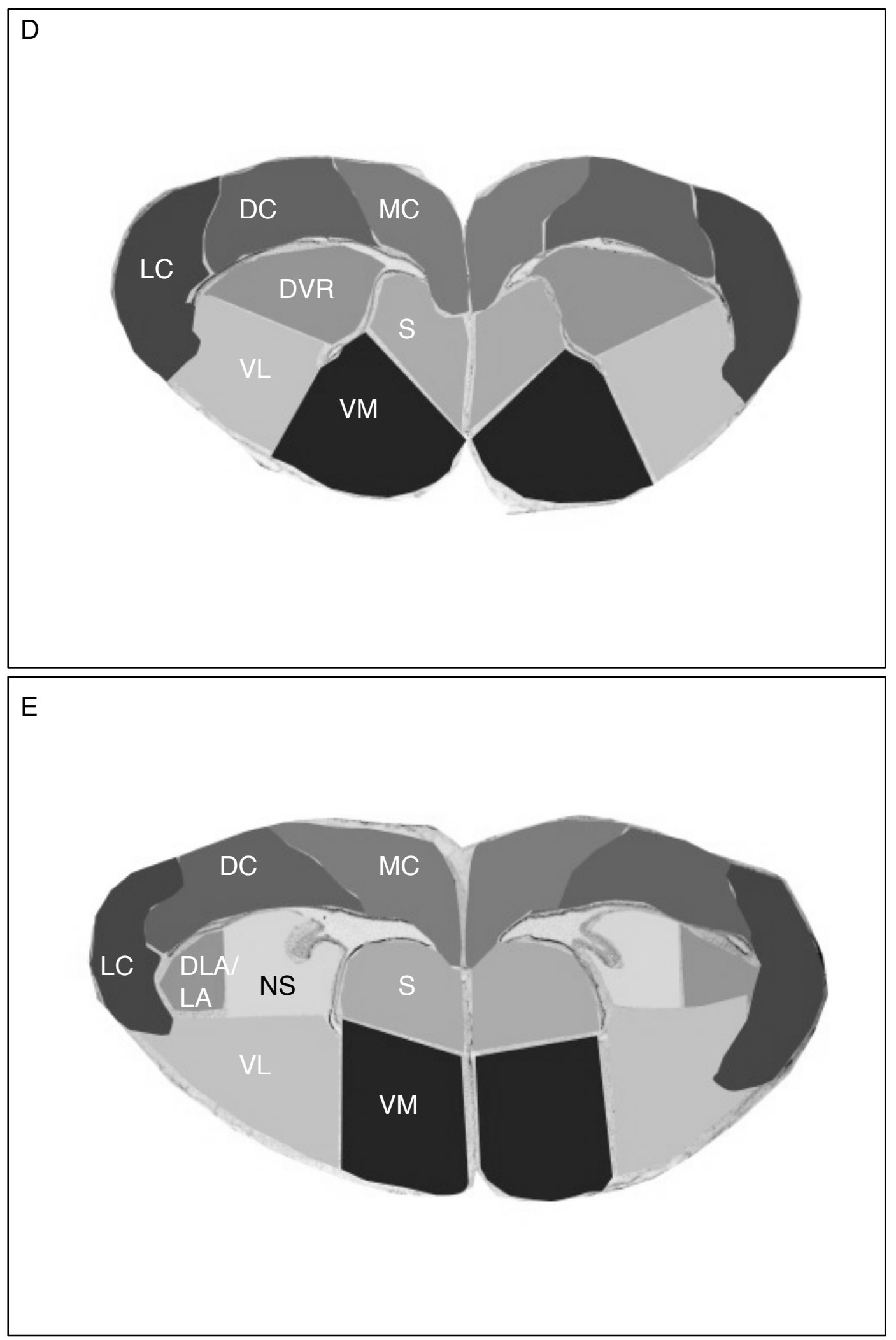




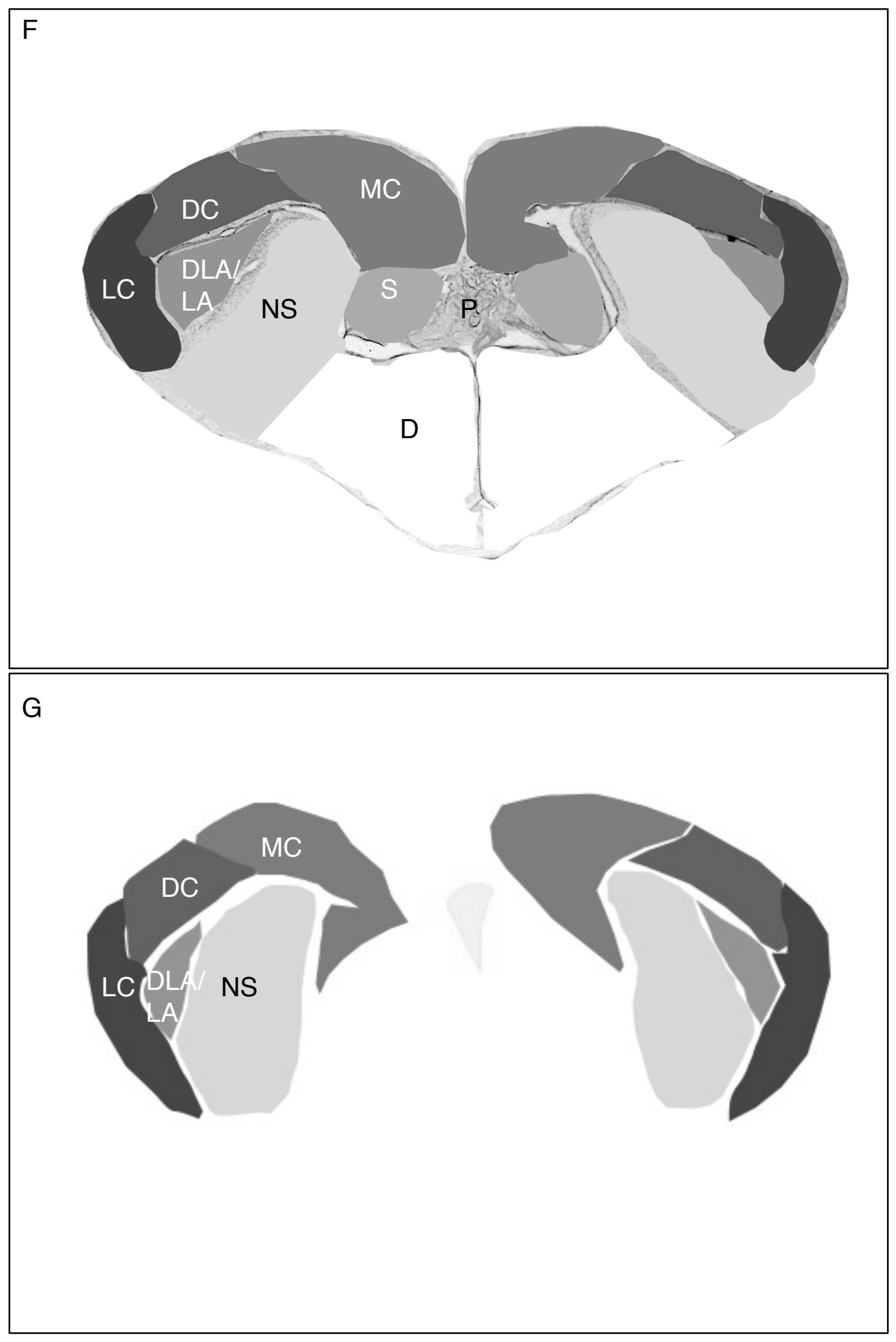

72 

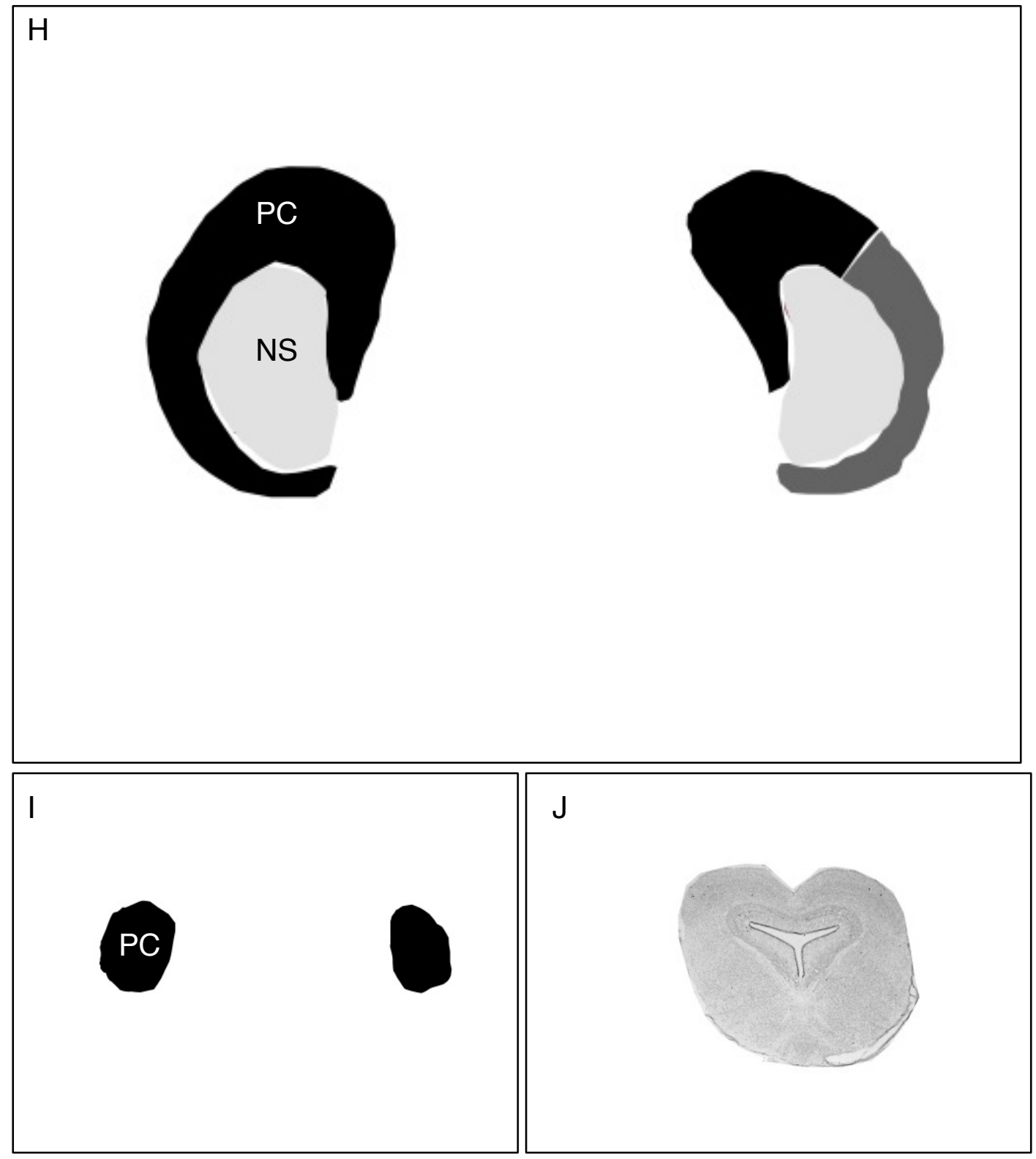

Figure 11: Every 16th section taken from a representative python cresyl violet stained, photographed and labeled using Photoshop CS3. Study regions determined for cell counts are highlighted. Regions correspond with quantification data in figs. 11,12 , and 13.

To determine the percentage of the originally proliferating cells that migrate into the parenchyma and survive, mean cell densities were calculated from complete regional snake brain data for all three treatments. Then the following calculations were performed: 


$$
\begin{aligned}
& \% \text { migration }_{2 \text { weeks }}=\frac{\text { mean regional parenchymal cell density } \text { weeks }_{\text {wean regional ependymal cell density }} \text { days }_{\text {dan }}}{\text { mean }} \\
& \% \text { survival }_{2 \text { months }}=\frac{\text { mean regional parenchymal cell density } \text { months }_{\text {man }}}{\text { mean regional ependymal cell density } \text { days }_{\text {din }}}
\end{aligned}
$$

In several regions, cells were marked in the parenchyma after only 2 days. These cells are likely of endothelial origin and they were not counted for the 2-day treatment. Since ventricular endothelial cell turnover has been determined for adult rats and mice as approximately 20 hours (Schultze \& Korr, 1981; Korr et al., 1975, respectively), it is likely that any endothelial cells potentially marked with BrdU in the parenchyma in the 2 week and 2 month treatments would no longer exist at the time of sacrifice. Thus, only ependymal, not parenchymal cells were counted at 2 days. But all parenchymal cells were subsequently counted throughout for the 2 week and 2 month groups.

\section{Results}

\section{Experiment 1}

Treatment had a significant effect on ependymal nuclei marking (overall cell density) ( $F=5.69$, d.f. $=2,9, p=0.025$; Fig. 12). A post-hoc Tukey-Kramer HSD confirmed a significant difference between the $50 \mathrm{mg} / \mathrm{kg}$ treatment and $250 \mathrm{mg} / \mathrm{kg}$ treatment $(p=0.026$; fig. 12). There was no difference between the $50 \mathrm{mg} / \mathrm{kg}$ treatment and the $100 \mathrm{mg} / \mathrm{kg}$ treatment $(p=0.784)$ or the $100 \mathrm{mg} / \mathrm{kg}$ treatment and the $250 \mathrm{mg} / \mathrm{kg}$ treatment $(p=0.116)$. 


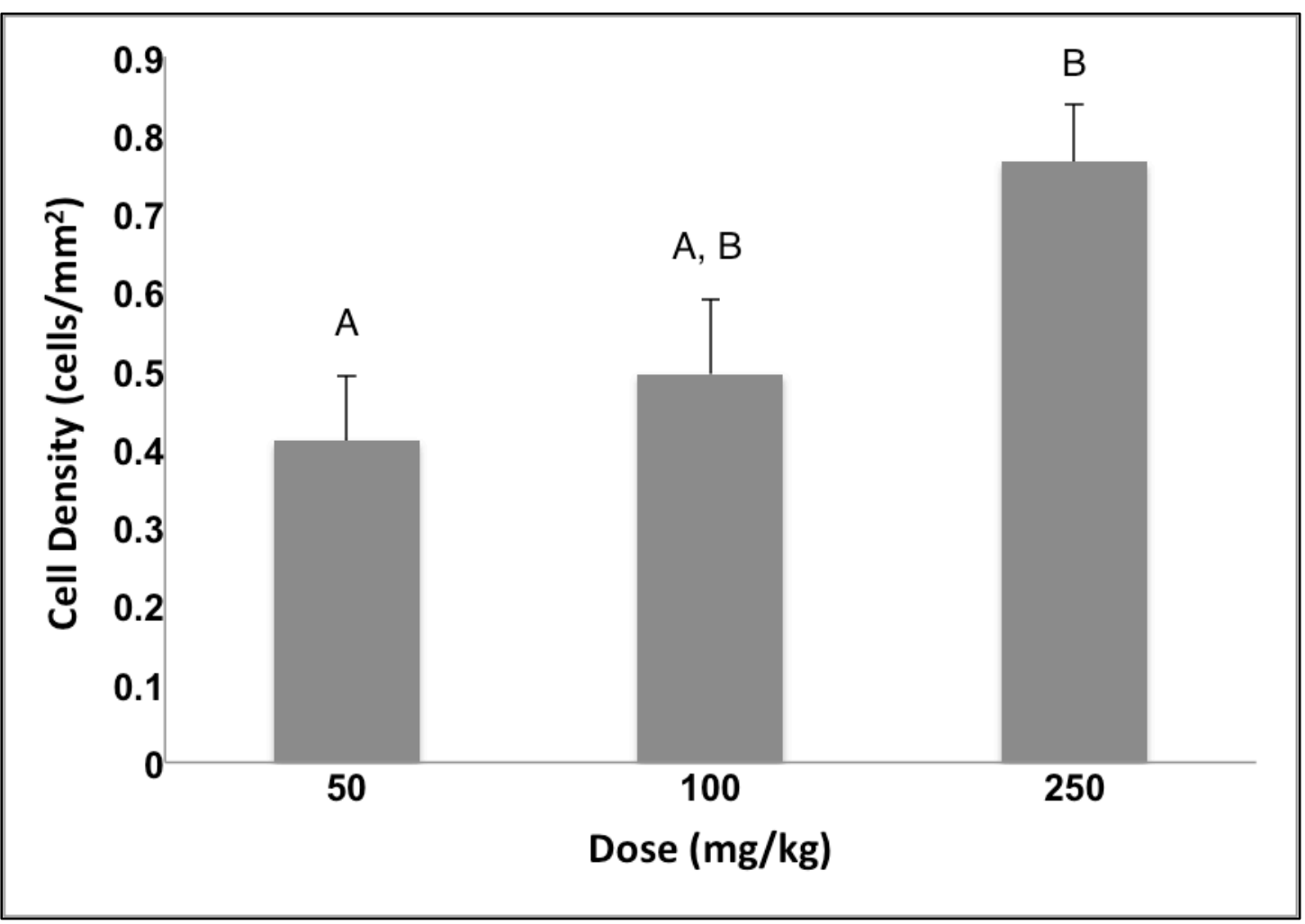

Figure 12. Mean cell new cell density (cells $/ \mathrm{mm}^{2} ; \pm$ SE) in the supraventricular ependymal zone for snakes exposed to $50 \mathrm{mg} / \mathrm{kg}, 100 \mathrm{mg} / \mathrm{kg}$, or $250 \mathrm{mg} / \mathrm{kg} \mathrm{BrdU}$.

\section{Experiment 2}

Cell proliferation was highest in the retrobulbar regions (AD, AV), the $A O B$, DLA, DVR, pNS, S, and pNS (fig. 13A, B). After 2 weeks, cells migrated most to the parenchyma of the retrobulbar regions, the AOB, VL, DVR, and aNS (fig. 13A, C). After 2 months, the new cells survived most in the parenchyma of the AOB, AV, DLA, DVR, and AD (fig. 13A, D). Regions with the highest migration

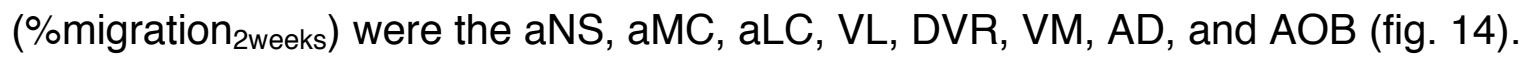
Regions with the highest survival (\%survival ${ }_{2}$ months) were the aLC, AOB, aNS, aMC, DVR, aDC, VM, and pLC (fig. 15). Even after 2 months, new ependymal cells did not migrate and remained in the ventricular zone of several regions (fig. 16). The regions 
with the greatest ependymal-cell-to-parenchymal-cell ratio after 2 months were the pDC, DLA/LA, aMC, and pLC.

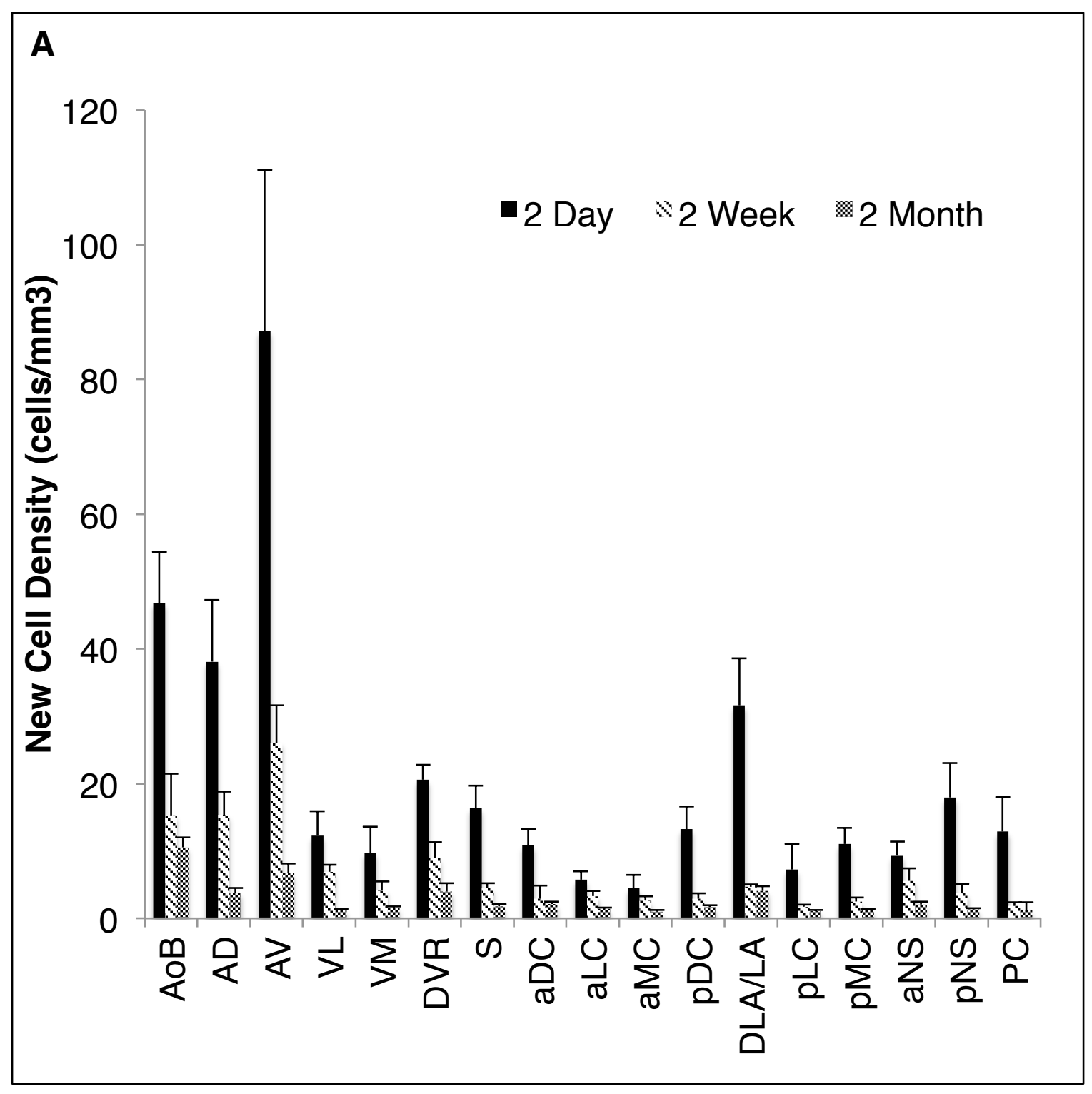




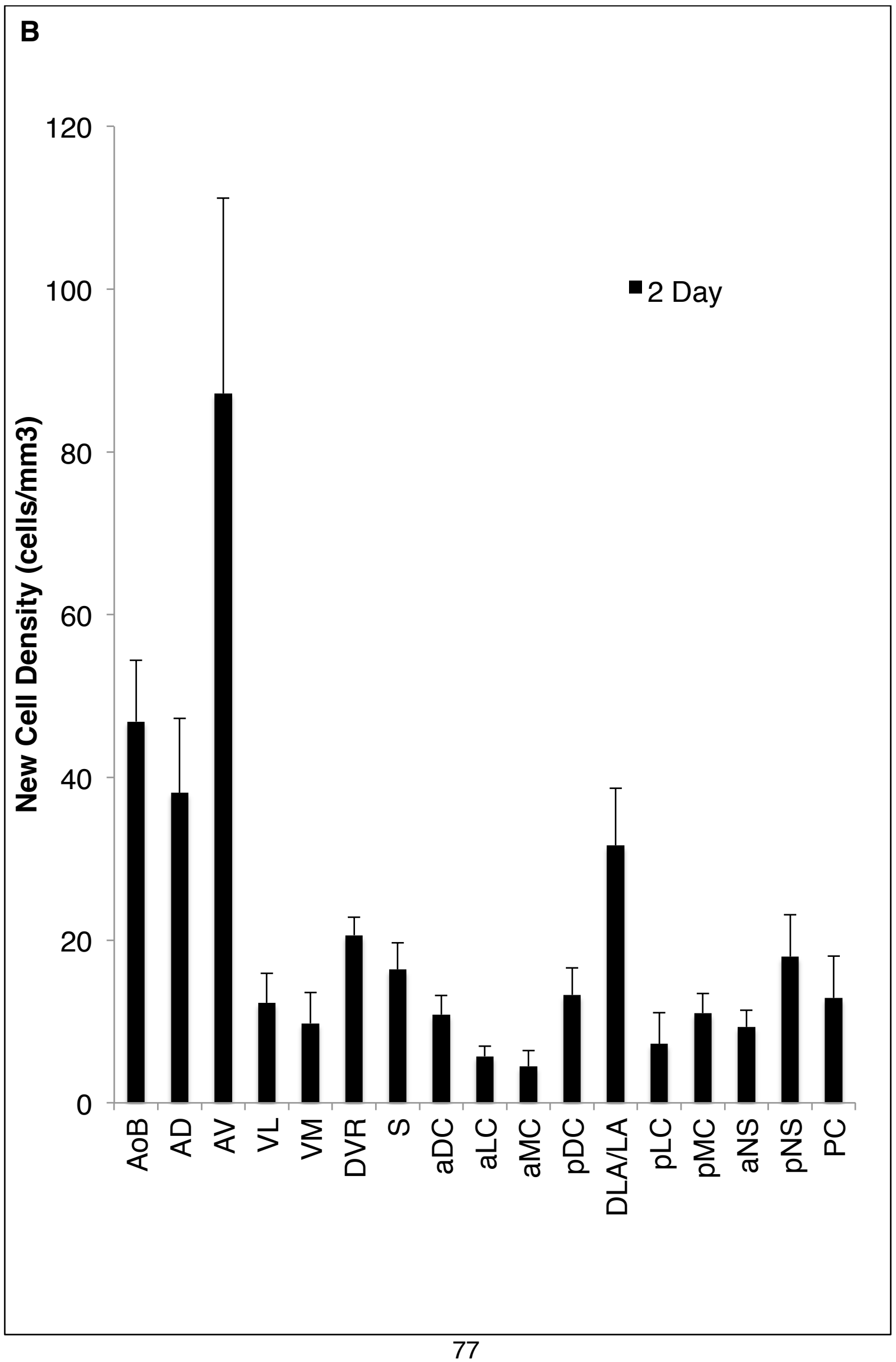




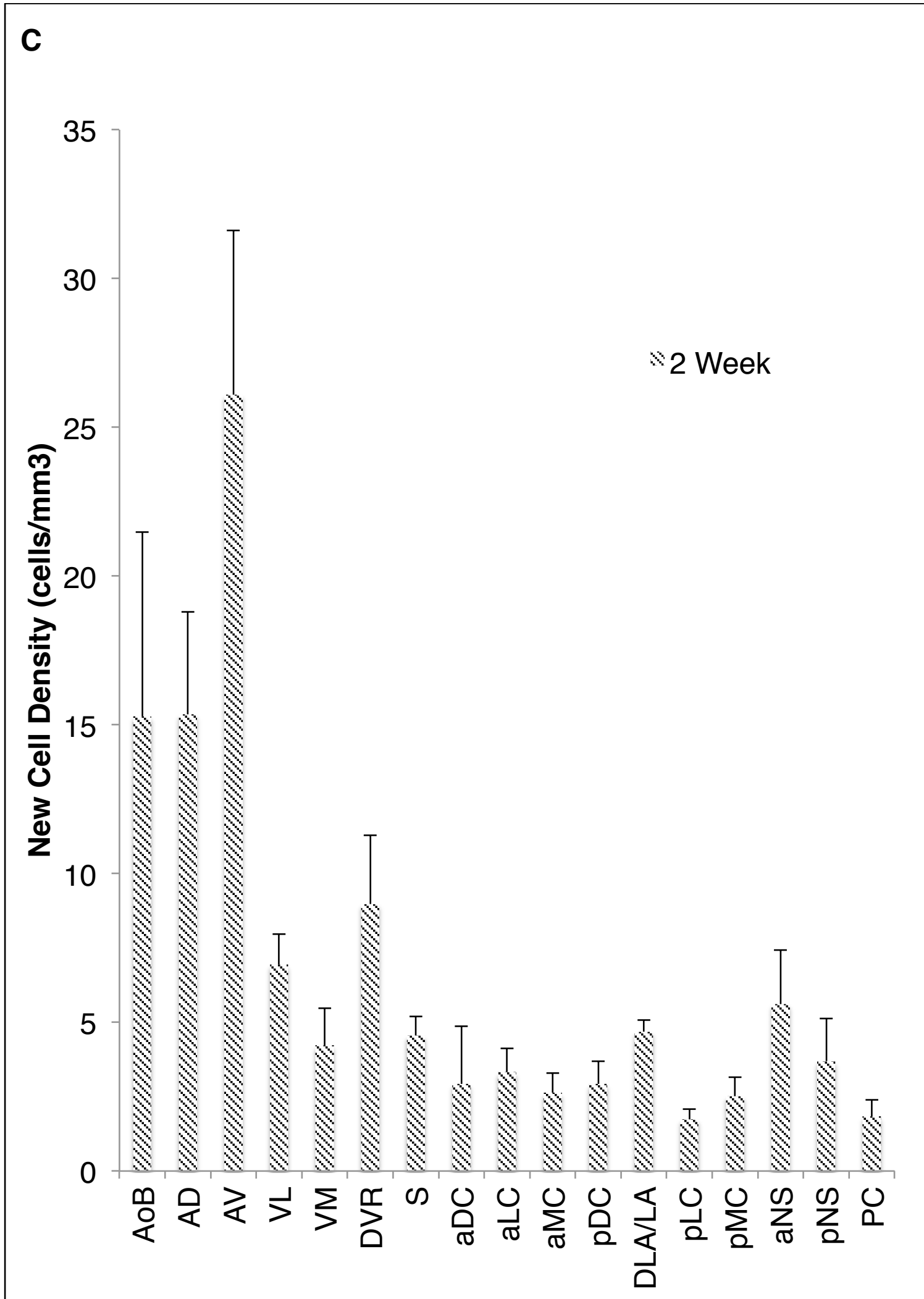




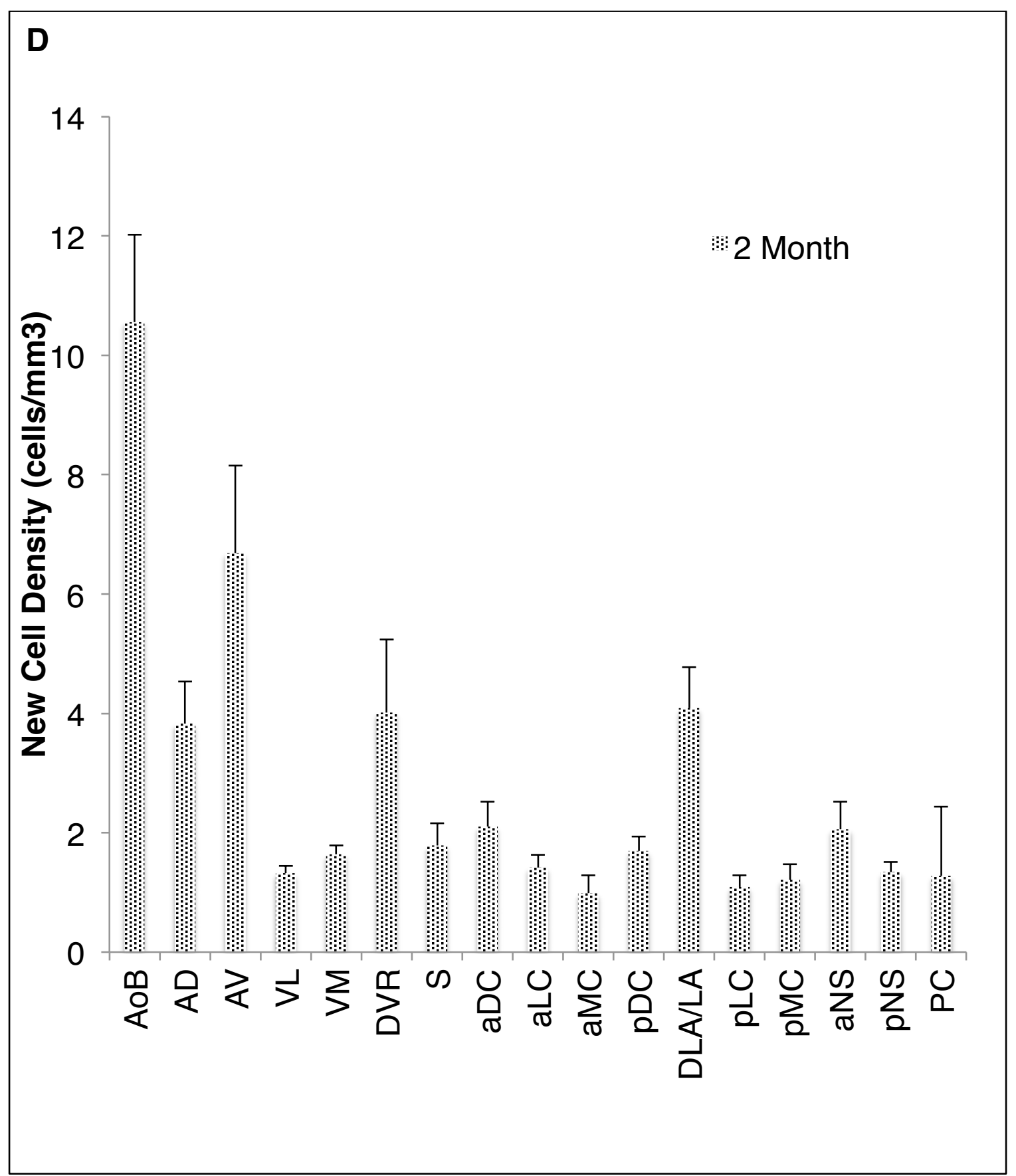

Figure 13: Density of new cells (cells $/ \mathrm{mm}^{3}$; mean \pm SE) located in regions of the $P$. regius telencephalon denoted in fig. 10, A. 2 days, 2 weeks, and 2 months postinjection. B. 2 days post-injection only. C. 2 weeks post-injection only. D. 2 months post-injection only. 


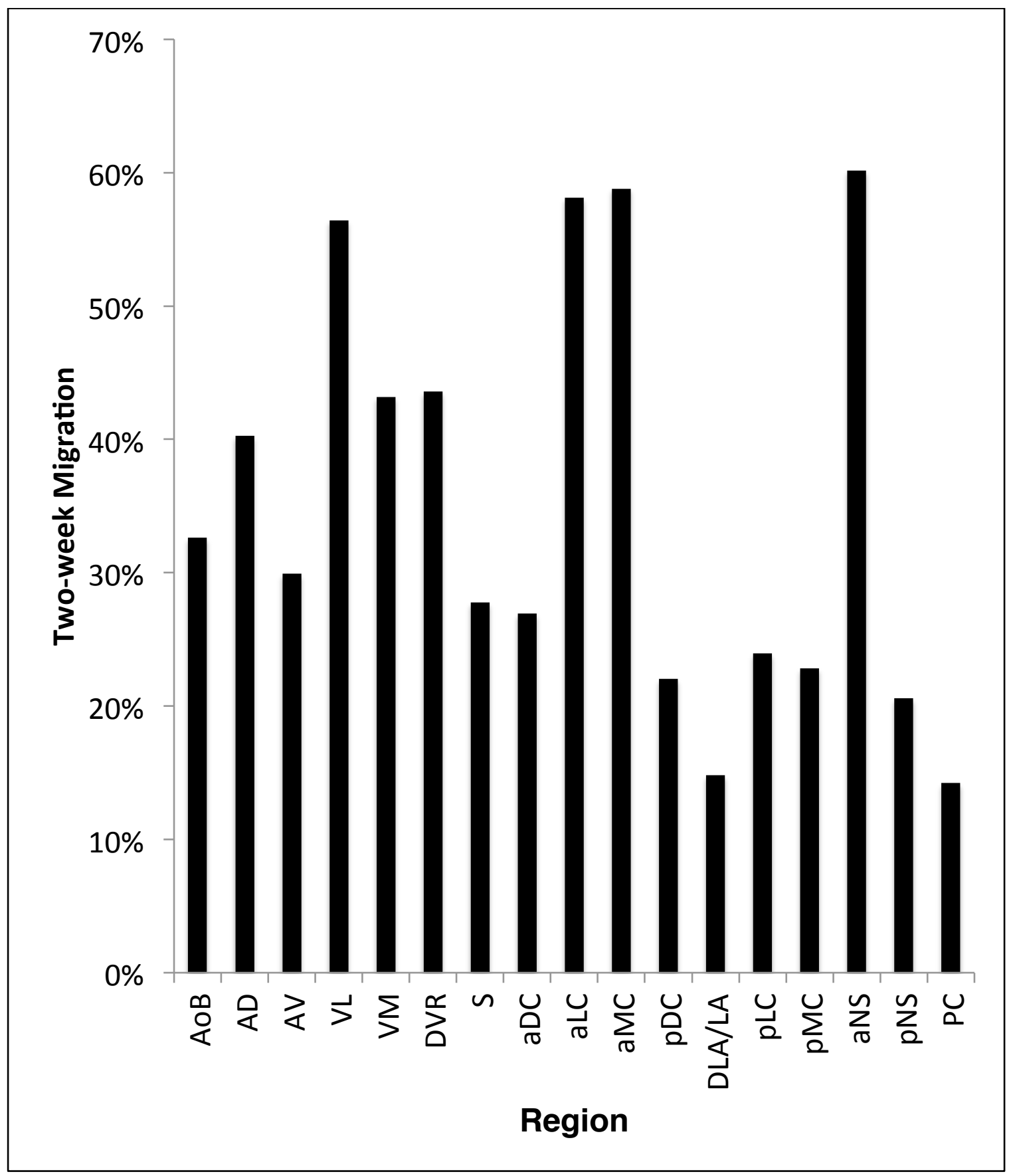

Figure 14: Regional migration of new cells (\%cells) determined from [(mean regional parenchymal cell density at 2 weeks)/(mean regional ependymal cell density at 2 days)] in the $P$. regius telencephalon, 2 weeks post-injection. 


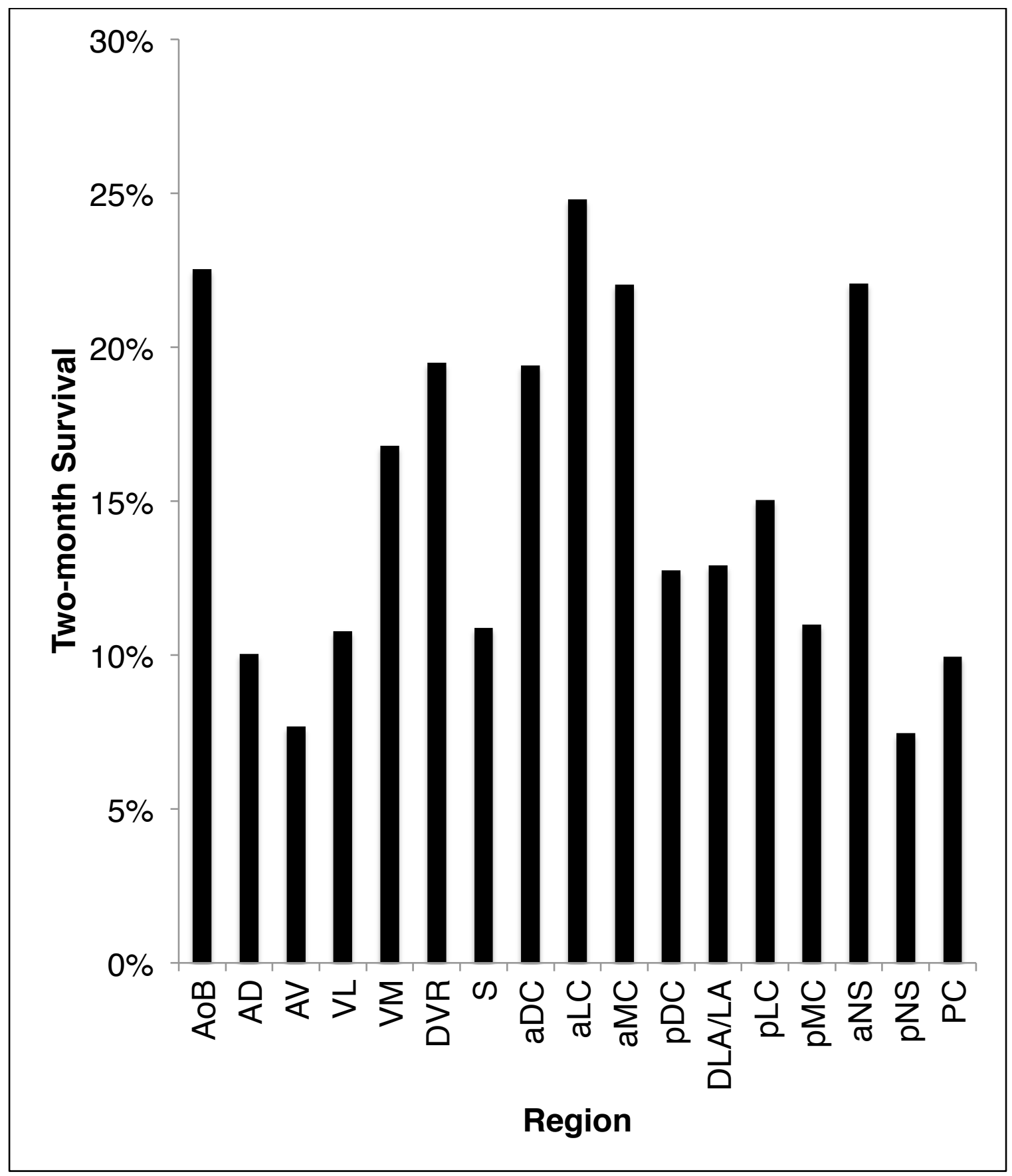

Figure 15: Regional survival of new cells (\%cells) determined from [(mean regional parenchymal cell density at 2 months)/(mean regional ependymal cell density at 2 days)] in the $P$. regius telencephalon, 2 months post-injection. 


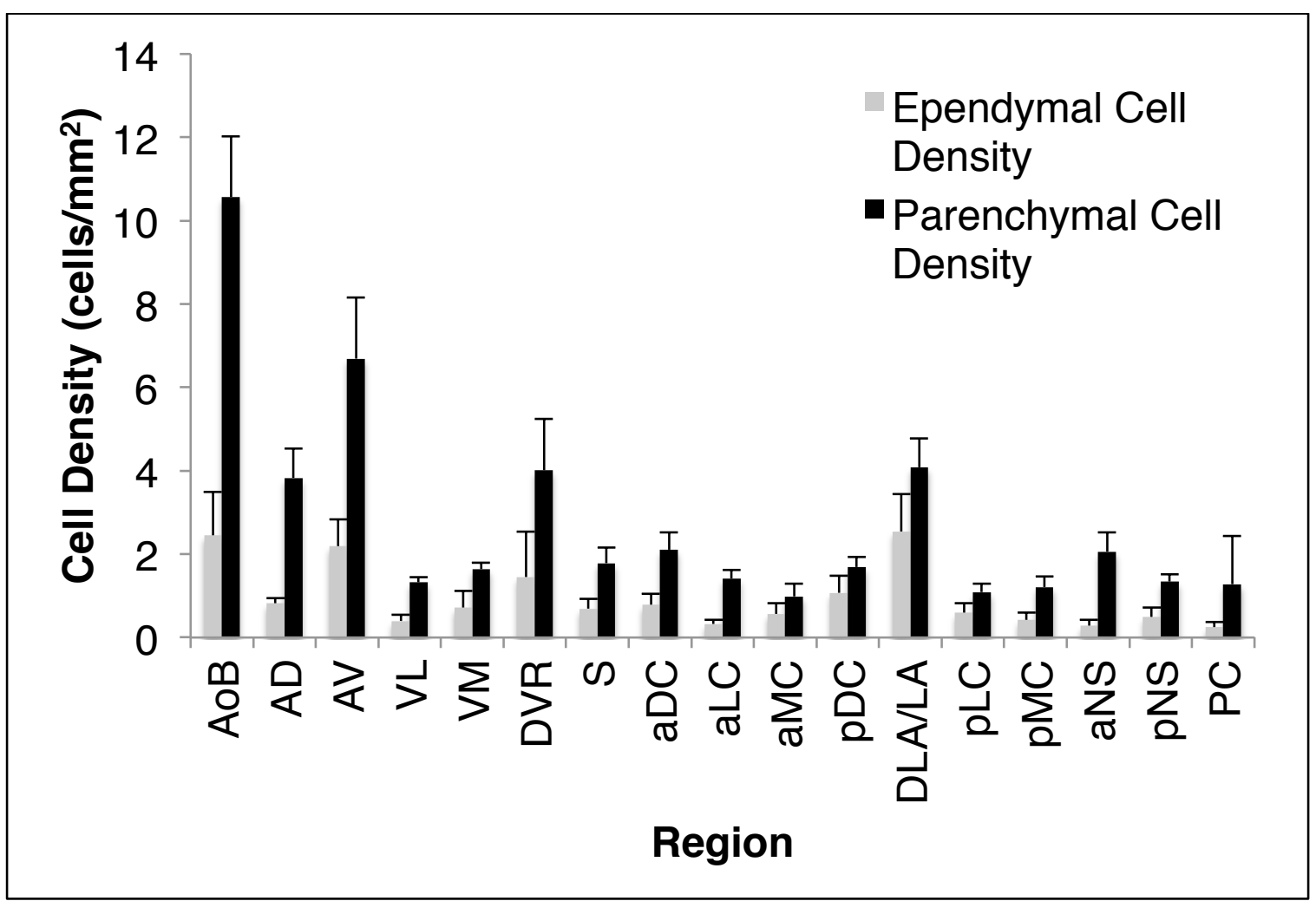

Figure 16: Comparison of cell density in the ependymal zone versus parenchymal zone 2-months post-BrdU injection.

Table 3: Telencephalon regions organized by high or low proliferation combined with high or low migration, and survival.

\begin{tabular}{|c|c|c|c|c|c|}
\hline & \multicolumn{2}{|c|}{ Migration } & \multicolumn{2}{|c|}{ Survival } \\
\hline & & High & Low & High & Low \\
\hline \multirow{2}{*}{ 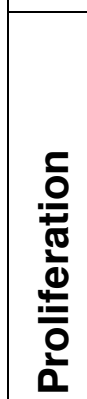 } & High & $\begin{array}{l}\text { AD, AV, DVR, } \\
\text { aNS }\end{array}$ & DLA/LA & $\begin{array}{l}\text { AOB, DVR, } \\
\text { aNS }\end{array}$ & $\mathrm{AD}, \mathrm{AV}$ \\
\hline & Low & $\begin{array}{l}\text { VL, VM, aLC, } \\
\text { aMC, }\end{array}$ & pLC & aLC, aMC & $\mathrm{VL}$ \\
\hline
\end{tabular}




\section{Discussion}

\section{Dosage of BrdU}

In accordance with previous studies of BrdU dose, we detected an effect of dose on ependymal cell marking. The highest tested dose $(250 \mathrm{mg} / \mathrm{kg})$ marked a significantly higher density of cells than the lowest tested dose $(50 \mathrm{mg} / \mathrm{kg})$. This finding supports previous studies of this relationship (Burns and Kuan, 2005; Cameron and Mckay, 2001; Hancock et al., 2009) and demonstrates that dose affects cell marking not only in mammalian species, but also in reptiles. In this experiment, the maximum BrdU dose was limited to $250 \mathrm{mg} / \mathrm{kg}$ because $\mathrm{BrdU}$ precipitated from solutions containing more than $20 \mathrm{mg} / \mathrm{mL}$ and injecting a large subcutaneous bolus (in excess of $21 \mathrm{~mL}$ for a $1.2 \mathrm{~kg}$ snake) is physically challenging, requiring multiple injection sites, which is potentially stressful to the animal. Since previous studies used much smaller animals $(<300 \mathrm{~g})$, experimenters were able to inject BrdU doses higher than 250 $\mathrm{mg} / \mathrm{kg}$ and determine the optimal dose. I expect doses larger than $250 \mathrm{mg} / \mathrm{kg}$ would mark significantly more cells than the $100 \mathrm{mg} / \mathrm{kg}$ dose, yet administration of higher doses would require using a solvent able to provide higher miscibility for BrdU in addition to, or in lieu of, using smaller snakes. While higher doses in a different solution could potentially provide further marking, this may not be necessary, as the $100 \mathrm{mg} / \mathrm{kg}$ dose yielded BrdU cell density that was not significantly different from the $250 \mathrm{mg} / \mathrm{kg}$ dose. Larger subcutaneous doses are inadvisable because the buildup of a large bolus creates considerable pressure against the syringe, causing leakage through the injection site post injection. These 
large pressures could damage the snakes' tissues, cause BrdU to leak, potentially exposing the administrator to $\mathrm{BrdU}-\mathrm{a}$ carcinogen-and expose snakes administered larger bolus volumes to less $\mathrm{BrdU} \mathrm{m} / \mathrm{m}$ relative to snakes administered smaller boluses.

\section{Proliferation, migration, and survival}

Two days after BrdU injection, cells were labeled throughout the telencephalon along the lateral ventricles, especially at the lateral sulci, indicating areas of proliferating cells. The greatest proliferation took place at the ventricles nearest the $A O B, A D, A V$, and DVR. Many of these newborn cells migrate to the parenchyma throughout the telencephalon and survive for at least 2 months. On the other hand, some of them continue to stay in the ependymal region and do not migrate even after 2 months. This system of reduced migration across the VZ parallels other squamate studies, and like in other squamate studies ( $P$. hispanica, $T$. mauritanica), differs from turtles, which exhibit even slower migration of proliferating cells across the VZ (Font et al., 2001). The ratio of ependymal-cells-to-parenchymal-cells in the DLA/ LA region and DC at least one month post injection appears to be consistent among all squamates (Font et al., 2001).

There appears to be a dichotomous relationship of neurogenic activity between brain regions involved with more short-term or long-term brain functions. Regions that relay regularly changing olfactory and vomeronasal stimuli as part of the amygdalar system (short-term functions) may require constant growth of new neurons and/or higher cell turnover. The DLA/LA region, which is considered the 
reptilian homologue to the basolateral amygdala, has high proliferation rates but does not seem to have as high of a survival rate. Additionally, in mammals, the regions involved in processing olfactory input (the rostral migratory stream; RMS) have relatively high neurogenic activity (Altman, 1969; Pencea et al., 2001). In reptiles, the homologs to the RMS are likely located in the retrobulbar regions (AD), the AV containing the TUB, and the AOB which relays vomeronasal and olfactory sensory information. These regions also seem to have high proliferation rates, but possibly lower survival.

Conversely, regions known for long-term functions like spatial memory, exploratory behavior and species-specific behavior like territorial displays, exhibited lower proliferation rates, but less attrition and higher survival. Examples of these regions are the MC and DC associated with spatial memory (Baird Day, et al., 2001;

Lopez et al., 2003; Holding et al., 2012), the VL containing the STR, associated with species-specific behavior and working memory (Greenberg, 1977; Packard and Knowlton, 2002; Tarr, 1982), and the VM containing the ACC responsible for exploratory behavior and behavioral reinforcement (Olds \& Milner, 1954; Distel, 1978; Greenberc et al., 1979; Parent, 1986).

\section{MC and DC: Hippocampal homologues}

The reptilian $\mathrm{MC}$ and $\mathrm{DC}$ are widely regarded as homologous to the mammalian and avian hippocampus (Bruce and Butler, 1984; Butler and Hodos, 1996; Rodriguez et al., 2002, Holding et al., 2012). The small-celled portion of reptilian cortex is considered homologous to the dentate gyrus of the mammalian 
hippocampus, and the large-cell portion is considered homologous to the CA fields of mammals (Treves et al., 2008). No CA-field subdivisions have been distinguished (Papp et al., 2007), although a system has been proposed for further investigation (Delgado-González et al., 2008). As in the dentate gyrus of the adult mammalian hippocampus (Kuhn et al., 1996; van Praag et al., 2002), the MC is associated with continuous neurogenesis during adulthood in reptiles (Bruce and Butler, 1984; Butler and Hodos, 1996; Casini et al., 1986; Hoogland et al., 1987, 1998; Lopez-Garcia et al., 1992, 2002). Integration of new granule cells is essential to hippocampal function in the mammalian dentate gyrus (Clelland et al., 2009; Dupret et al., 2008; Saxe et al., 2006; Shors et al., 2001). Recent studies have demonstrated that new granule cells allow for "pattern separation"-the formation of distinct memory representations originating from similar information (Sahay et al., 2011a). Pattern separation is the orthogonalization of input that prevents memories from interfering from one another (Sahay et al., 2011b). While there is no direct evidence for pattern separation in reptiles, the two systems are so functionally and structurally similar that a system similar to CA3 could potentially occur in reptiles and should be investigated.

\section{The basal regions: The striatum and the nucleus accumbens}

Very recently, it has become clear that adult neurogenesis takes place in the human STR, displacing the previous canon that it only takes place in the olfactory bulb and hippocampus (Kempermann, 2014). Using carbon-14 dating techniques, Ernst et al. (2014) found that striatal interneurons undergo turnover at a rate of $2.7 \%$ annually, and most impressively, that these neurons are depleted in Huntington's 
disease patients. Other mammalian studies have supported these findings (Arvidsson et al., 2002; Dayer et al., 2005; Luzzati et al., 2006; Yamashita et al., 2006), but none of them until now showed complete cell proliferation, neurogenesis, and functional integration in an undamaged brain (Bonfanti and Peretto, 2011).

For a couple decades, there has been limited evidence for adult neurogenesis in the STR of lizards (Penafiel et al., 2001; Pérez-Cañellas and García-Verdugo, 1996) and turtles (Pérez-Cañellas et al., 1997). When Pérez-Cañellas and GarcíaVerdugo (1996) observed BrdU-labelled brain tissue from T. mauritanica, they saw very few cells in the STR and high variability among individual study animals. The cells did not concentrate in any specific area and instead were uniformly distributed. The new cells also appeared to move both radially and tangentially, instead of following the radial processes of radial glial cells indicating migration similar to the RMS system in mammals. In the current study, the high proliferation rate and low 2month survival within the STR may be indicating a similar migration. New cells may be proliferating at the ventricular ependymal layer, migrating out to the parenchyma, and then continuing to travel rostrally out of the STR to other brain regions. Sagittal sectioning could show whether cells are moving rostrally in the STR as well as other regions.

There has been little literature about adult neurogenesis in the ACC, likely because evidence is lacking that it occurs there in mammals. In reptiles, migrating neurons have been found in ACC of $P$. hispanica, as evidenced by the neuronal marker PSA-NCAM (Ramirez-Castillejo et al., 2002a), but whether the cells were of 
proliferative origin has not been confirmed. In amphibians, Almli and Wilczynski (2007) found cell proliferation and survival after 30 days in the ACC of Hyla cinerea (American green tree frog). It has been further supported in Lithobates catesbeianus (American bullfrog) and Xenopus laevis (African clawed frog), but the final phenotype of these cells is yet to be determined (D'Amico et al., 2011; Simmons et al., 2008). In mammals, the ACC has been implicated as responsible for rewardseeking behavior and motivation (Cador et al., 1989; Knutson et al., 2001), including addiction-based behavior (Hoebel et al., 1983). While it is likely that there is a link between adult neurogenesis in the ACC, sensory systems, and reinforcement based on what is perceived, there are so few data regarding adult neurogenesis in the ACC that it is too early to make any hypotheses as to what is taking place in this system.

\section{Amygdaloid regions}

The mammalian amygdala is a site where modulation and memory consolidation occurs in response to emotional stimuli such as fear (Martínez-Garcia et al., 2009) or during reward processes (Stuber et al., 2011). However, the amygdala itself is not a memory storage site (Malin and McGaugh, 2006). It is also important in processing information about pheromones and other olfactory or vomeronasal input, causing it to directly influence the endocrine system (Halpern and Martínez-Marcos, 2003) and behavior during confrontations with conspecifics (agonistic behavior) (Meredith and Westberry, 2004). Support for mammalian amygdalar neurogenesis has been limited to studies indicating proliferation, cell genesis, and specification in Orictolagus cuniculus (New Zealand white rabbits) (Luzzati et al., 2006), Mus musculus 
(laboratory mice) (Shapiro et al., 2009), and Saimiri sciureus (common squirrel monkeys) and Macaca fascicularis (crab-eating macaques) (Bernier et al., 2002). In the present study I have found the reptilian DLA/LA is a region of high proliferation, but low migration and survival, which coincides with its role, not in storage, but in encoding sensory memory.

\section{Olfaction and the RMS}

The generalized $A D$ as defined in this paper likely contains the rostral migratory stream (RMS). In mammals, the RMS is well known as a highly neurogenerative and neuromigratory region, and has been given the name, "Rostral Migratory Stream," because it is where neuronal precursors migrate from the ependymal zone to the olfactory bulb. The findings of this study confirm studies in other reptiles (Peñafiel et al., 1996; Pérez-Cañellas et al., 1997), indicating the presence of a RMS similar to that of fish (Grandel et al., 2006) and mammals (Pencea et al., 2001). There is no evidence indicating an RMS in amphibians or humans, and limited evidence in birds (Kaslin et al., 2008). These anatomical differences are likely related to differences in the importance of olfaction and/or pheromone signaling in different taxa.

The RMS system could also be responsible for what appears to be higher proliferation and lower parenchymal survival of cells in the retrobulbar regions compared to the more caudal telencephalon. Cells could be surviving at 2 weeks and 2 months and then migrate rostrally out of the study region and into the olfactory bulbs so they are not counted as surviving cells. For example, the RMS cells migrate 
in mice at an average rate of $30 \mu \mathrm{m} / \mathrm{hr}$ (Lois and Alvarez-Buylla, 1994). At that rate they could completely migrate out of the study area within 2 months. Further study using sagittal instead of transverse sections could clarify whether RMS migration or attrition is responsible for this result.

\section{$D V R$}

The most prominent pallial structure in reptiles is the DVR (Holmgren, 1925, Northucutt, 1981, Ulinski, 1983). It appears to exhibit not only high proliferation, but also high relative migration at 2 weeks and survival at 2 months. This is not surprising because the DVR has been implicated as a site for processing of sensory information, association, and output for modulation of behavior. A region essential to so many functions likely requires neurogeneration and long-term cellular turnover throughout adulthood in order to provide plasticity for behaviors in response to environmental changes.

Several previous studies in reptiles have found evidence of DVR cell genesis (Delgado-Gonzalez et al., 2011; Font et al., 2001; Marchioro et al., 2005). The mammalian homologue to the reptilian DVR may be the neocortex, claustroamygdaloid regions, or a combination of both; however, the debate over this homology has elicited controversy in the field of evolutionary biology (Bruce and Neary, 1995; Karten, 1997; Molnár and Butler, 2002; Striedter, 1997). Adult neurogenesis in mammals does not occur in the neocortex (Bhardwaj et al., 2006), but there has been evidence of proliferation and cell specification (without identifying neurogenesis as such) in both the amygdala and piriform cortex of rodents and 
primates (Bernier et al., 2002; Bonfanti and Peretto, 2011; Pencea et al., 2001;

Shapiro et al., 2007). Thus, if the function of the amygdala and piriform cortex relies on neurogenesis in both mammals and reptiles, the fact that the DVR does exhibit adult neurogenesis may provide further support for a homology with the mammalian amygdala/piriform cortex.

Comparing reptiles to birds, it is likely the nidopallium is the avian homolog to the reptilian DVR (Bruce, 2009). The nidopallium also receives new neurons during adulthood. The caudal nidopallium (nidopallium caudale, "NC") stores song-specific characteristics for later recall, and has been found to be activated in canaries and zebra finches when they are exposed to songs of conspecifics (Bolhuis and Gahr, 2006). Hormones also appear to influence neurogenesis in the nidopallium of songbirds. Testosterone triggers and modulates seasonal surges in neuro- and angiogenesis (Chen et al., 2013). Estrogen receptors and telencephalic aromatase are densely distributed in the NC and they, in conjunction, influence cell survival (Gahr et al., 1993; Shen et al., 1995). Whether or not similar systems exist in reptiles is yet to be determined. The scarcity of studies investigating the roles of hormones in adult neurogenesis in reptiles leaves room for further investigation. The DVR could also potentially be a site where seasonal changes in neurogenesis correspond with pheromones and other cues in reptiles instead of auditory cues as in birds. While studies have investigated the role of pheromones in neurogenesis in other regions (Font et al., 2012), or changes in neurogenesis in the DVR in response to temperature and season (Delgado-Gonzalez et al., 2011; Delgado-González et al., 
2008; Penafiel et al., 2001), no studies thus far have investigated how seasonal pheromonal and hormonal changes affect DVR neurogenesis in adult reptiles.

\section{Olfactory and chemosensory processing}

In reptiles, olfactory information enters the brain through the main olfactory bulb (MOB) and is relayed to the lateral (pyriform) cortex (LC). Vomeronasal information, on the other hand, enters through the accessory olfactory bulb (AOB), which transmits to the nucleus sphericus (NS) (Lohman and Smeets, 1993; Lanuza and Halpern, 1997). Due to the importance of pheromone perception, the NS is very well developed in snakes and occupies almost the entire caudal half of the subcortical telencephalon (Schwenk, 1993; Halpern, 1980; Lanuza \& Halpern, 1997). The aLC is most likely involved in the convergence of chemosensory and olfactory processing, with projections to the MC for spatial association and memory (Lanuza \& Halpern, 1997).

The vomeronasal-AOB pathway terminates at the NS in squamates, and the NS appears to control the vomeronasal system, so that NS neurogenesis should be directly related to neuronal turnover in the vomeronasal epithelium and may affect motor function in response to chemoreception (Lohman and Smeets, 1993; Lanuza and Halpern, 1997; Distel, 1978; Simon, 1983, Perez-Sanchez et al., 1989).

The NS of reptiles in total is considered homologous to the posterior medial cortical nucleus of the amygdala in rodents - a secondary vomeronasal center that is part of the vomeronasal amygdala (Gutiérrez-Castellanos et al., 2014; MartinezGarcía et al., 2002). The posterior cortical nucleus of the amygdala in female prairie 
(Microtus ochrogaster) and meadow (M. pennsylvanicus) voles expresses adult neurogenesis colocalized with estrogen receptor-a (Fowler et al., 2005), and neurogenesis increases in response to exposure to conspecific males (Fowler et al., 2002). It is likely that the neurogenesis in this region in mammals corresponds to pheromonal and olfactory input for two reasons: (a) the amygdala receives direct input from the olfactory bulb, and (b) there is some evidence that exposure to male bedding alone also elicits an effect (Fowler et al., 2008). In P. hispanica, the NS exhibits the highest rate of incorporation of new neurons (Font et al., 2001). There have been no studies of neurogenesis in the NS of reptiles in response to pheromonal input, but Delgado-González et al. (2008) found there to be seasonal plasticity, indicating pheromonal changes could potentially be associated with NS neurogenesis.

The development of the NS is clearly related to chemosensory function and ecology (Halpern and Martínez-Marcos, 2003). Balaban (1978) studied P. s. elegans, which spend considerable time underwater and are thus not exposed to consistent olfactants. He found that they completely lack the NS region, which may be further emphasizing olfactary- versus non-olfactory-oriented evolutionary development. The NS may undergo neurogenesis to provide a new population of cells that can process new chemosensory signals as $P$. regius changes environments. These data indicate further experimentation is necessary to determine how pheromones and environmental changes affect NS neuroplasticity. 


\section{The septum}

Font et al. (1998b) posited that the lateral septum is involved in the expression of appetitive behaviors (e.g. food and water intake), aggressive/defensive behavior, and reproductive physiology in reptiles, and may be considered a "distributor of behaviors" (Distel, 1978; Krohmer and Crews, 1987a; Tarr, 1977). The septum may mediate social memory including relating olfactory cues to parental behavior, intraspecific aggression, dominant-subordinate relationships, or defensive/agonistic behaviors and territoriality; which is why it is considered key to the social behavior network (Dantzer et al., 1988; Lanuza and Martínez-García, 2009; Numan, 2000; Sheehan and Numan, 2000; Yang and Wilczynski, 2007). In mammals, the main afferent to the lateral septum is a projection from the hippocampal formation (Sheehan et al., 2004), which provides spatial and nonspatial contextual information. Hence the lateral and medial septum are likely responsible for territorial motivation-behaviors in response to contextual cues (Newman, 1999). In P. regius, the septum appears to undergo proliferation at rates consistent with the rest of the telencephalon, albeit lower than average. This proliferation rate differs from Trachemys scripta, Podarcis hispanica, and $T$. mauritanica, for which septal proliferation is either exceptionally low or nonexistent (Perez-Cañellas et al., 1997; Perez-Cañellas and Garcia-Verdugo, 1996; Font et al., 1997). 


\section{Rostral-caudal effects}

Cell migration was also considerably lower in the caudalmost portions of the telencephalon (DLA/LA, PC, pMC, $\mathrm{pDC}, \mathrm{pLC}$ ) - a trend that is best illustrated by the contrast between the aNS and pNS. Almost $60 \%$ of cells in the aNS migrated to the parenchyma after two weeks, yet only $\sim 21 \%$ of pNS cells entered the parenchyma over the same period, indicating the aNS has almost three times the migration rate of the pNS. This rostral to caudal gradient was also found by Holtzman and Halpern (1991) in embryonic Thamnophis spp. This might occur because the caudal portion has higher proximity to the rest of the telencephalon and thus plays a larger systemic role in olfaction and reinforcement with other systems.

There was also a contrast between the $\mathrm{aMC}$ and $\mathrm{pMC}$. Proportional migration after 2 weeks is approximately $2.5 \mathrm{x}$ higher in the aMC than the $\mathrm{pMC}$, and proportional survival after 2 months is approximately $2 x$ higher. This rostral-caudal trend is also strong in the LC wherein the difference between caudal and rostral is largest after 2 weeks (approximately $2.4 x$ rostral-caudal). This trend is weaker in the DC (approximately $1.5 x$ rostral-caudal). This coincides with other reptile studies that have found caudal-rostral differences in the MC. Hoogland et al. (1994) argued that, in contrast to ground-dwelling geckos, Gekko gecko (tokay geckos) have a medial cortex that is hodologically divided into two separate regions, one rostral and one caudal, which better enables them to spatially navigate walls and ceilings in 3dimensional space. Since both climbing trees and burrowing underground in 3dimensions is part of the behavioral repertoire of $P$. regius, they too may require a 
MC system that allows for two interconnected but structurally and functionally different MC systems (Hoogland and Vermeulen-Vanderzee, 1995). Regional variation in the MC of snakes is further supported by Roth et al. (2006), who found sex differences in cortex volume relative to telencephalon volume only in the caudal half of the medial cortex.

\section{Conclusions}

This study is intended to serve as a preliminary investigation of proliferation, migration, and survival of newly born cells in pythons. BrdU administration was dose-dependent as in mammals, and it was determined that the most appropriate dose for BrdU administration is $100 \mathrm{mg} / \mathrm{kg}$ when it is dissolved in saline solution. When measuring the proliferation, migration, and survival of new cells in several telencephalic regions, some regions exhibited high proliferation, with low relative migration and survival (and for other regions the result was vice-versa). These trends may be due to differences in regional function. Regions involved in short-term or spontaneous functions like olfactory processing may require more neurogenesis in response to rapidly changing environments, while regions with long-term functions like spatial memory may require lower cell turnover as cellular perpetuity becomes a higher priority.

Contrary to what was predicted based on trends among squamate taxa, there was relatively little proliferation in the MC. As predicted, however, there was relatively high proliferation in the AOB, DVR, and NS. Also as predicted, there was relatively high migration/survival in $\mathrm{MC}, \mathrm{AOB}, \mathrm{DVR}$, and NS. This further clarifies the 
regional differences in proliferation and survival of brain cells throughout squamate reptiles.

Cell types were not distinguished using immunohistochemical markers, stains or other techniques. To date, no published studies have successfully used neuronal markers outside of the posterior DVR in adult snakes, and glial markers have limited reliability (Nomura et al., 2013; personal observation). Future studies should focus on determining the phenotype of BrdU marked cells (as neurons or glial cells), however it may require further steps in developing markers for use in adult snake brain tissue because antibodies for neuronal markers (DCX, Tuj1, NeuN) refined for use in mammals have been unsuccessful in labeling cells in snake brain tissue in pilot studies (personal observation).

Additionally, determining which genes and proteins are responsible for developmental differences can reveal aspects of human evolution. For example, Aboitiz's (2011) comparative investigation has suggested Wnt signaling has contributed to substantial elaboration of the dorsal pallium in mammals, while Pax6 upregulation is responsible for the expansion of the ventral pallium in nonmammalian amniotes. Further functional studies determining which proteins are responsible for the upregulation of neurogenesis and neuroregeneration are especially important because they could provide insight into possible therapies for neural diseases.

Generalized regions were used for calculating cell density in this study, which provides less specific data for analysis. Regions like the VM that have smaller nuclei 
(subregions) could potentially have very high density of new cells in some of these nuclei. But this density could potentially go undetected because only the entire region was investigated and not the subregions. Future studies should apply stains for distinguishing smaller brain nuclei and determine whether cells are migrating to those specific nuclei within the larger regions defined in this study.

Finally, it is likely not coincidental that regions expected to be contributing to olfaction and basal-amygdalar function (ACC, STR, DLA/LA, and LC) have highest proximity to the sulci of the ventricles of snakes. I expect this occurs because cells tend to proliferate and migrate outward from "hot spots," which allows organisms like $P$. regius that rely on discrimination of olfactory stimuli to have a continuous supply of neurons to aid in processing of odors and associating them with positive or negative stimuli in new environments. This hypothesis is contrary to the findings of Font et al. (2001) in other reptiles, and may be limited only to snakes. This proposition, along with many of the other hypotheses stated heretofore, may be further refuted or supported by additional studies in a wider range of snake species.

Snakes exhibit several unique characteristics, including limbless body structures, infrared sensory systems, and specialized pheromonal sensory systems that can provide new insights into evolutionary physiology. It is of great benefit to neurophysiology that a wide range of snake species be further investigated to determine trends that can better uncover systems underlying neurogenesis and neuroplasticity in an evolutionary context. 


\section{Abbreviations}

\begin{tabular}{|c|c|}
\hline$A C C$ & Nucleus Accumbens \\
\hline $\mathrm{ACH}$ & Acetylcholine \\
\hline$A D$ & Anterior Dorsal Region \\
\hline$A D V R$ & Anterior Dorsal Ventricular Ridge \\
\hline$a D C$ & Anterior Dorsal Cortex \\
\hline$a L C$ & Anterior Lateral Cortex \\
\hline$a M C$ & Anterior Medial Cortex \\
\hline aNS & Anterior Nucleus Sphericus \\
\hline$A O B$ & Acessory Olfactory Bulb \\
\hline$A V$ & Anterior Ventral Region \\
\hline$B r d U$ & 5-bromo-2'-deoxyuridine \\
\hline$B r d U$-ir & BrdU-immunoreactive \\
\hline$D$ & Diencephalon \\
\hline$D C$ & Dorsal Cortex \\
\hline$D L A / L A$ & $\begin{array}{l}\text { Dorsal Lateral Amygdala/Lateral Amygdala } \\
\text { Region }\end{array}$ \\
\hline$D V R$ & Dorsal Ventricular Ridge \\
\hline$G A B A$ & Y-Aminobutyric acid \\
\hline$L C$ & Lateral Cortex \\
\hline$M B$ & Midbrain \\
\hline$M C$ & Medial Cortex \\
\hline NS & Nucleus Sphericus \\
\hline$O B$ & Olfactory Bulb \\
\hline$O T$ & Optic Tectum \\
\hline$P$ & Pineal Gland \\
\hline$P C$ & Posterior Cortex \\
\hline$P D V R$ & Posterior Dorsal Ventricular Ridge \\
\hline$p D C$ & Posterior Dorsal Cortex \\
\hline$p L C$ & Posterior Lateral Cortex \\
\hline$p M C$ & Posterior Medial Cortex \\
\hline$p N S$ & Posterior Nucleus Sphericus \\
\hline RMS & Rostral Migratory Stream \\
\hline$S$ & Septum \\
\hline STR & Striatum \\
\hline TUB & Olfactory Tubercle \\
\hline$V L$ & Ventral Lateral Region \\
\hline$V M$ & Ventral Medial Region \\
\hline
\end{tabular}




\section{Bibliography}

Aboitiz F. 2011. Genetic and developmental homology in amniote brains. Toward conciliating radical views of brain evolution. Brain Research Bulletin 84(2):125-136.

Aboitiz F, Morales D, Montiel J. 2003. The evolutionary origin of the mammalian isocortex: towards an integrated developmental and functional approach. Behavioral and Brain Sciences 26(5):535-552.

Abrous DN, Koehl M, Le Moal M. 2005. Adult neurogenesis: from precursors to network and physiology. Physiological Reviews 85(2):523-569.

Almli LM, Wilczynski W. 2007. Regional distribution and migration of proliferating cell populations in the adult brain of Hyla cinerea (Anura, Amphibia). Brain Research 1159:112-118.

Altman J. 1962. Are new neurons formed in the brains of adult mammals. Science 135(3509):1127-1128.

Altman J. 1969. Autoradiographic and histological studies of postnatal neurogenesis. IV. Cell proliferation and migration in the anterior forebrain, with special reference to persisting neurogenesis in the olfactory bulb. The Journal of comparative neurology 137(4):433-457.

Alvarez-Buylla A, Theelen M, Nottebohm F. 1990. Proliferation "hot spots" in adult avian ventricular zone reveal radial cell division. Neuron 5(1):101-109.

Amano T, Duvarci S, Popa D, Paré D. 2011. The fear circuit revisited: contributions of the basal amygdala nuclei to conditioned fear. The Journal of Neuroscience 31(43):15481-15489.

Amrein I, Dechmann DK, Winter Y, Lipp H-P. 2007. Absent or low rate of adult neurogenesis in the hippocampus of bats (Chiroptera). PLoS One 2(5):e455.

Amrein I, Slomianka L, Lipp HP. 2004. Granule cell number, cell death and cell proliferation in the dentate gyrus of wild - living rodents. European Journal of Neuroscience 20(12):3342-3350.

Andersen JB, Rourke BC, Caiozzo VJ, Bennett AF, Hicks JW. 2005. Physiology: postprandial cardiac hypertrophy in pythons. Nature 434(7029):37-38. 
Arvidsson A, Collin T, Kirik D, Kokaia Z, Lindvall O. 2002. Neuronal replacement from endogenous precursors in the adult brain after stroke. Nature medicine 8(9):963-970.

Aubret F, Bonnet X, Harris M, Maumelat S. 2005a. Sex differences in body size and ectoparasite load in the ball python, Python regius. Journal of Herpetology 39(2):315-320.

Aubret F, Bonnet X, Shine R, Maumelat S. 2003. Clutch size manipulation, hatching success and offspring phenotype in the ball python (Python regius). Biological Journal of the Linnean Society 78(2):263-272.

Aubret F, Bonnet X, Shine R, Maumelat S. 2005b. Energy expenditure for parental care may be trivial for brooding pythons, Python regius. Animal Behaviour 69(5):1043-1053.

Aubret F, Bonnet X, Shine R, Maumelat S. 2005c. Why do female ball pythons (Python regius) coil so tightly around their eggs? Evolutionary Ecology Research 7(5):743.

Baird Day L, Crews D, Wilczynski W. 1999a. Relative Medial and Dorsal Cortex Volume in Relation to Foraging Ecology in Congeneric Lizards. Brain, Behavior and Evolution 54(6):314-322.

Baird Day L, Crews D, Wilczynski W. 1999b. Spatial and reversal learning in congeneric lizards with different foraging strategies. Animal Behaviour 57(2):393-407.

Baird Day L, Crews D, Wilczynski W. 2001. Effects of medial and dorsal cortex lesions on spatial memory in lizards. Behavioural brain research 118(1):2742.

Balaban CD. 1978. Structure of anterior dorsal ventricular ridge in a turtle (Pseudemys scripta elegans). Journal of Morphology 158(3):291-322.

Bannigan JG. 1985. The effects of 5 - bromodeoxyuridine on fusion of the cranial neural folds in the mouse embryo. Teratology 32(2):229-239.

Barker DG, Barker TM. 2006. Ball Pythons: The History, Natural History, Care and Breeding: VPI Library.

Barker JM, Boonstra R, Wojtowicz JM. 2011. From pattern to purpose: how comparative studies contribute to understanding the function of adult neurogenesis. European Journal of Neuroscience 34(6):963-977. 
Barnea A, Nottebohm F. 1994. Seasonal recruitment of hippocampal neurons in adult free-ranging black-capped chickadees. Proceedings of the National Academy of Sciences 91(23):11217-11221.

Barnea A, Nottebohm F. 1996. Recruitment and replacement of hippocampal neurons in young and adult chickadees: an addition to the theory of hippocampal learning. Proceedings of the National Academy of Sciences 93(2):714-718.

Bartkowska K, Djavadian RL, Taylor JR, Turlejski K. 2008. Generation recruitment and death of brain cells throughout the life cycle of Sorex shrews (Lipotyphla). European Journal of Neuroscience 27(7):1710-1721.

Berman DS, Regal PJ. 1967. The Loss of the Ophidian Middle Ear. Evolution 21(3):641-643.

Bernier PJ, Bédard A, Vinet J, Lévesque M, Parent A. 2002. Newly generated neurons in the amygdala and adjoining cortex of adult primates. Proceedings of the National Academy of Sciences 99(17):11464-11469.

Berson DM, Hartline PH. 1988. A tecto-rotundo-telencephalic pathway in the rattlesnake: evidence for a forebrain representation of the infrared sense. The Journal of Neuroscience 8(3):1074-1088.

Bhardwaj RD, Curtis MA, Spalding KL, Buchholz BA, Fink D, Björk-Eriksson T, Nordborg C, Gage FH, Druid H, Eriksson PS, Frisén J. 2006. Neocortical neurogenesis in humans is restricted to development. Proceedings of the National Academy of Sciences 103(33):12564-12568.

Blau A, Powers AS. 1989. Discrimination learning in turtles after lesions of the dorsal cortex or basal forebrain. Psychobiology.

Bolhuis JJ, Gahr M. 2006. Neural mechanisms of birdsong memory. Nature Reviews Neuroscience 7(5):347-357.

Bonfanti L, Peretto P. 2011. Adult neurogenesis in mammals - a theme with many variations. European Journal of Neuroscience 34(6):930-950.

Boonstra R, Galea L, Matthews S, Wojtowicz J. 2001. Adult neurogenesis in natural populations. Canadian Journal of Physiology and Pharmacology 79(4):297302.

Bradbury MW. 1979. The concept of a blood-brain barrier. London: Wiley. 
Bruce LL. 2007. Evolution of the nervous system in reptiles. In: Kaas JH, editor. Evolution of Nervous Systems. Waltham: Academic Press.

Bruce LL. 2009. Evolution of the nervous system in reptiles. In: Kaas JH, editor. Evolutionary Neuroscience. Oxford, UK: Academic Press.

Bruce LL, Butler AB. 1984. Telencephalic connections in lizards. I. Projections to cortex. Journal of Comparative Neurology 229(4):585-601.

Bruce LL, Neary T. 1995. Afferent projections to the ventromedial hypothalamic nucleus in a lizard, Gekko gecko. Brain, Behavior and Evolution 46(1):14-29.

Budinger E, Heil P, Hess A, Scheich H. 2006. Multisensory processing via early cortical stages: Connections of the primary auditory cortical field with other sensory systems. Neuroscience 143(4):1065-1083.

Burns KA, Kuan CY. 2005. Low doses of bromo - and iododeoxyuridine produce near - saturation labeling of adult proliferative populations in the dentate gyrus. European Journal of Neuroscience 21(3):803-807.

Butler AB, Hodos W. 2005. Comparative Vertebrate Neuroanatomy: Evolution and Adaptation: Wiley. com.

Butler AB, Reiner A, Karten HJ. 2011. Evolution of the amniote pallium and the origins of mammalian neocortex. Annals of the New York Academy of Sciences 1225(1):14-27.

Butler J, Reid J. 1986. Habitat preferences of snakes in the southern Cross River State, Nigeria. Studies in Herpetology:483-488.

Cador M, Robbins TW, Everitt BJ. 1989. Involvement of the amygdala in stimulusreward associations: Interaction with the ventral striatum. Neuroscience 30(1):77-86.

Cameron HA, Mckay RD. 2001. Adult neurogenesis produces a large pool of new granule cells in the dentate gyrus. The Journal of comparative neurology 435(4):406-417.

Cansdale G. 1961. West African Snakes. London: Longman.

Carey J. 1967. The nuclear pattern of the telencephalon of the blacksnake, Coluber constrictor constrictor. In: Hassler R, Stephan $\mathrm{H}$, editors. Evolution of the Forebrain. New York: Plenum Press. p 73-80. 
Castoe TA, de Koning A, Hall KT, Yokoyama KD, Gu W, Smith EN, Feschotte C, Uetz P, Ray DA, Dobry J. 2011. Sequencing the genome of the Burmese python (Python molurus bivittatus) as a model for studying extreme adaptations in snakes. Genome Biology 12(7):406.

Chen Z, Ye R, Goldman SA. 2013. Testosterone modulation of angiogenesis and neurogenesis in the adult songbird brain. Neuroscience 239(0):139-148.

Christensen CB, Christensen-Dalsgaard J, Brandt C, Madsen PT. 2012. Hearing with an atympanic ear: good vibration and poor sound-pressure detection in the royal python, Python regius. The Journal of Experimental Biology 215(2):331-342.

Christie BR, Cameron HA. 2006. Neurogenesis in the adult hippocampus. Hippocampus 16(3):199-207.

Clelland CD, Choi M, Romberg C, Clemenson GD, Fragniere A, Tyers $P$, Jessberger S, Saksida LM, Barker RA, Gage FH, Bussey TJ. 2009. A Functional Role for Adult Hippocampal Neurogenesis in Spatial Pattern Separation. Science 325(5937):210-213.

Conant R. 1993. The oldest snake. Bulletin of the Chicago Herpetological Society 28(4):77-78.

Crews D, Wilczynski W. 2000. Relative medial and dorsal cortex volume in relation to foraging ecology in congeneric lizards. Brain, Behavior and Evolution 54(6):314-322.

Crosby EC, DeJonge BR, Schneider RC. 1967. Evidence for some of the trends in the phylogenetic development of the vertebrate telencephalon. In: Hassler R, Stephan $\mathrm{H}$, editors. Evolution of the Forebrain. New York: Plenum Press.

Curwen AO. 1939. The telencephalon of Tupinambis nigropunctatus III. amygdala. The Journal of comparative neurology 71(3):613-636.

D'Amico LA, Boujard D, Coumailleau P. 2011. Proliferation, migration and differentiation in juvenile and adult Xenopus laevis brains. Brain Research 1405(0):31-48.

Da Cunha C, Gomez AA, Blaha CD. 2012. The role of the basal ganglia in motivated behavior. Reviews in the neurosciences 23(5-6):747-767. 
Dantzer R, Koob GF, Le Moal M. 1988. Septal vasopressin modulates social memory in male rats. Brain Research 457(1):143-147.

Darvas M, Fadok JP, Palmiter RD. 2011. Requirement of dopamine signaling in the amygdala and striatum for learning and maintenance of a conditioned avoidance response. Learning \& Memory 18(3):136-143.

Das GD, Altman J. 1971. Postnatal neurogenesis in the cerebellum of the cat and tritiated thymidine autoradiography. Brain Research 30(2):323-330.

Davis KM, Burghardt GM. 2011. Turtles (Pseudemys nelsoni) learn about visual cues indicating food from experienced turtles. Journal of Comparative Psychology 125(4):404.

Dayer AG, Cleaver KM, Abouantoun T, Cameron HA. 2005. New GABAergic interneurons in the adult neocortex and striatum are generated from different precursors. The Journal of Cell Biology 168(3):415-427.

de Buffrenil M. 1995. Les elevages de reptiles du Benin, du Ghana et du Togo. Report of a study undertaken for the CITES Secretariat.

Delgado-Gonzalez F, Gonzalez-Granero S, Trujillo-Trujillo C, García-Verdugo J, Damas-Hernandez M. 2011. Study of adult neurogenesis in the Gallotia galloti lizard during different seasons. Brain Research 1390:50-58.

Delgado-González FJ, Alonso-Fuentes A, Delgado-Fumero A, García-Verdugo JM, González-Granero S, Trujillo-Trujillo CM, Damas-Hernández MC. 2008. Seasonal differences in ventricular proliferation of adult Gallotia galloti lizards. Brain Research 1191(0):39-46.

Dias BG, Ataya RS, Rushworth D, Zhao J, Crews D. 2007. Effect of incubation temperature and androgens on dopaminergic activity in the leopard gecko, Eublepharis macularius. Developmental Neurobiology 67(5):630-636.

Distel H. 1978. Behavior and electrical brain stimulation in the green iguana, Iguana iguana L. II. Stimulation effects. Experimental Brain Research 31(3):353-367.

Doetsch F, Scharff C. 2001. Challenges for brain repair: insights from adult neurogenesis in birds and mammals. Brain, Behavior and Evolution 58(5):306-322.

Dombrowski PA, Maia TV, Boschen SL, Bortolanza M, Wendler E, Schwarting RKW, Brandão ML, Winn P, Blaha CD, Da Cunha C. 2013. Evidence that conditioned avoidance responses are reinforced by positive prediction errors 
signaled by tonic striatal dopamine. Behavioural Brain Research 241(0):112119.

Dupret D, Revest J-M, Koehl M, Ichas F, De Giorgi F, Costet P, Abrous DN, Piazza PV. 2008. Spatial Relational Memory Requires Hippocampal Adult Neurogenesis. PLoS ONE 3(4):e1959.

Durward A. 1930. The cell masses in the forebrain of Sphenodon punctatum. Journal of Anatomy 65(Pt 1):8.

Eisthen H, Polese G. 2007. Evolution of vertebrate olfactory subsystems. In: Kaas $\mathrm{JH}$, editor. Evolution of Nervous Systems: Elsevier Ltd. p 355-406.

Enok S, Simonsen LS, Pedersen SV, Wang T, Skovgaard N. 2012. Humoral regulation of heart rate during digestion in pythons (Python molurus and Python regius). Journal Article 302(10):R1176-R1183.

Ernst A, Alkass K, Bernard S, Salehpour M, Perl S, Tisdale J, Possnert G, Druid H, FrisÈn J. 2014. Neurogenesis in the Striatum of the Adult Human Brain. Cell 156(5):1072-1083.

Fallon JH. 1983. The islands of Calleja complex of rat basal forebrain II: Connections of medium and large sized cells. Brain Research Bulletin 10(6):775-793.

Fetcho JR. 1987. A review of the organization and evolution of motoneurons innervating the axial musculature of vertebrates. Brain Research Reviews $12(3): 243-280$.

Fleischhauer K. 1957. Untersuchungen am Ependym des Zwischen-und Mittelhirns der Landschildkröte (Testudo graeca). Zeitschrift für Zellforschung und Mikroskopische Anatomie 46(6):729-767.

Flores D, Tousignant A, Crews D. 1994. Incubation temperature affects the behavior of adult leopard geckos (Eublepharis macularius). Physiology \& Behavior 55(6):1067-1072.

Font C, Hoogland PV, van der Zee EV, Pérez-Clausell J, Martínez-García F. 1995a. The septal complex of the telencephalon of the lizard Podarcis hispanica. I. Chemoarchitectonical organization. The Journal of comparative neurology 359(1):117-130.

Font C, Lanuza E, Martinez-Marcos A, Hoogland PV, Martinez-Garcia F. 1998a. Septal complex of the telencephalon of lizards: III. Efferent connections and general discussion. Journal of Comparative Neurology 401(4):525-548. 
Font C, Lanuza E, Martinez-Marcos A, Hoogland PV, Martinez-Garcia F. 1998b. Septal complex of the telencephalon of lizards: III. Efferent connections and general discussion. The Journal of comparative neurology 401(4):525-548.

Font C, Martínez-Marcos A, Lanuza E, Hoogland PV, Martínez-Garciá F. 1997a. Septal complex of the telencephalon of the lizard Podarcis hispanica. II. Afferent connections. The Journal of comparative neurology 383(4):489-511.

Font E, Barbosa D, Sampedro C, Carazo P. 2012. Social behavior, chemical communication, and adult neurogenesis: Studies of scent mark function in Podarcis wall lizards. General and Comparative Endocrinology 177(1):9-17.

Font E, Desfilis E, Pérez-Cañellas M, Alcántara S, García-Verdugo JM. 1997b. 3Acetylpyridine-induced degeneration and regeneration in the adult lizard brain: a qualitative and quantitative analysis. Brain Research 754(1):245-259.

Font E, Desfilis E, Pérez-Cañellas MM, García-Verdugo JM. 2001. Neurogenesis and neuronal regeneration in the adult reptilian brain. Brain, Behavior and Evolution 58(5):276-295.

Font E, García-Verdugo J, Desfilis E, Pérez-Cañellas M. 1995b. Neuron-Glia Interrelations During 3-Acetylpyridine-Induced Degeneration and Regeneration in the Adult Lizard Brain. In: Vernadakis A, Roots B, editors. Neuron-Glia Interrelations During Phylogeny: Humana Press. p 275-302.

Font E, García-Verdugo JM, Alcántara S, López-García C. 1991. Neuron regeneration reverses 3-acetylpyridine-induced cell loss in the cerebral cortex of adult lizards. Brain Research 551(1):230-235.

Fowler CD, Johnson F, Wang Z. 2005. Estrogen regulation of cell proliferation and distribution of estrogen receptor-a in the brains of adult female prairie and meadow voles. The Journal of comparative neurology 489(2):166-179.

Fowler CD, Liu Y, Ouimet C, Wang Z. 2002. The effects of social environment on adult neurogenesis in the female prairie vole. Journal of Neurobiology 51(2):115-128.

Fowler CD, Liu Y, Wang Z. 2008. Estrogen and adult neurogenesis in the amygdala and hypothalamus. Brain Research Reviews 57(2):342-351.

Friedman D, Crews D. 1985a. Role of the anterior hypothalamus-preoptic area in the regulation of courtship behavior in the male Canadian red-sided garter snake 
(Thamnophis sirtalis parietalis): lesion experiments. Behav Neuroscience 99(5):942-949.

Friedman D, Crews D. 1985b. Role of the anterior hypothalamus-preoptic area in the regulation of courtship behavior in the male Canadian red-sided garter snake Thamnophis sirtalis parietalis: Intracranial implantation experiments. Hormones and Behavior 19(2):122-136.

Gaalema DE. 2011. Visual discrimination and reversal learning in rough-necked monitor lizards Varanus rudicollis. Journal of Comparative Psychology 125(2):246.

Gahr M, Güttinger H-R, Kroodsma DE. 1993. Estrogen receptors in the avian brain: Survey reveals general distribution and forebrain areas unique to songbirds. The Journal of comparative neurology 327(1):112-122.

García-Verdugo J, Berbel P, López-García C. 1981. Estudio con Golgi y con microscopía electrónica de los ependimocitos de la corteza cerebral del lagarto Lacerta galloti. Trabajos del Instituto Cajal 72:269-278.

Garcia-Verdugo J, Farinas I, Molowny A, Lopez-Garcia C. 1986. Ultrastructure of putative migrating cells in the cerebral cortex of Lacerta galloti. Journal of Morphology 189(2):189-197.

Goffinet A. 1983. The embryonic development of the cortical plate in reptiles: a comparative study in Emys orbicularis and Lacerta agilis. The Journal of comparative neurology 215(4):437-452.

Goldman SA, Nottebohm F. 1983. Neuronal production, migration, and differentiation in a vocal control nucleus of the adult female canary brain. Proceedings of the National Academy of Sciences 80(8):2390-2394.

Gonzalez A, Russchen FT, Lohman AHM. 1990. Afferent Connections of the Striatum and the Nucleus accumbens in the Lizard Gekko gecko (Part 1 of 2). Brain, Behavior and Evolution 36(1):39-48.

González-Granero S, Lezameta M, García-Verdugo JM. 2011. Adult neurogenesis in reptiles. In: Seki T, Sawamoto K, Parent J, Alvarez-Bylla A, editors. Neurogenesis in the Adult Brain I: Springer. p 169-189.

Goris RC. 2011. Infrared organs of snakes: an integral part of vision. Journal of Herpetology 45(1):2-14. 
Gorr TA, Mable BK, Kleinschmidt T. 1998. Phylogenetic analysis of reptilian hemoglobins: Trees, rates, and divergences. J Mol Evol 47(4):471-485.

Gorzula S, Nsiah W, Oduro W. Survey of the status and management of the Royal Python (Python regius) in Ghana; 1997.

Goss RJ. 1992. The evolution of regeneration: adaptive or inherent? Journal of Theoretical Biology 159(2):241-260.

Gould E, Beylin A, Tanapat P, Reeves A, Shors TJ. 1999. Learning enhances adult neurogenesis in the hippocampal formation. Nature Neuroscience 2(3):260265.

Gould E, Gross CG. 2002. Neurogenesis in adult mammals: some progress and problems. The Journal of Neuroscience 22(3):619-623.

Gould E, McEwen BS, Tanapat P, Galea LA, Fuchs E. 1997. Neurogenesis in the dentate gyrus of the adult tree shrew is regulated by psychosocial stress and NMDA receptor activation. The Journal of Neuroscience 17(7):2492-2498.

Gould E, Tanapat P, McEwen BS, Flügge G, Fuchs E. 1998. Proliferation of granule cell precursors in the dentate gyrus of adult monkeys is diminished by stress. Proceedings of the National Academy of Sciences 95(6):3168-3171.

Grandel H, Kaslin J, Ganz J, Wenzel I, Brand M. 2006. Neural stem cells and neurogenesis in the adult zebrafish brain: Origin, proliferation dynamics, migration and cell fate. Developmental Biology 295(1):263-277.

Gratzner HG. 1982. Monoclonal antibody to 5-bromo-and 5-iododeoxyuridine: a new reagent for detection of DNA replication. Science 218(4571):474-475.

Greenberg N. 1977. A Neuroethological Study of Display Behavior in the Lizard Anolis Carolinensis (Reptilia, Lacertilia, Iguanidae). American Zoologist 17(1):191-201.

Greenberg N, Scott M, Crews D. 1984. Role of the amygdala in the reproductive and aggressive behavior of the lizard, Anolis carolinensis. Physiology \& Behavior 32(1):147-151.

Grisham W, Powers AS. 1989. Function of the dorsal and medial cortex of turtles in learning. Behavioral neuroscience 103(5):991.

Groenewegen HJ, der Zee EV-V, te Kortschot A, Witter MP. 1987. Organization of the projections from the subiculum to the ventral striatum in the rat. A study 
using anterograde transport of Phaseolus vulgaris leucoagglutinin. Neuroscience 23(1):103-120.

Gross CG. 2000. Neurogenesis in the adult brain: death of a dogma. Nature Reviews Neuroscience 1(1):67-73.

Guirado S, Dávila JC, Real MÁ, Medina L. 1999. Nucleus accumbens in the lizard Psammodromus algirus: chemoarchitecture and cortical afferent connections. The Journal of comparative neurology 405(1):15-31.

Gutiérrez-Castellanos N, Pardo-Bellver C, Martínez-García F, Lanuza E. 2014. The vomeronasal cortex - afferent and efferent projections of the posteromedial cortical nucleus of the amygdala in mice. European Journal of Neuroscience 39(1):141-158.

Hall WC, Ebner FF. 1970. Thalamotelencephalic projections in the turtle (Pseudemys scripta). Journal of Comparative Neurology 140(1):101-122.

Halpern M. 1976. The efferent connections of the olfactory bulb and accessory olfactory bulb in the snakes, Thamnophis sirtalis and Thamnophis radix. Journal of Morphology 150(2 Pt. 2):553-578.

Halpern M. 1980. The telencephalon of snakes. Comparative Neurology of the Telencephalon: Springer. p 257-295.

Halpern M. 1992. Nasal chemical senses in reptiles: structure and function. Biology of the Reptilia 18:423-523.

Halpern M, Martínez-Marcos A. 2003. Structure and function of the vomeronasal system: an update. Progress in Neurobiology 70(3):245-318.

Hancock A, Priester C, Kidder E, Keith JR. 2009. Does 5-bromo-2' -deoxyuridine (BrdU) disrupt cell proliferation and neuronal maturation in the adult rat hippocampus in vivo. Behavioural Brain Research 199(2):218-221.

Harlow P, Grigg G. 1984. Shivering thermogenesis in a brooding diamond python, Python spilotes spilotes. Copeia:959-965.

Hastings NB, Gould E. 2003. Neurons inhibit neurogenesis. Nature Medicine 9(3):264-266.

Heimer L. 2003. A new anatomical framework for neuropsychiatric disorders and drug abuse. American Journal of Psychiatry 160(10):1726-1739. 
Heise PJ, Maxson LR, Dowling HG, Hedges SB. 1995. Higher-level snake phylogeny inferred from mitochondrial DNA sequences of 12S rRNA and 16S rRNA genes. Molecular Biology and Evolution 12(2):259-265.

Hitt JC, Bryon DM, Modianos DT. 1973. Effects of rostral medial forebrain bundle and olfactory tubercle lesions upon sexual behavior of male rats. Journal of Comparative and Physiological Psychology 82(1):30-36.

Hoebel B, Monaco A, Hernandez L, Aulisi E, Stanley BG, Lenard L. 1983. Selfinjection of amphetamine directly into the brain. Psychopharmacology 81(2):158-163.

Holding ML, Frazier JA, Taylor EN, Strand CR. 2012. Experimentally altered navigational demands induce changes in the cortical forebrain of free-ranging Northern Pacific Rattlesnakes (Crotalus o. oreganus). Brain, Behavior and Evolution 79(3):144-154.

Holmgren N. 1922. Points of view concerning forebrain morphology in lower vertebrates. Journal of Comparative Neurology 34(5):391-459.

Holtzman DA, Halpern M. 1991. Incorporation of 3H - thymidine in the embryonic vomeronasal and olfactory epithelia of garter snakes. The Journal of comparative neurology 304(3):435-449.

Holtzman DA, Harris TW, Aranguren G, Bostock E. 1999. Spatial learning of an escape task by young corn snakes, Elaphe guttata guttata. Animal Behaviour 57(1):51-60.

Hoogland PV, Martinez-Garcia F, Vermeulen-Vanderzee E. 1994. Are rostral and caudal parts of the hippocampus of the lizard Gekko gecko related to different types of behaviour? European Journal of Morphology 32(2-4):275-278.

Hoogland PV, Vermeulen-Vanderzee E. 1995. Efferent connections of the lateral cortex of the lizard Gekko gecko: evidence for separate origins of medial and lateral pathways from the lateral cortex to the hypothalamus. Journal of Comparative Neurology 352(3):469-480.

Hutchison VH, Dowling HG, Vinegar A. 1966. Thermoregulation in a brooding female Indian python, Python molurus bivittatus. Science 151(3711):694-695.

Ikemoto S. 2003. Involvement of the Olfactory Tubercle in Cocaine Reward: Intracranial Self-Administration Studies. The Journal of Neuroscience 23(28):9305-9311. 
Ikemoto S. 2007. Dopamine reward circuitry: Two projection systems from the ventral midbrain to the nucleus accumbens-olfactory tubercle complex. Brain Research Reviews 56(1):27-78.

Ikemoto S, Panksepp J. 1999. The role of nucleus accumbens dopamine in motivated behavior: a unifying interpretation with special reference to rewardseeking. Brain Research Reviews 31(1):6-41.

Ivazov NI. 1983. Role of the hippocampal cortex and dorsal ventricular ridge in conditioned reflex activity of the anguid lizard scheltopusik (Ophisaurus apodue). Neurosci Behav Physiol 13(6):397-403.

Jacobs LF. 2003. The evolution of the cognitive map. Brain, Behavior and Evolution 62(2):128-139.

Jarvis ED, Gunturkun O, Bruce L, Csillag A, Karten H, Kuenzel W, Medina L, Paxinos G, Perkel DJ, Shimizu T, Striedter G, Wild JM, Ball GF, Dugas-Ford J, Durand SE, Hough GE, Husband S, Kubikova L, Lee DW, Mello CV, Powers A, Siang C, Smulders TV, Wada K, White SA, Yamamoto K, Yu J, Reiner A, Butler AB. 2005. Avian brains and a new understanding of vertebrate brain evolution. Nature Reviews Neuroscience 6(2):151-159.

Källen B. 1951. Contributions to the knowledge of the medial wall of the reptilian forebrain. Cells Tissues Organs 13(1-2):90-100.

Kaplan M. 1982. Proliferation of subependymal cells in the adult primate CNS: differential uptake of DNA labelled precursors. Journal fur Hirnforschung 24(1):23-33.

Karten HJ. 1997. Evolutionary developmental biology meets the brain: the origins of mammalian cortex. Proceedings of the National Academy of Sciences 94(7):2800-2804.

Karten HJ. 2013. Neocortical Evolution: Neuronal Circuits Arise Independently of Lamination. Current Biology 23(1):R12-R15.

Kaslin J, Ganz J, Brand M. 2008. Proliferation, neurogenesis and regeneration in the non-mammalian vertebrate brain. Philosophical Transactions of the Royal Society B: Biological Sciences 363(1489):101-122.

Kempermann G. 2014. Off the Beaten Track: New Neurons in the Adult Human Striatum. Cell 156(5):870-871. 
Kempermann G, Gage FH. 1999. Experience - dependent regulation of adult hippocampal neurogenesis: Effects of long - term stimulation and stimulus withdrawal. Hippocampus 9(3):321-332.

Kempermann G, Kuhn HG, Gage FH. 1997. More hippocampal neurons in adult mice living in an enriched environment. Nature 386(6624):493-495.

Kempermann G, Kuhn HG, Gage FH. 1998. Experience-induced neurogenesis in the senescent dentate gyrus. The Journal of Neuroscience 18(9):3206-3212.

Kirn JR, Fishman Y, Sasportas K, Alvarez-Buylla A, Nottebohm F. 1999. Fate of new neurons in adult canary high vocal center during the first 30 days after their formation. Journal of Comparative Neurology 411(3):487-494.

Kirsche W. 1967. Über postembryonale Matrixzonen im Gehirn verschiedener Vertebraten und deren Beziehung zur Hirnbauplanlehre. Zeitschrift fur Mikroskopisch-Anatomische Forschung 77:313-406.

Knutson B, Adams CM, Fong GW, Hommer D. 2001. Anticipation of increasing monetary reward selectively recruits nucleus accumbens. The Journal of Neuroscience 21(16):RC159.

Kobayashi S, Kishida R, Goris RC, Yoshimoto M, Ito H. 1992. Visual and infrared input to the same dendrite in the tectum opticum of the python, Python regius electron-microscopic evidence. Brain Research 597(2):350-352.

Koob GF, Riley SJ, Smith SC, Robbins TW. 1978. Effects of 6-hydroxydopamine lesions of the nucleus accumbens septi and olfactory tubercle on feeding, locomotor activity, and amphetamine anorexia in the rat. Journal of Comparative and Physiological Psychology 92(5):917-927.

Korr H, Koeser K, Oldenkott S, Schmidt H, Schultze B. 1989. X-ray dose-effect relationship on unscheduled DNA synthesis and spontaneous unscheduled DNA synthesis in mouse brain cells studied in vivo. Radiation and Environmental Biophysics 28(1):13-26.

Korr H, Schultze B. 1989. Unscheduled DNA synthesis in various types of cells of the mouse brain in vivo. Experimental Brain Research 74(3):573-578.

Kravitz AV, Tye LD, Kreitzer AC. 2012. Distinct roles for direct and indirect pathway striatal neurons in reinforcement. Nature Neuroscience 15(6):816-818. 
Krohmer RW, Boyle MH, Lutterschmidt DI, Mason RT. 2010. Seasonal aromatase activity in the brain of the male red-sided garter snake. Hormones and Behavior 58(3):485-492.

Krohmer RW, Crews D. 1987a. Facilitation of courtship behavior in the male redsided garter snake (Thamnophis sirtalis parietalis) following lesions of the septum or nucleus sphericus. Physiology \& Behavior 40(6):759-765.

Krohmer RW, Crews D. 1987b. Temperature activation of courtship behavior in the male red-sided garter snake (Thamnophis sirtalis parietalis): role of the anterior hypothalamus-preoptic area. Behavioral neuroscience 101(2):228236.

Krohmer RW, DeMarchi GA, Baleckaitis DD, Lutterschmidt DI, Mason RT. 2011. Brain nuclei in actively courting red-sided garter snakes: A paradigm of neural trimorphism. Physiology \& Behavior 102(5):532-537.

Kuhn H, Dickinson-Anson H, Gage F. 1996. Neurogenesis in the dentate gyrus of the adult rat: age-related decrease of neuronal progenitor proliferation. The Journal of Neuroscience 16(6):2027-2033.

Kuhn HG, Cooper-Kuhn CM. 2007. Bromodeoxyuridine and the detection of neurogenesis. Current Pharmaceutical Biotechnology 8(3):127-131.

LaDage LD, Riggs BJ, Sinervo B, Pravosudov VV. 2009. Dorsal cortex volume in male side-blotched lizards, Uta stansburiana, is associated with different space use strategies. Animal Behaviour 78(1):91-96.

LaDage LD, Roth TC, Cerjanic AM, Sinervo B, Pravosudov VV. 2012. Spatial memory: are lizards really deficient? Biology Letters 8(6):939-941.

Lanuza E, Belekhova M, Martinez-Marcos A, Font C, Martinez-Garcia F. 1998. Identification of the reptilian basolateral amygdala: an anatomical investigation of the affernts to the posterior dorsal ventricular ridge of the lizard Podarcis hispanica. European Journal of Neuroscience 10(11):35173534.

Lanuza E, Halpern M. 1997a. Afferent and efferent connections of the nucleus sphericus in the snake Thamnophis sirtalis: Convergence of olfactory and vomeronasal information in the lateral cortex and the amygdala. The Journal of comparative neurology 385(4):627-640.

Lanuza E, Halpern M. 1997b. Afferent and efferent connections of the nucleus sphericus in the snake Thamnophis sirtalis: convergence of olfactory and 
vomeronasal information in the lateral cortex and the amygdala. The Journal of comparative neurology 385(4):627-640.

Lanuza E, Halpern M. 1998. Efferents and Centrifugal Afferents of the Main and Accessory Olfactory Bulbs in the Snake Thamnophis sirtalis. Brain, Behavior and Evolution 51(1):1-22.

Lanuza E, Martínez-García F. 2009. Evolution of septal nuclei. Encyclopedia of Neurocience:1270-1278.

Leuner B, Glasper ER, Gould E. 2009. Thymidine analog methods for studies of adult neurogenesis are not equally sensitive. Journal of Comparative Neurology 517(2):123-133.

Li Y, Liu W, Oo TF, Wang L, Tang Y, Jackson-Lewis V, Zhou C, Geghman K, Bogdanov M, Przedborski S, Beal MF, Burke RE, Li C. 2009. Mutant LRRK2R1441G BAC transgenic mice recapitulate cardinal features of Parkinson's disease. Nat Neurosci 12(7):826-828.

Lindsey BW, Tropepe V. 2006. A comparative framework for understanding the biological principles of adult neurogenesis. Progress in neurobiology 80(6):281-307.

Lois C, Alvarez-Buylla A. 1994. Long-distance neuronal migration in the adult mammalian brain. Science 264(5162):1145-1148.

Lopez JC, Vargas JP, Gomez Y, Salas C. 2003. Spatial and non-spatial learning in turtles: the role of medial cortex. Behav Brain Res 143(2):109-120.

Lopez-Garcia C, Molowny A, Garcia-Verdugo J, Ferrer I. 1988. Delayed postnatal neurogenesis in the cerebral cortex of lizards. Developmental Brain Research 43(2):167-174.

Lopez-Garcia C, Molowny A, Garcia-Verdugo J, Martinez-Guijarro F, Bernabeu A. 1990. Late generated neurons in the medial cortex of adult lizards send axons that reach the Timm-reactive zones. Developmental Brain Research 57(2):249-254.

Lopez-Garcia C, Molowny A, Nacher J, Ponsoda X, Sancho-Bielsa F, Alonso-Llosa G. 2002. The lizard cerebral cortex as a model to study neuronal regeneration. Anais da Academia Brasileira de Ciências 74(1):85-104. 
Lopez-Garcia C, Nacher J, Castellano B, de la Iglesia J, Molowny A. 1994.

Transitory disappearance of microglia during the regeneration of the lizard medial cortex. Glia 12(1):52-61.

Lopez-Garcia C, Tineo P, Del Corral J. 1984. Increase of the neuron number in some cerebral cortical areas of a lizard, Podarcis hispanica,(Steind., 1870), during postnatal periods of life. Journal fur Hirnforschung 25(3):255-259.

Luiselli L. 2006. Why do males and females of Python regius differ in ectoparasite load? Amphibia-Reptilia 27(3):469-471.

Luiselli L, Akani GC, Eniang EA, Politano E. 2007. Comparative ecology and ecological modeling of sympatric pythons, Python regius and Python sebae. Biology of the boas and pythons. Eagle Mountain, UT: Eagle Mountain Publishing, LC. p 88-100.

Luiselli L, Angelici FM. 1998. Sexual size dimorphism and natural history traits are correlated with intersexual dietary divergence in royal pythons (Python regius) from the rainforests of southeastern Nigeria. Italian Journal of Zoology 65(2):183-185.

Luzzati F, Bonfanti L, Fasolo A, Peretto P. 2009. DCX and PSA-NCAM expression identifies a population of neurons preferentially distributed in associative areas of different pallial derivatives and vertebrate species. Cerebral cortex 19(5):1028-1041.

Luzzati F, De Marchis S, Fasolo A, Peretto P. 2006. Neurogenesis in the Caudate Nucleus of the Adult Rabbit. The Journal of Neuroscience 26(2):609-621.

Lynch TP, Cass CE, Paterson AR. 1977. Defective transport of thymidine by cultured cells resistant to 5 - bromodeoxyuridine. Journal of Supramolecular Structure 6(3):363-374.

Manrod JD, Hartdegen R, Burghardt GM. 2008. Rapid solving of a problem apparatus by juvenile black-throated monitor lizards (Varanus albigularis albigularis). Anim Cogn 11(2):267-273.

Marchioro M, de Azevedo Mota Nunes J-M, Rabelo Ramalho A, Molowny A, PerezMartinez E, Ponsoda X, Lopez-Garcia C. 2005. Postnatal neurogenesis in the medial cortex of the tropical lizard Tropidurus hispidus. Neuroscience 134(2):407-413.

Marchioro M, Pimentel HdC, Santos ML, Lima MM, dos Santos JR, Martí XP, Molowny A, Garcia CL. 2012. Low temperature-acclimation impairs cellular 
migration in the adult cerebral cortex of the tropical lizard, Tropidurus hispidus (Spix, 1825)(Squamata: Tropiduridae). Archives Italiennes de Biologie 150(1):22-30.

Margotta V, Morelli A, Alfei L. 1999. PCNA positivity in the telencephalic matrix areas in the adult of a lizard, Podarcis sicula. Journal für Hirnforschung 39(3):271.

Martinez-Garcia F, Amiguet M, Olucha F, Lopez-Garcia C. 1986. Connections of the lateral cortex in the lizard Podarcis hispanica. Neuroscience Letters 63(1):3944.

Martinez-García F, Martínez-Marcos A, Lanuza E. 2002. The pallial amygdala of amniote vertebrates: evolution of the concept, evolution of the structure. Brain Research Bulletin 57(3-4):463-469.

Martínez-Garcia F, Novejarque A, Lanuza E. 2009. The Evolution of the Amygdala in Vertebrates. Evolutionary Neuroscience:313.

Martínez-García F, Novejarque A, Lanuza E. 2007. Evolution of the amygdala in vertebrates. Evolution of Nervous Systems 2:255-334.

Martínez-García F, Olucha FE, Teruel V, Lorente MJ. 1993. Fiber Connections of the Amygdaloid Formation of the Lizard Podarcis hispanica. Brain, Behavior and Evolution 41(3-5):156-162.

Martinez-Garcia F, Olucha FE, Teruel V, Lorente MJ, Schwerdtfeger WK. 1991. Afferent and efferent connections of the olfactory bulbs in the lizard Podarcis hispanica. The Journal of comparative neurology 305(2):337-347.

Martínez-Guijarro F, López-García C. 1994. Postnatal increase of GABA-and PV-IR cells in the cerebral cortex of the lizard Podarcis hispanica. Brain Research 634(1):168-172.

Martínez-Marcos A, Lanuza E, Halpern M. 1999. Organization of the ophidian amygdala: chemosensory pathways to the hypothalamus. Journal of Comparative Neurology 412(1):51-68.

Mason RT. 1992. Reptilian pheromones. Biology of the Reptilia 18:114-228.

McCurley K. 2005. The Complete Ball Python: A Comprehensive Guide to Care, Breeding, and Genetic Mutations: E. C. O. Herpetological Publishing \& Distribution. 
Medina L, Abellán A, Desfilis E. 2013. A Never-Ending Search for the Evolutionary Origin of the Neocortex: Rethinking the Homology Concept. Brain, Behavior and Evolution 81(3):150-153.

Medina L, Bupesh M, Abellan A. 2011. Contribution of genoarchitecture to understanding forebrain evolution and development, with particular emphasis on the amygdala. Brain, Behavior and Evolution 78(3):216-236.

Meerlo P, Mistlberger RE, Jacobs BL, Craig Heller H, McGinty D. 2009. New neurons in the adult brain: the role of sleep and consequences of sleep loss. Sleep Medicine Reviews 13(3):187-194.

Meredith M, Westberry JM. 2004. Behavioral/Systems/Cognitive: Distinctive responses in the medial amygdala to same-species and different-species pheremones. The Journal of Neuroscience 24(25):5719-5725.

Mick G, Cooper H, Magnin M. 1993. Retinal projection to the olfactory tubercle and basal telencephalon in primates. The Journal of comparative neurology 327(2):205-219.

Miller MW, Nowakowski RS. 1988. Use of bromodeoxyuridine-immunohistochemistry to examine the proliferation, migration and time of origin of cells in the central nervous system. Brain Research 457(1):44-52.

Minelli G, Del Grande P, Mambelli M. 1977. Preliminary study of the regenerative processes of the dorsal cortex of the telencephalon of Lacerta viridis. Zeitschrift fur Mikroskopisch-Anatomische Forschung 91(2):241.

Mink JW. 2003. The basal ganglia and involuntary movements: Impaired inhibition of competing motor patterns. Archives of Neurology 60(10):1365-1368.

Molenaar GJ. 1978a. The sensory trigeminal system of a snake in the possession of infrared receptors. I. The sensory trigeminal nuclei. Journal of Comparative Neurology 179(1):123-135.

Molenaar GJ. 1978b. The sensory trigeminal system of a snake in the possession of infrared receptors. II. The central projections of the trigeminal nerve. Journal of Comparative Neurology 179(1):137-151.

Molnár Z, Butler AB. 2002. Neuronal changes during forebrain evolution in amniotes: an evolutionary developmental perspective. Progress in Brain Research 136:21-38. 
Molowny A, Nacher J, Lopez-Garcia C. 1995. Reactive neurogenesis during regeneration of the lesioned medial cerebral cortex of lizards. Neuroscience 68(3):823-836.

Moran A, Wojcik L, Cangiane L, Schade Powers A. 1998. Dorsal Cortex Lesions Impair Habituation in Turtles (Chrysemys picta). Brain, Behavior and Evolution 51(1):40-47.

Moreno N, González A. 2007. Evolution of the amygdaloid complex in vertebrates, with special reference to the anamnio-amniotic transition. Journal of Anatomy 211(2):151-163.

Moreno N, Morona R, López JM, González A. 2010. Subdivisions of the turtle Pseudemys scripta subpallium based on the expression of regulatory genes and neuronal markers. The Journal of comparative neurology 518(24):48774902.

Morris YA, Crews D. 1990. The effects of exogenous neuropeptide $Y$ on feeding and sexual behavior in the red-sided garter snake (Thamnophis sirtalis parietalis). Brain Research 530(2):339-341.

Nacher J, Ramirez C, Palop J, Artal P, Molowny A, Lopez-Garcia C. 1999. Microglial cells during the lesion-regeneration of the lizard medial cortex. Histology and Histopathology 14(1):103.

Newman EA, Gruberg ER, Hartline PH. 1980. The infrared trigemino - tectal pathway in the rattlesnake and in the python. Journal of Comparative Neurology 191(3):465-477.

Newman SW. 1999. The medial extended amygdala in male reproductive behavior a node in the mammalian social behavior network. Annals of the New York Academy of Sciences 877(1):242-257.

Nieuwenhuyis R, ten Donkelaar HJ, Nicholson C. 1998. The Central Nervous System of Vertebrates: With Posters: Springer.

Nomura T, Gotoh H, Ono K. 2013a. Changes in the regulation of cortical neurogenesis contribute to encephalization during amniote brain evolution. Nature Communications 4.

Nomura T, Kawaguchi M, Ono K, Murakami Y. 2013b. Reptiles: A New Model for Brain Evo - Devo Research. Journal of Experimental Zoology Part B: Molecular and Developmental Evolution:1-17. 
Nomura T, Takahashi M, Hara Y, Osumi N. 2008. Patterns of neurogenesis and amplitude of Reelin expression are essential for making a mammalian-type cortex. PloS ONE 3(1):e1454.

Northcutt RG. 1981. Evolution of the telencephalon in nonmammals. Annual Review of Neuroscience 4(1):301-350.

Numan RE. 2000. The behavioral neuroscience of the septal region: Springer-Verlag Publishing.

Olson AK, Eadie BD, Ernst C, Christie BR. 2006. Environmental enrichment and voluntary exercise massively increase neurogenesis in the adult hippocampus via dissociable pathways. Hippocampus 16(3):250-260.

Owen R. 1848. On The Archetype and Homologies of the Vertebrate Skeleton. London: John Van Vorst, Paternoster Row.

Packard MG, Knowlton BJ. 2002. Learning and memory functions of the basal ganglia. Annual Review of Neuroscience 25(1):563-593.

Papp G, Witter MP, Treves A. 2007. The CA3 network as a memory store for spatial representations. Learning \& Memory 14(11):732-744.

Peñafiel A, Gutiérrez A, Martín R, Perez-Canellas MM, de la Calle A. 1996. A tangential neuronal migration in the olfactory bulbs of adult lizards. NeuroReport 7(7):1257-1260.

Penafiel A, Rivera A, Gutierrez A, Trias S, De La Calle A. 2001. Temperature affects adult neurogenesis in the lizard brain. International Journal of Developmental Biology 45:S83-S84.

Pencea V, Bingaman KD, Freedman LJ, Luskin MB. 2001. Neurogenesis in the subventricular zone and rostral migratory stream of the neonatal and adult primate forebrain. Experimental Neurology 172(1):1-16.

Pérez-Cañellas MM, Font E, García-Verdugo JM. 1997. Postnatal neurogenesis in the telencephalon of turtles: evidence for nonradial migration of new neurons from distant proliferative ventricular zones to the olfactory bulbs. Developmental Brain Research 101(1):125-137.

Pérez-Cañellas MM, García-Verdugo JM. 1996. Adult neurogenesis in the telencephalon of a lizard: a [3H]thymidine autoradiographic and 
bromodeoxyuridine immunocytochemical study. Developmental Brain Research 93(1-2):49-61.

Platel R. 1974. Poids encéphalique et indice d'encéphalisation chez les reptiles sauriens. Zoologischer Anzeiger 192(5-6):332-382.

Powers AS, Hanusch B. Effect of enriched environment on adult neurogenesis in turtles (Chysemys picta); 2012. p 157.

Radmilovich M, Fernández A, Trujillo-Cenóz O. 2003. Environment temperature affects cell proliferation in the spinal cord and brain of juvenile turtles. Journal of Experimental Biology 206(17):3085-3093.

Rakic P. 2002. Adult neurogenesis in mammals: an identity crisis. The Journal of Neuroscience 22(3):614-618.

Ramirez C, Nacher J, Molowny A, Sanchez-Sanchez F, Irurzun A, Lopez-Garcia C. 1997. Photoperiod-temperature and neuroblast proliferation-migration in the adult lizard cortex. Neuroreport 8(9):2337-2342.

Ramirez-Castillejo C, Nacher J, Molowny A, Ponsoda X, Lopez-Garcia C. 2002a. PSA-NCAM immunocytochemistry in the cerebral cortex and other telencephalic areas of the lizard Podarcis hispanica: Differential expression during medial cortex neuronal regeneration. The Journal of comparative neurology 453(2):145-156.

Ramirez-Castillejo C, Nacher J, Molowny A, Ponsoda X, Lopez-Garcia C. 2002b. PSA - NCAM immunocytochemistry in the cerebral cortex and other telencephalic areas of the lizard Podarcis hispanica: Differential expression during medial cortex neuronal regeneration. Journal of Comparative Neurology 453(2):145-156.

Ramon y Cajal P. 1917. Nuevo estudio del encéfalo de los reptiles. Trabajos del Laboratorio de Investigaciones Biológicas 15(1917):271-291.

Ramon y Cajal P. 1918. Nuevo estudio del encéfalo de los reptiles. Trabajos del Laboratorio de Investigaciones Biológicas Univ. Madrid(16):309-333.

Ramón y Cajal S. 1928. Degeneration and Regeneration of the Nervous System. Day RM, translator. London: Oxford Univ. Press.

Rattenborg N, Martinez-Gonzalez D. 2011. A bird-brain view of episodic memory. Behavioural Brain Research 222(1):236-245. 
Rodriguez F, Lopez JC, Vargas JP, Gomez Y, Broglio C, Salas C. 2002.

Conservation of spatial memory function in the pallial forebrain of reptiles and ray-finned fishes. The Journal of Neuroscience 22(7):2894-2903.

Roth ED, Lutterschmidt WI, Wilson DA. 2006. Relative medial and dorsal cortex volume in relation to sex differences in spatial ecology of a snake population. Brain, Behavior and Evolution 67(2):103-110.

Russchen FT, Jonker AJ. 1988. Efferent connections of the striatum and the nucleus accumbens in the lizard Gekko gecko. The Journal of comparative neurology 276(1):61-80.

Sahay A, Scobie KN, Hill AS, O'Carroll CM, Kheirbek MA, Burghardt NS, Fenton AA, Dranovsky A, Hen R. 2011a. Increasing adult hippocampal neurogenesis is sufficient to improve pattern separation. Nature 472(7344):466-470.

Sahay A, Wilson Donald A, Hen R. 2011b. Pattern Separation: A Common Function for New Neurons in Hippocampus and Olfactory Bulb. Neuron 70(4):582-588.

Saijo E. 2007. Thesis: neurogenesis and gliogenesis in adult bullfrog brains.: Arizona State University.

Sakata JT, Crews D. 2003. Embryonic temperature shapes behavioural change following social experience in male leopard geckos, Eublepharis macularius. Animal Behaviour 66(5):839-846.

Sampedro C, Font E, Desfilis E. 2008. Size variation and cell proliferation in chemosensory brain areas of a lizard (Podarcis hispanica): effects of sex and season. European Journal of Neuroscience 28(1):87-98.

Saxe MD, Battaglia F, Wang J-W, Malleret G, David DJ, Monckton JE, Garcia ADR, Sofroniew MV, Kandel ER, Santarelli L, Hen R, Drew MR. 2006. Ablation of hippocampal neurogenesis impairs contextual fear conditioning and synaptic plasticity in the dentate gyrus. Proceedings of the National Academy of Sciences 103(46):17501-17506.

Schmitz C, Axmacher B, Zunker U, Korr H. 1999. Age-related changes of DNA repair and mitochondrial DNA synthesis in the mouse brain. Acta neuropathologica 97(1):71-81.

Schroeder DM. 1981. Tectal projections of an infrared sensitive snake, Crotalus viridis. The Journal of comparative neurology 195(3):477-500. 
Schultz RL. 1969. Zur postnatalen Biomorphose des Ependyms im Telencephalon von Lacerta agilis agilis. Zeitschrift fur Mikroskopisch-Anatomische Forschung $81: 111-152$.

Schwenk K. 1993. The evolution of chemoreception in squamate reptiles: a phylogenetic approach. Brain, Behavior and Evolution 41(3-5):124-137.

Scott JW, McBride RL, Schneider SP. 1980. The organization of projections from the olfactory bulb to the piriform cortex and olfactory tubercle in the rat. The Journal of comparative neurology 194(3):519-534.

Secor SM, Diamond J. 1998. A vertebrate model of extreme physiological regulation. Nature 395(6703):659-662.

Secor SM, Fehsenfeld D, Diamond J, Adrian TE. 2001. Responses of python gastrointestinal regulatory peptides to feeding. Proceedings of the National Academy of Sciences 98(24):13637-13642.

Seki T, Arai Y. 1993. Highly polysialylated neural cell adhesion molecule (NCAM-H) is expressed by newly generated granule cells in the dentate gyrus of the adult rat. The Journal of Neuroscience 13(6):2351-2358.

Selden JR, Dolbeare F, Clair JH, Miller JE, McGettigan K, DiJohn JA, Dysart GR, DeLuca JG. 1994. Validation of a flow cytometric in vitro DNA repair (UDS) assay in rat hepatocytes. Mutation Research/DNA Repair 315(2):147-167.

Selden JR, Dolbeare F, Clair JH, Nichols WW, Miller JE, Kleemeyer KM, Hyland RJ, DeLuca JG. 1993. Statistical confirmation that immunofluorescent detection of DNA repair in human fibroblasts by measurement of bromodeoxyuridine incorporation is stoichiometric and sensitive. Cytometry 14(2):154-167.

Shao H, Fan L, Xu X, Xu W, Liu B, Wang J, Liu N, Zhao S. 2012. Characterization of adult neurogenesis in lizard Phrynocephalus vlangalii (Agamidae: Reptilia). Italian Journal of Zoology 79(4):547-558.

Shapiro LA, Ng K, Zhou Q-Y, Ribak CE. 2009. Subventricular zone-derived, newly generated neurons populate several olfactory and limbic forebrain regions. Epilepsy \& Behavior 14(1, Supplement 1):74-80.

Shapiro LA, Ng KL, Zhou Q-Y, Ribak CE. 2007. Olfactory enrichment enhances the survival of newly born cortical neurons in adult mice. NeuroReport 18(10). 
Sheehan T, Numan M. 2000. The Septal Region and Social Behavior. In: Numan R, editor. The Behavioral Neuroscience of the Septal Region: Springer New York. p 175-209.

Sheehan TP, Chambers RA, Russell DS. 2004. Regulation of affect by the lateral septum: implications for neuropsychiatry. Brain Research Reviews 46(1):71117.

Shen P, Schlinger BA, Campagnoni AT, Arnold AP. 1995. An atlas of aromatase mRNA expression in the zebra finch brain. The Journal of comparative neurology 360(1):172-184.

Shine R, Ambariyanto, Harlow PS, Mumpuni. 1999. Ecological attributes of two commercially-harvested python species in northern Sumatra. Journal of Herpetology:249-257.

Shine R, Harlow P, Keogh J. 1998. The influence of sex and body size on food habits of a giant tropical snake, Python reticulatus. Functional Ecology 12(2):248-258.

Shors TJ, Miesegaes G, Beylin A, Zhao M, Rydel T, Gould E. 2001. Neurogenesis in the adult is involved in the formation of trace memories. Nature 410(6826):372-376.

Simmons AM, Horowitz SS, Brown RA. 2008. Cell Proliferation in the Forebrain and Midbrain of the Adult Bullfrog, Rana catesbeiana. Brain, Behavior and Evolution 71(1):41-53.

Slowinski JB, Lawson R. 2002. Snake phylogeny: evidence from nuclear and mitochondrial genes. Molecular phylogenetics and evolution 24(2):194-202.

Smeets WAJ, Medina L. 1995. The efferent connections of the nucleus accumbens in the lizard Gekko gecko. Anatomy and Embryology 191(1):73-81.

Smeets WJ. 1988. Distribution of dopamine immunoreactivity in the forebrain and midbrain of the snake Python regius: a study with antibodies against dopamine. The Journal of comparative neurology 271(1):115-129.

Smeets WJAJ, Hoogland PV, Voorn P. 1986. The distribution of dopamine immunoreactivity in the forebrain and midbrain of the lizard Gekko gecko: An immunohistochemical study with antibodies against dopamine. The Journal of comparative neurology 253(1):46-60. 
Smeets WJAJ, Jonker AJ, Hoogland PV. 1987. Distribution of Dopamine in the Forebrain and Midbrain of the Red-Eared Turtle, Pseudemys scripta elegans, Reinvestigated Using Antibodies against Dopamine (Part 1 of 2). Brain, Behavior and Evolution 30(3-4):121-131.

Stahlschmidt ZR, DeNardo DF. 2008. Alternating egg-brooding behaviors create and modulate a hypoxic developmental micro-environment in Children's pythons (Antaresia childreni). Journal of Experimental Biology 211(10):1535-1540.

Stahlschmidt ZR, DeNardo DF. 2009. Effect of nest temperature on egg-brooding dynamics in Children's pythons. Physiology \& Behavior 98(3):302-306.

Stahlschmidt ZR, DeNardo DF. 2010. Parental behavior in pythons is responsive to both the hydric and thermal dynamics of the nest. The Journal of Experimental Biology 213(10):1691-1696.

Starin E, Burghardt G. 1992. African rock pythons (Python sebae) in the Gambia: observations on natural history and interactions with primates. The Snake 24(1):50-62.

Striedter GF. 1997. The Telencephalon of Tetrapods in Evolution; pp. 205-213. Brain, Behavior and Evolution 49(4):205-213.

Stuber GD, Sparta DR, Stamatakis AM, van Leeuwen WA, Hardjoprajitno JE, Cho S, Tye KM, Kempadoo KA, Zhang F, Deisseroth K, Bonci A. 2011. Excitatory transmission from the amygdala to nucleus accumbens facilitates reward seeking. Nature 475(7356):377-380.

Sugerman RA, Demski LS. 1978. Agonistic Behavior Elicited by Electrical Stimulation of the Brain in Western Collared Lizards, Crotaphytus collaris. Brain, Behavior and Evolution 15(5-6):446-469.

Swanson L, Risold P-Y. 2000. On the Basic Architecture of the Septal Region. In: Numan R, editor. The Behavioral Neuroscience of the Septal Region: Springer New York. p 1-14.

Swanson LW, Petrovich GD. 1998. What is the amygdala? Trends in neurosciences 21(8):323-331.

Tarr RS. 1977. Role of the amygdala in the intraspecies aggressive behavior of the iguanid lizard, Sceloporus occidentalis. Physiology \& Behavior 18(6):11531158. 
Tarr RS. 1982. Species typical display behavior following stimulation of the reptilian striatum. Physiology \& Behavior 29(4):615-620.

ten Donkelaar HJ. 1988. Evolution of the red nucleus and rubrospinal tract. Behavioural Brain Research 28(1-2):9-20.

Tineo P, Planelles M, Del-Corral J. 1987. Modifications in cortical ependyma of the lizard, Podarcis hispanica, during postnatal development. Journal für Hirnforschung 28(5):485.

Tramontin AD, Brenowitz EA. 2000. Seasonal plasticity in the adult brain. Trends in Neurosciences 23(6):251-258.

Treves A, Tashiro A, Witter MP, Moser El. 2008. What is the mammalian dentate gyrus good for? Neuroscience 154(4):1155-1172.

Ubeda-Bañon I, Novejarque A, Mohedano-Moriano A, Pro-Sistiaga P, Insausti R, Martinez-Garcia F, Lanuza E, Martinez-Marcos A. 2008. Vomeronasal inputs to the rodent ventral striatum. Brain Research Bulletin 75(2-4):467-473.

Ulinski PS. 1974. Cytoarchitecture of cerebral cortex in snakes. Journal of Comparative Neurology 158(3):243-266.

Ulinski PS. 1975. Corticoseptal projections in the snakes Natrix sipedon and Thamnophis sirtalis. Journal of Comparative Neurology 164(3):375-388.

Ulinski PS. 1978. Organization of anterior dorsal ventricular ridge in snakes. Journal of Comparative Neurology 178(3):411-449.

Ulinski PS. 1983. Dorsal ventricular ridge: a treatise on forebrain organization in reptiles and birds. Anatomy and Embryology 203:95-108.

Ulinski PS. 1990. The Cerebral Cortex of Reptiles. In: Jones EG, Peters A, editors. Comparative Structure and Evolution of Cerebral Cortex, Part I. New York: Plenum. p 139-215.

Ulinski PS, Rainey WT. 1980. Intrinsic organization of snake lateral cortex. Journal of Morphology 165(1):85-116.

van Praag H, Kempermann G, Gage FH. 1999. Running increases cell proliferation and neurogenesis in the adult mouse dentate gyrus. Nature Neuroscience 2(3):266-270. 
van Praag H, Schinder AF, Christie BR, Toni N, Palmer TD, Gage FH. 2002.

Functional neurogenesis in the adult hippocampus. Nature 415(6875):10301034.

Vertes RP, Hoover WB. 2008. Projections of the paraventricular and paratenial nuclei of the dorsal midline thalamus in the rat. The Journal of comparative neurology 508(2):212-237.

Vidal N, David P. 2004. New insights into the early history of snakes inferred from two nuclear genes. Molecular Phylogenetics and Evolution 31(2):783-787.

Vinegar A, Hutchinson VH, Dowling HG. 1970. Metabolism, energetics, and thermoregulation during brooding of snakes of the genus Python (Reptilia, Boidae). Zoologica 55:19-48.

Warner FJ. 1931. The cell masses of the telecephalon and diencephalon of the rattlesnake Crotalus atrox. Proceedings of the National Academy of Sciences 34:1156-1163.

Warner FJ. The Fibre Tracts of the Fore brain of the American Diamond - Back Rattlesnake (Crotalus adamanteus); 1946. Wiley Online Library. p 22-32.

Warner FJ. 1947. The development of the forebrain of the American Diamond-Back Rattlesnake. Proceedings of the Zoological Society of London 116:22-32.

Wesson DW, Wilson DA. 2010. Smelling Sounds: Olfactory-Auditory Sensory Convergence in the Olfactory Tubercle. The Journal of Neuroscience 30(8):3013-3021.

Wilkinson A, Chan H-M, Hall G. 2007. Spatial learning and memory in the tortoise (Geochelone carbonaria). Journal of Comparative Psychology 121(4):412.

Wilkinson A, Mandl I, Bugnyar T, Huber L. 2010. Gaze following in the red-footed tortoise (Geochelone carbonaria). Anim Cogn 13(5):765-769.

Wise PA, Vickaryous MK, Russell AP. 2009. An embryonic staging table for in ovo development of Eublepharis macularius, the leopard gecko. The Anatomical Record 292(8):1198-1212.

Wojtowicz JM, Kee N. 2006. BrdU assay for neurogenesis in rodents. Nature Protocols 1(3):1399-1405.

Yamashita T, Ninomiya M, Hernández Acosta P, García-Verdugo JM, Sunabori T, Sakaguchi M, Adachi K, Kojima T, Hirota Y, Kawase T, Araki N, Abe K, 
Okano H, Sawamoto K. 2006. Subventricular zone-derived neuroblasts migrate and differentiate into mature neurons in the post-stroke adult striatum. The Journal of Neuroscience 26(24):6627-6636.

Yanes C, Monzon-Mayor M, Ghandour MS, de Barry J, Gombos G. 1990. Radial glia and astrocytes in developing and adult telencephalon of the lizard Gallotia galloti as revealed by immunohistochemistry with anti-GFAP and anti-vimentin antibodies. The Journal of comparative neurology 295(4):559-568.

Yanes-Méndez C, Martin-Trujillo J, Pérez-Batista M, Monzón-Mayor M, Marrero A. 1988. Ependymogenesis of the lizard basal areas. II. Sulcus. Zeitschrift fur Mikroskopisch-Anatomische Forschung 102:573-589.

Yanes-Mendez C, Martin-Trujillo J, Perez-Batista M, Mozon-Mayor M, Marrero A. 1988. Ependymogenesis of the lizard basal areas. I. Ependymal zones. Zeitschrift fur Mikroskopisch-Anatomische Forschung 102:555-572.

Yang E-J, Wilczynski W. 2007. Social experience organizes parallel networks in sensory and limbic forebrain. Developmental Neurobiology 67(3):285-303.

Yin HH, Knowlton BJ, Balleine BW. 2004. Lesions of dorsolateral striatum preserve outcome expectancy but disrupt habit formation in instrumental learning. European Journal of Neuroscience 19(1):181-189.

Zelano C, Bensafi M, Porter J, Mainland J, Johnson B, Bremner E, Telles C, Khan R, Sobel N. 2005. Attentional modulation in human primary olfactory cortex. Nat Neurosci 8(1):114-120.

Zelano C, Montag J, Johnson B, Khan R, Sobel N. 2007. Dissociated Representations of Irritation and Valence in Human Primary Olfactory Cortex. Journal of Neurophysiology 97(3):1969-1976.

Zuri I, Bull C. 2000. The use of visual cues for spatial orientation in the sleepy lizard (Tiliqua rugosa). Canadian Journal of Zoology 78(4):515-520. 


\section{Appendix}

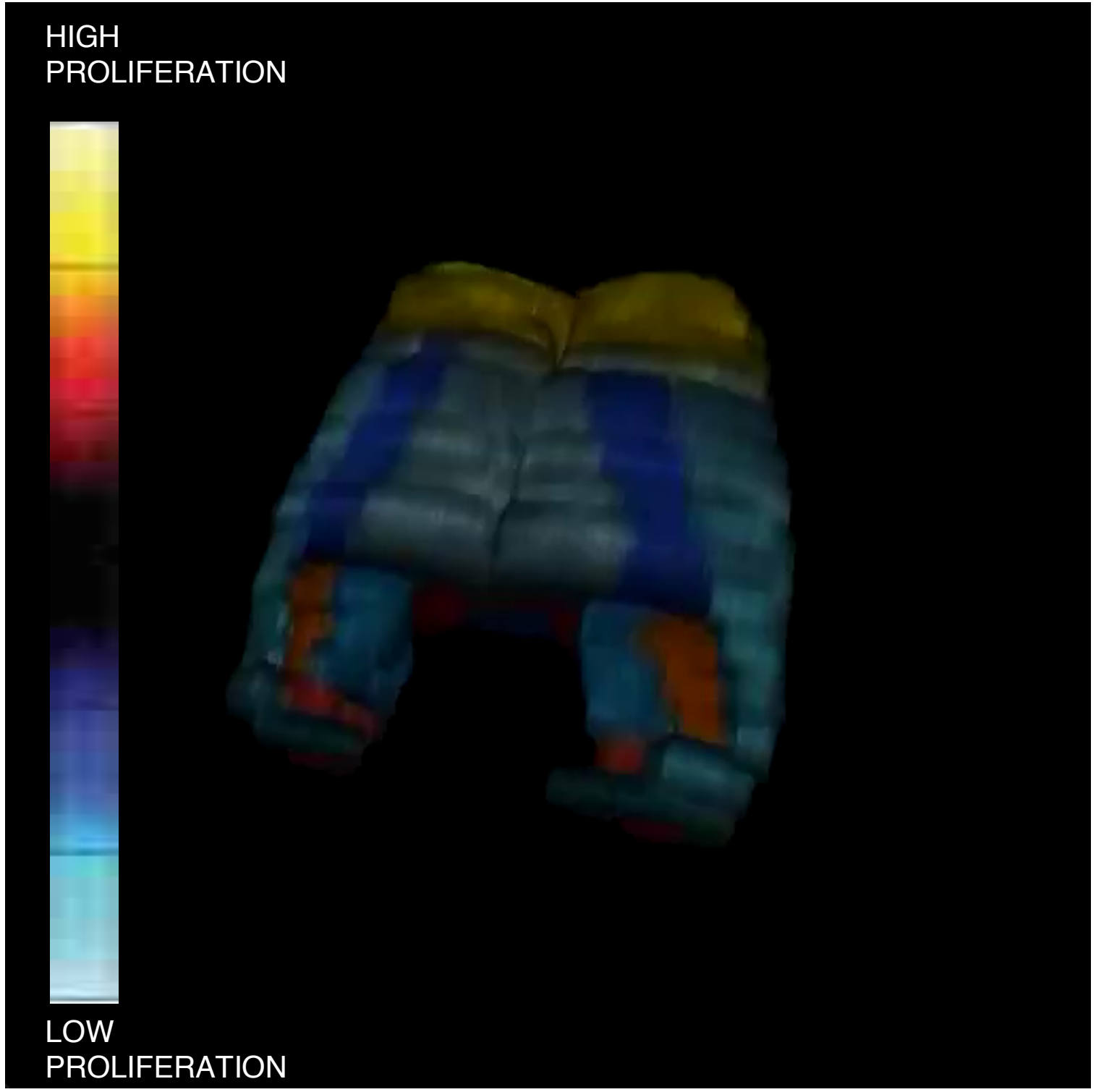

Figure 17: Heat map representing proliferation (2 days) in the telencephalon of $P$. regius. Hot colors (yellow, orange, red) represent areas of high proliferation, while cold colors (purple, blue, light blue) represent areas of low proliferation. The rostral end and caudal end are topmost and bottommost, respectively. 3D video can be found at http://youtu.be/zMj8d42o3_4. 


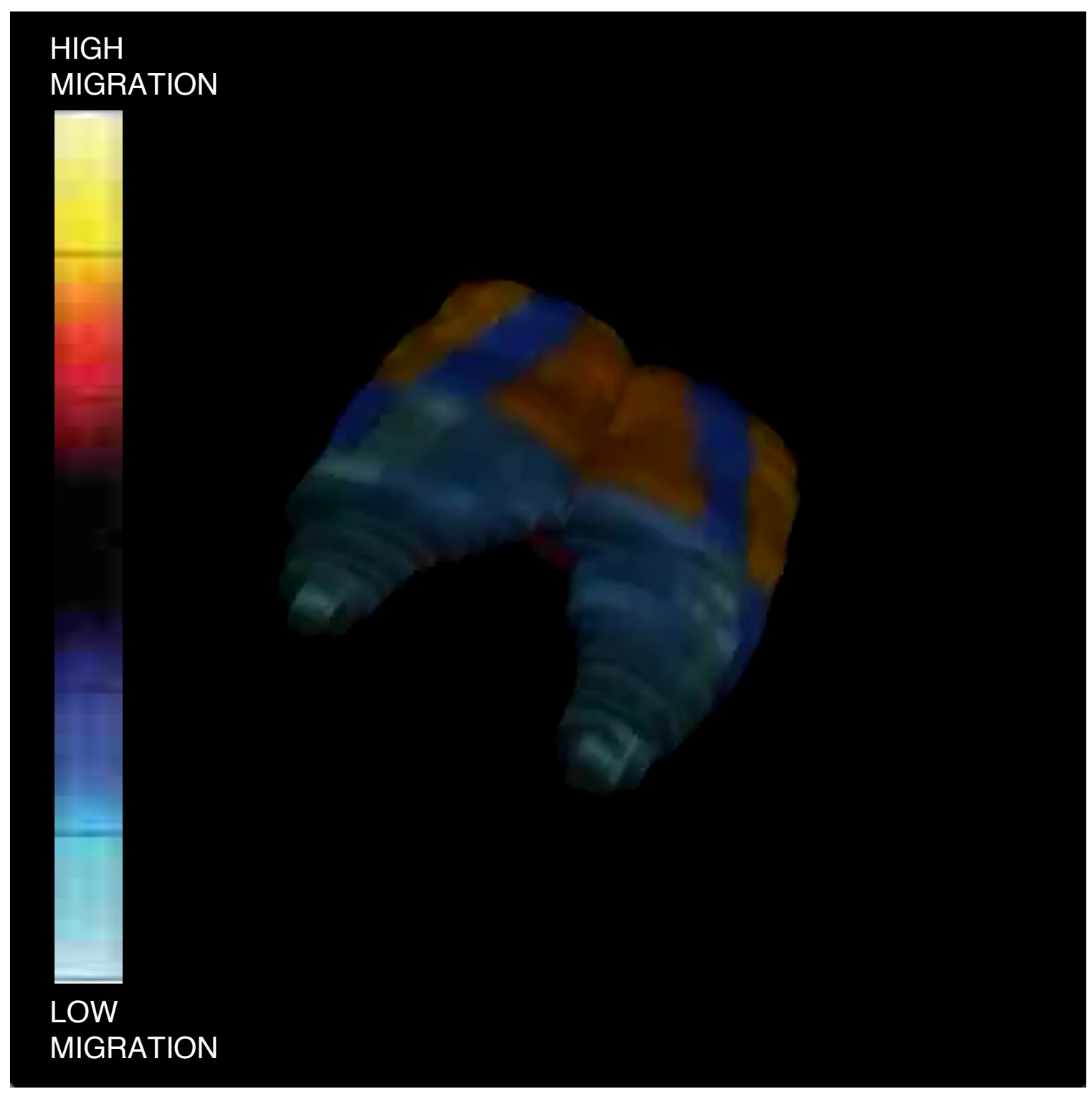

Figure 18: Heat map representing migration (2 weeks) in the telencephalon of $P$. regius. Hot colors (yellow, orange, red) represent areas of high migration, while cold colors (purple, blue, light blue) represent areas of low migration. The rostral end and caudal end are topmost and bottommost, respectively. 3D video can be found at http://youtu.be/QZXKkCTCHsM. 


\section{$\mathrm{HIGH}$}

SURVIVAL

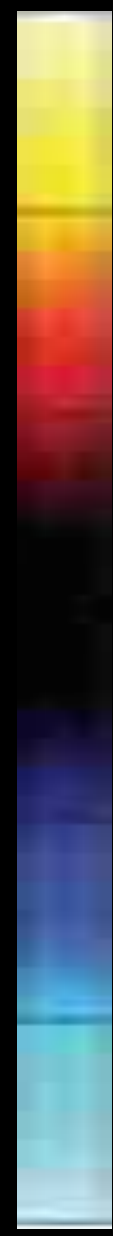

LOW

SURVIVAL

Figure 19: Heat map representing survival (2 months) in the telencephalon of $P$. regius. Hot colors (yellow, orange, red) represent areas of high proliferation, while cold colors (purple, blue, light blue) represent areas of low proliferation. The rostral end and caudal end are topmost and bottommost, respectively. 3D video can be found at http://youtu.be/usnQ5F0AQJk. 